University of San Diego

Digital USD

Dissertations

Theses and Dissertations

2014-08-01

\title{
Educating the Whole Child: Evidence of Health and Wellness Instruction in the Schools Serving Low-Income Students
}

Andria M. Shook PhD

University of San Diego

Follow this and additional works at: https://digital.sandiego.edu/dissertations

Part of the Leadership Studies Commons

\section{Digital USD Citation}

Shook, Andria M. PhD, "Educating the Whole Child: Evidence of Health and Wellness Instruction in the Schools Serving Low-Income Students" (2014). Dissertations. 867.

https://digital.sandiego.edu/dissertations/867

This Dissertation: Open Access is brought to you for free and open access by the Theses and Dissertations at Digital USD. It has been accepted for inclusion in Dissertations by an authorized administrator of Digital USD. For more information, please contact digital@sandiego.edu. 


\title{
EDUCATING THE WHOLE CHILD: EVIDENCE OF HEALTH AND WELLNESS
} INSTRUCTION IN SCHOOLS SERVING LOW-INCOME STUDENTS

by

\author{
Andria M. Shook
}

A dissertation submitted in partial fulfillment of the requirements for the degree of

\author{
Doctor of Philosophy
}

August 2014

\author{
Dissertation Committee \\ Frank Kemerer, Ph.D., Chair \\ Zachary Gabriel Green, Ph.D., Member \\ Fred Galloway, Ed.D., Member \\ University of San Diego
}


(C) Copyright by Andria M. Shook All Rights Reserved 2014 


\begin{abstract}
Educators in the United States are expressing concern about student physical and mental well-being. Childhood obesity has more than doubled in the past three decades, and today, one in five children experiences symptoms of mental illness. Low-income children are especially subject to these conditions. The long-term consequences for the country as a whole are significant. Schools are particularly well placed to address these problems by supporting the well-being of the whole child.
\end{abstract}

Efforts have begun in select schools and districts to incorporate health and wellness instruction into the school day. This study identifies existing health and wellness components that three participating Title I schools in one school district have incorporated into their health and wellness program. The study also examines how socioeconomically different students have responded both physically and psychologically to their school's program.

Findings from this mixed-methodological study indicate socioeconomically different students physically and psychologically respond to health and wellness in three important ways. First, low-income students at participating schools evidenced parents and children collectively engaging in regular physical activity. Higher-income students also identified parents as physically active, but parent physical activity regularly occurred separate from the child. Second, although all students expressed dissatisfaction with school lunches, the way students responded varied by student socioeconomic status and caused concern for district personnel. Psychologically, low-income students identified personal experiences with on-campus bullying or interpersonal conflict while more 
affluent students spoke to such situations as third party observers, or said bullying is not a problem at their school.

School district stakeholders recognize that differences in leadership, staff, and resources exist at participating schools and have created three different health and wellness programmatic models. School A maximizes staff and volunteer enthusiasm to promote physical wellness, School B offers district health and wellness components provided to all schools, and School $\mathrm{C}$ takes strides to support mental wellness. This study delineates the programmatic constructs and student physical and psychological responses at the three schools to highlight the importance of school-based health and wellness reform. The study also discusses the relationship of the three programs to the Whole School, Whole Community, Whole Child model. 


\section{ACKNOWLEDGEMENTS}

It is with heartfelt gratitude that I recognize individuals who have been integral to my doctoral studies, the completion of this dissertation, and the doors that have opened as a result. With their guidance and unwavering support, I've been granted access to a world of possibilities to advocate for child wellness.

To Drs. Fred Galloway and Zachary Gabriel Green for their guidance throughout my coursework their contribution to this document. Both men offer diverging skillsets and perspectives, but compliment one another to enhance the final product. Thank you both for your support and wisdom.

To my colleagues, mentors, and friends from the Center of Education Policy and Law (CEPAL) at the University of San Diego. Thank you for offering your knowledge and expertise about interview protocols, IRB logistics, and data analysis. A special thanks to Dr. Michael Corke for his unwavering support, constant encouragement, and quantitative expertise that helped me keep moving forward, and to Scott Himelstein for the connections and opportunities you have generated since I joined the CEPAL team in 2010.

To Dr. Frank Kemerer for being the right person, at the right place, at the right time. Your mentorship from the onset of this program has been priceless. Prior to embarking on this dissertation journey, someone once shared, "finding the right doctoral advisor and/or dissertation chair can make or break your experience." I will always be grateful for finding the perfect doctoral advisor and dissertation chair. Thank you for everything. 
To my friends and family- related or otherwise- who have shared in this long journey. A special thanks to my sister Lindsey who urged me down this path at a pivotal point in life, Nancy who offered her writing expertise to be a second reader, Guillermo who never once allowed me to give up, and to my mother Becky for her constant support and encouragement from day one. One person cannot successfully complete this journey alone, but with the support of loved ones anything is possible. 


\section{TABLE OF CONTENTS}

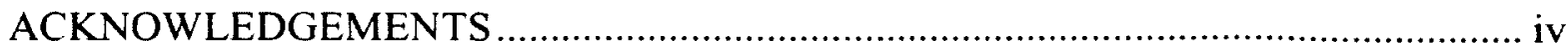

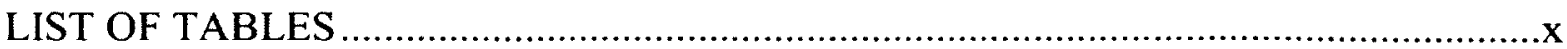

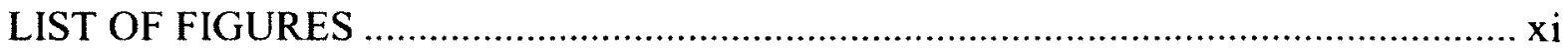

CHAPTER ONE: BACKGROUND AND PURPOSE OF THE STUDY ….................. 1

Child Wellness Research and Practice ................................................................... 1

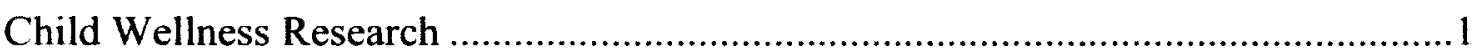

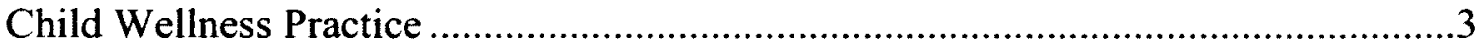

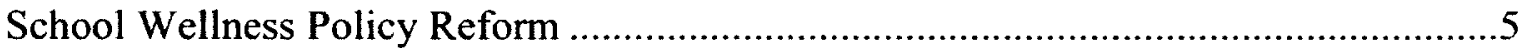

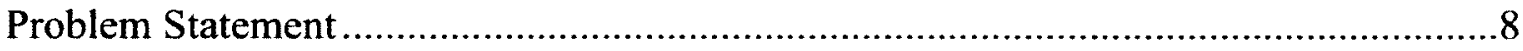

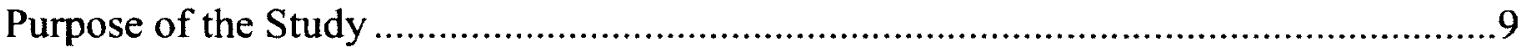

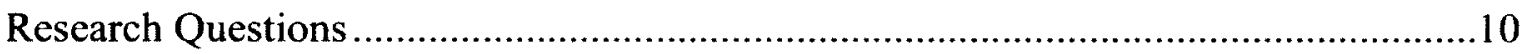

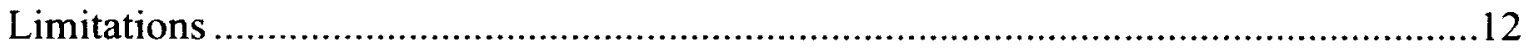

CHAPTER TWO: REVIEW OF THE LITERATURE ........................................ 14

Students' Physical Response to Health and Wellness Instruction .............................15

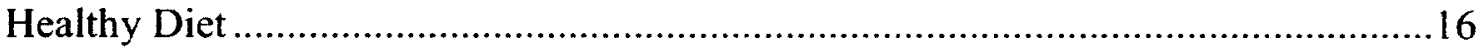

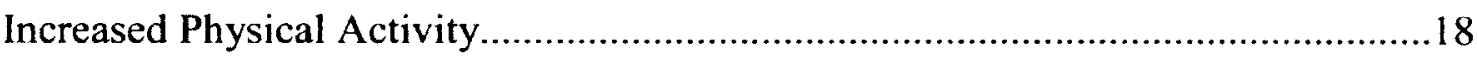

Changes in Weight Loss/Body Mass Index (BMI) ........................................21

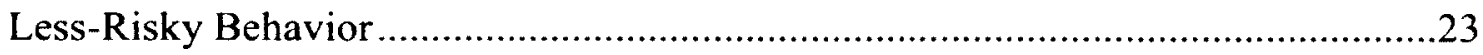

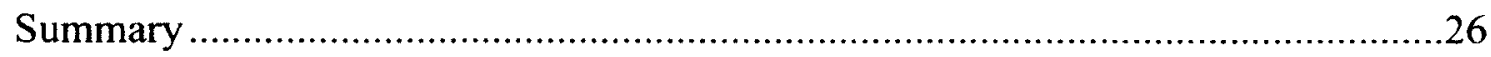

Students' Physiological Response to Health and Wellness Instruction .....................27

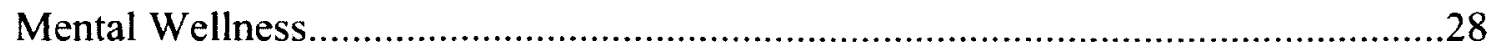




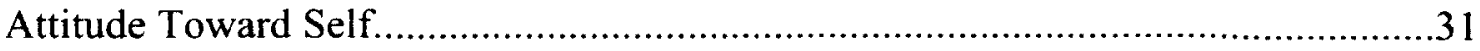

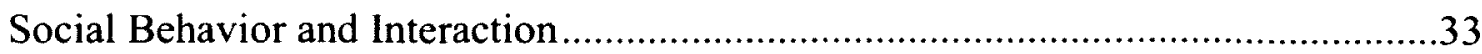

Summary

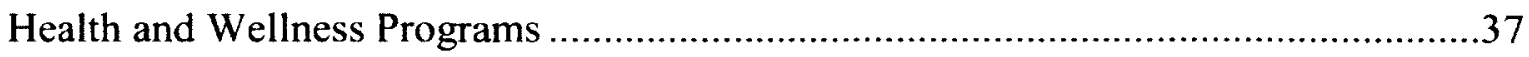

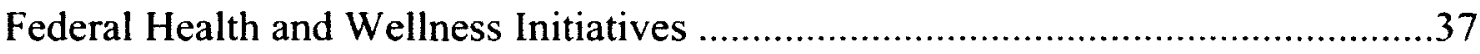

Independent Health and Wellness Programs ....................................................45

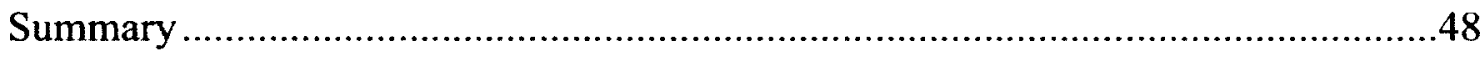

CHAPTER THREE: METHODOLOGY

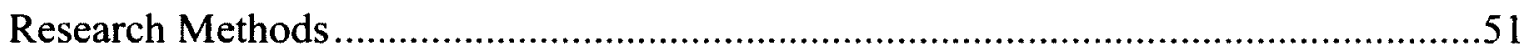

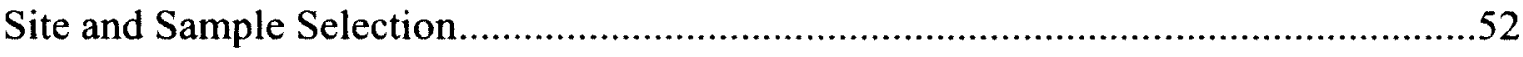

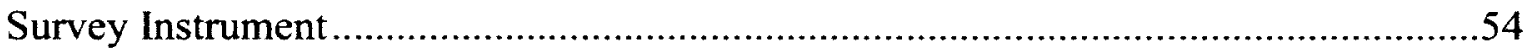

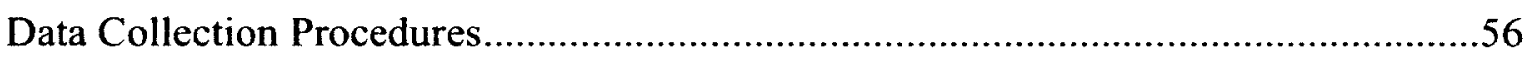

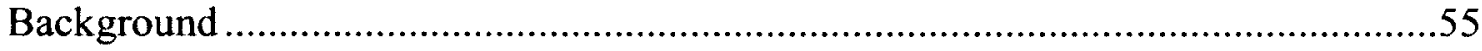

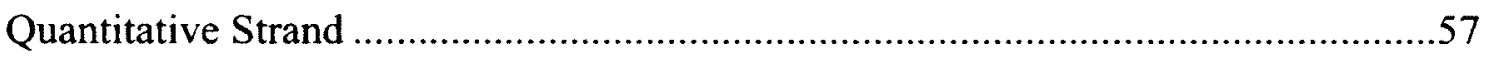

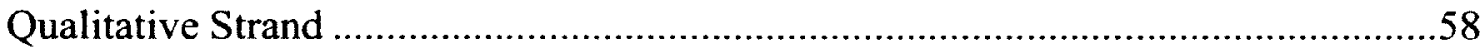

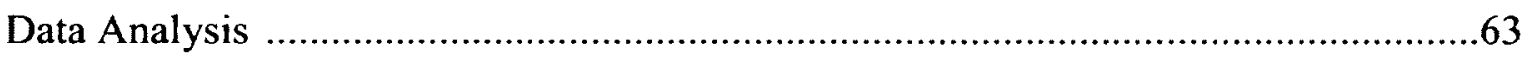

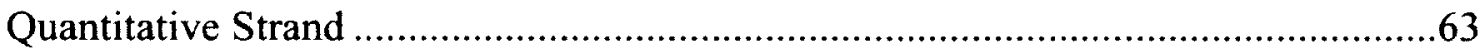

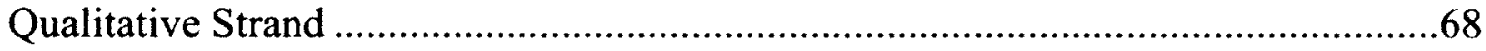

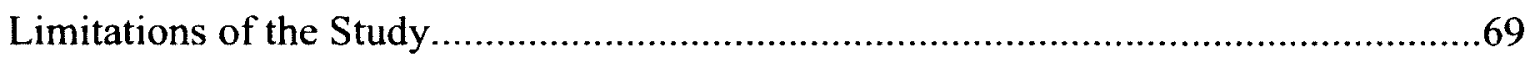

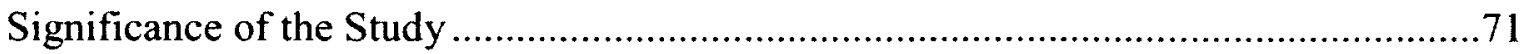

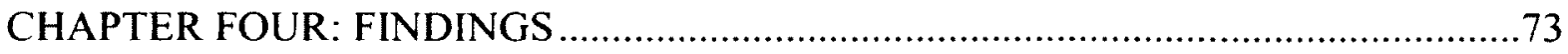

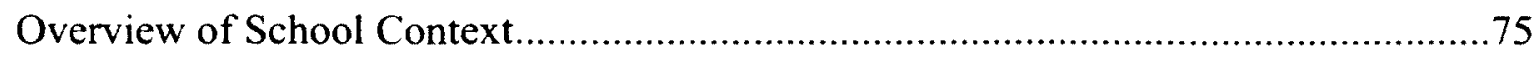

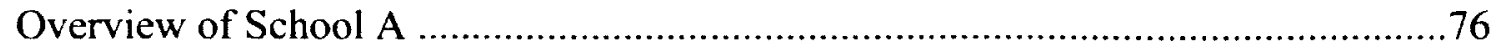




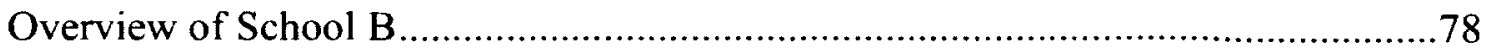

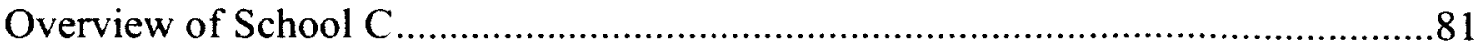

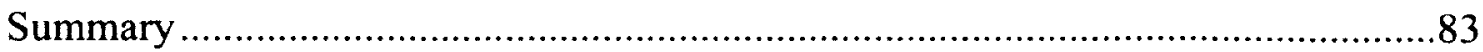

Socioeconomic Impact of Students' Physical Response to Health and Wellness ........84

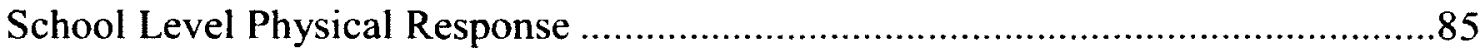

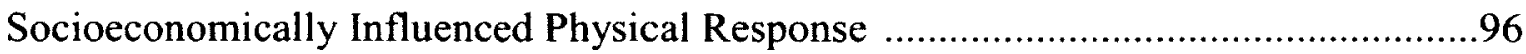

Summary

Socioeconomic Impact of Students' Psychological Response to Health and Wellness

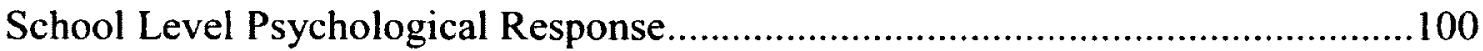

Socioeconomically Influenced Psychological Response …....................................109

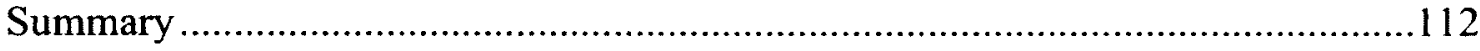

Surfside Union School District Health and Wellness Construct ..................................113

SUSD Perception of School Health and Wellness ................................................115

School Health and Wellness Components .......................................................122

SUSD Health and Wellness Programmatic Summary ........................................137

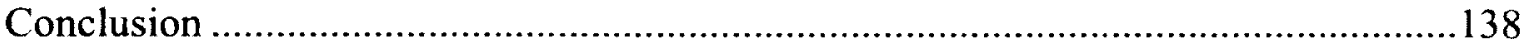

CHAPTER FIVE: IMPLICATIONS AND RECOMMENDATIONS .........................142

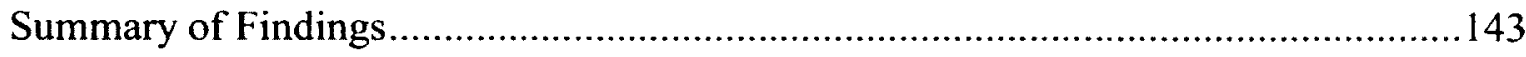

Physical Response to Health and Wellness .......................................................143

Psychological Response to Health and Wellness................................................148

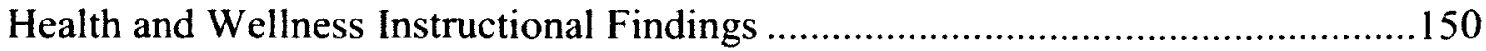

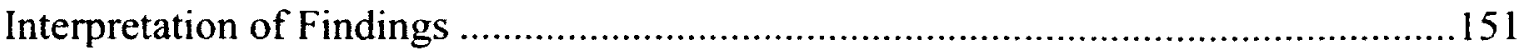


School A

School B

School C 160

Summary 163

Limitations 164

Implications for Future Research 169

Concluding Remarks 172

References 175

Appendices

A. Surfside Union School District Superintendent Interview Protocol 198

B. Surfside Union School District Personnel Interview Protocol 200

C. Surfside Union School District School Stakeholder Interview Protocol .......202

D. Surfside Union School District Parent Volunteer Interview Protocol .204

E. Surfside Union School District Student Focus Group Interview Protocol .....206

F. Surfside Union School District Health and Wellness Instructor Focus Group Interview Protocol 208

G. Physical Health and Subcategory Scores: California Healthy Kids Survey Question Compilation 210

H. Psychological Health and Subcategory Scores: California Healthy Kids

Survey Question Compilation. 212

I. Surfside Union School District Health and Wellness Components 


\section{LIST OF TABLES}

Table 1. The Development of the Coordinated School Health Program

Table 2. The Development of the Whole School, Whole Community, Whole Child

Model

Table 3. Free or Reduced Price Meal Eligibility for Surfside Union School District by

School .54

Table 4. Observed Activities by Surfside Union School District School

Table 5. Participating Surfside Union School District Stakeholders and Community

Personnel

Table 6. School Level Differences by Participating Surfside Union School District

School

Table 7. Changes in Physical Health Score by Participating Surfside Union School

District School

Table 8. Changes in Psychological Health Score by Participating Surfside Union School

District School 102

Table 9. Health and Wellness Components: School A 124

Table 10. Health and Wellness Components: School B 130

Table 11. Health and Wellness Components: School C 134 


\section{LIST OF FIGURES}

Figure 1. The Whole School, Whole Community, Whole Child model ........................43 


\section{CHAPTER ONE}

\section{BACKGROUND AND PURPOSE OF THE STUDY}

Educators and policymakers in the United States are expressing concern about student physical and mental well-being. The rate of childhood obesity has more than doubled in the past three decades (Centers for Disease Control and Prevention, 2013a), and today, one in five children and adolescents experiences symptoms of mental illness (Eaton et al., 2010). An array of conditions surface as a result of poor physical and mental wellness throughout childhood, and the United States has witnessed the impact on more and more of the population each year. The holistic well-being of youth has begun to receive attention politically, medically, and educationally. Despite this attention, children continue to fall victim to reversible conditions like obesity, behavioral issues, and social challenges resulting from an absence of physical and mental health.

\section{Child Wellness Research and Practice}

\section{Child Wellness Research}

Many children eat less nutritious foods, are less physically active, and carry unsafe levels of body weight despite society's knowledge and advanced understanding of medicine and technology. Poor physical wellness throughout childhood has been found to result in becoming overweight or obese in adulthood if not earlier in life (Center for Disease Control and Prevention, 2013a). The World Health Organization (WHO) describes childhood obesity as one of the most serious public health challenges in the $21^{\text {st }}$ Century. Overweight or obese children are more susceptible to an array of physical health conditions including but not limited to asthma, sleep apnea, diabetes, and hypertension (Au, 2012; CDC, 2013a; Haboush, 2010; Siegrist, 2011; Tercyak, 2006). 
The WHO estimates that 43 million children under the age of five meet the criteria to be classified as overweight (World Health Organization, 2012).

Being mentally well is equally important to physical wellness, yet ten to twenty percent of children worldwide experience mental disorders (Lee, Tiley, \& White, 2009; WHO, 2014), and only half receive the necessary mental health services (Dvorsky, 2013; Merikangas et. al., 2010). The National Institute of Mental Health (NIH) found that approximately eight and eleven percent of adolescents, respectively, suffer from anxiety and depressive disorders (NIH, 2014). When a student's mental wellness needs are not met, the student is susceptible to a number of conditions including, but not limited to, obsessive-compulsive disorder, social phobia, post-traumatic stress disorder, depression, and suicidal tendencies (NIH, 2014). Students receiving support for these challenging conditions have greater potential to join the $80 \%$ of students with a happier, healthier quality of life.

Research affirms health-related problems hinder the motivation and learning ability of urban low-income and minority youth (Basch, 2010). Rates of obesity are higher for children from low-income households and for minority children (Kumanyika \& Grier, 2006; Ogden, Carroll, Curtin, McDowell, Tabek, \& Flegal, 2006; Richmond \& Subramanian, 2008). Regardless of gender or age, children of a lower socioeconomic status (SES) are reported to have greater risk of obesity than wealthier children (Keane et al., 2012; Kumanyika \& Grier, 2006; Ogden, Carroll, \& Flegal, 2008; Richmond \& Subramanian, 2008) severely compromising their physical well-being.

Children residing in low-income communities are additionally vulnerable to crime and violence (Berman, Kurtines, Silverman, \& Serafini, 1996). This exposure results in 
emotional consequences such as post-traumatic stress disorder symptoms (Berman et al., 1996), psychological distress (Hill, Levermore, Twaite, \& Jones, 1996; Jenkins \& Bell, 1994) or anxiety (Kuther \& Fisher, 1998). Unless a child has means to engage in wellness activities outside the school day (through sports teams, physical activity, counseling, good nutrition, etcetera), school becomes an important opportunity for the child to access such services (Centers for Disease Control and Prevention, 2013a).

"Studies have provided evidence that poor nutrition and limited physical activity among today's children and youth negatively impact their physical, social, and emotional health as well as their school attendance, learning, and academic achievement" (Argon, Berends, Ellis \& Gonzalez, 2010). Findings of this nature stress a need for children to be exposed to programs and activities that support their holistic well-being to enhance both academic success and overall quality of life. As mentioned, school is likely to be the way many low-income students receive physical or mental wellness support. Unfortunately, most schools recovering from the political and financial repercussions of the No Child Left Behind Act (NCLB) of 2001 do not have the means to offer such services, and children's needs are left unmet (Leviton, 2008). This will be discussed in more detail later in the chapter.

\section{Child Wellness Practice}

Many private and public organizations have organized to support the holistic well-being of children. Chapter 2 will offer a landscape of current health and wellness programs that are emerging in low-income school communities. Two prominent initiatives promoted at the federal level have gained momentum and will be detailed 
within Chapter 2: Local School Wellness Policies and the Coordinated School Health Program.

Local School Wellness Policies (LWPs) were a federal requirement created to improve health and wellness and reduce rates of childhood obesity. As of the 2006-2007 school year, federal law mandated all local educational agencies participating in the National School Lunch Program to create and uphold a LWP for each governed school. The goal of LWPs is to promote better nutrition and regular physical activity of children (Center for Disease Control and Prevention, 2014). While data is yet to indicate a comprehensive change in school behavior or improvement when LWPs are present, federal and local efforts are being made to address the issue and mandate student health and wellness is addressed.

The Centers for Disease Control and Prevention (CDC) recommend the Coordinated School Health (CSH) strategy to enhance both student health and academic learning. The $\mathrm{CDC}$ recognizes a clear link between student health and academic success, and additionally views child health as a "fundamental part of the mission of schools" (CDC, 2013b). Goals of CSH include but are not limited to building partnerships among school health and education professionals, enhancing communication among health and education professionals in the community, and helping students engage in healthimproving behaviors while avoiding risky behaviors (CDC, 2013b). Detailed information about $\mathrm{CSH}$ and its ongoing transition to the Whole School, Whole Community, Whole Child model is available in Chapter 2. 


\section{School Wellness Policy Reform}

Education policy resulting from the No Child Left Behind Act (NCLB) required schools in the United States to prioritize academic standards and test scores due to low proficiency rates in English language arts, math, and science. (Center on Education Policy, 2007; Leviton, 2008; Ravitch, 2010; Trost \& van der Mars, 2009). Because a lack of accountability existed, NCLB emerged with the intention to improve the quality and access to rigorous academic instruction. As a result, however, children were "taught to the test" for over a decade in hopes to acquire the basic knowledge outlined in gradelevel standards to progress to the succeeding grade. The result of NCLB accountability was a phenomenon coined as curriculum narrowing, which resulted in the instructional depletion of subjects such as social studies, physical education, foreign language, and the arts (King \& Zucker, 2005; National Board on Educational Testing and Public Policy, 2003). While NCLB was well intended, under resourced schools in particular experienced curriculum narrowing, and the holistic attention to student wellness was ignored. At present, many schools remain depleted of both enrichment and student services that are necessary for a child's well-being and arguably for their academic success.

Recent reform efforts resulting from the forthcoming Common Core standards have encouraged schools to begin moving from a strict adherence to standardized assessmentcentered instruction toward more outcome-based instruction in hopes of maximizing learning. These standards require students to possess certain socio-emotional competencies that allow them to successfully collaborate, understand one another's 
perspectives, and persevere to solve problems (www.corestandards.org, 2013). These $21^{\text {st }}$ century skills are unlike anything previously mandated through NCLB, and they are expected to challenge students in interpersonal ways that require added support attainable through health and wellness instruction (Durlak, Weissberg, Dymnicki, Taylor, \& Schellinger, 2011).

California's transition to the Common Core standards is one of two ways that schools in this state are politically encouraged to incorporate health and wellness instruction to meet their students' holistic needs and maximize academic success. Another push for health and wellness instruction involves California Senate Bill 330, a recent revision to Section 51900.5 of the California Education Code. This measure requires the Instructional Quality Commission to consider including a category specifically for mental health instruction within the next revision of the Health Framework for California Public Schools (Legislative Counsel's Digest, Oct. 2, 2013). This bill requires one or more experts in the mental health and education fields to contribute to the development of this framework to ensure students are educated about all aspects of mental health. Instructional practices to enhance an awareness of mental illness and promote wellness are outlined and encouraged given recent statistics for mental illness (Legislative Counsel's Digest, Oct. 2, 2013). The Legislature recognizes the importance of mental health services and recommends the State Board of Education adopt these forthcoming measures upon the Health Framework's next revision.

Education reform efforts like the Common Core standards and S.B. 330 are encouraging schools and districts in California and other states throughout the country to find ways to introduce health and wellness instruction through governmental programs, 
partnerships with foundations, or private organizations invested in child wellness. Local Wellness Programs, the CDC's Coordinated School Health program, before and afterschool enrichment programs, and health and wellness school-day instruction are a few examples of reform measures currently surfacing at select schools.

Researchers in this field grapple with the cause and effect of obesity and child wellness, and some practitioners continue to search for ways to reverse the statistics and support the whole child within the public school system. Most researchers and practitioners agree that a healthy school environment should provide the necessary physical and mental resources for students so they have the opportunity to succeed academically (Carr, Schaible, \& Thomas, 2013). Such support is infrequently provided in public school environments today.

Present health and wellness-related education policy (physical education, health standards, instructional minutes, etcetera) does not have strict accountability measures, lacks priority during the school day, and is often overshadowed by core academic instruction. As a result, children from low-income communities are most susceptible to being denied access to health and wellness services because their schools are more likely to prioritize standardized academics over wellness (Kumanyika \& Grier, 2006). Even within low-income families where health and wellness support is provided, risk factors introduced in Chapter 2 still exist. Schools should serve as an additional partner and provide students with the necessary health and wellness support to become healthy, successful adults. 


\section{Problem Statement}

Due to policy measures, limited social and monetary capital, and minimal evidence of best practices, school-based health and wellness activities are believed to be more prevalent in highly resourced communities for three reasons. First, many lowerperforming schools do not have the option to incorporate health and wellness activities or programs into the school day. The No Child Left Behind Act's accountability measures require instruction to be centered on subjects that appear on annual standardized assessments (Center on Education Policy, 2007), and attention to lower academic proficiency scores make health and wellness a secondary concern. Although teachers and school leaders may value health and wellness activities, pressure to meet Annual Yearly Progress (AYP) benchmarks influence schools to align instruction to annual standardized assessments.

Second, lower performing schools may struggle to acquire the appropriate leadership, community support, and funding to attend to student health and wellness. Such stakeholders may not necessarily be against health and wellness instruction; they simply may not perceive a connection between health and wellness services and academic growth, or they hold a stronger sense of urgency for those outcomes that appear on annual standardized assessments. Additionally, monetary funding to allocate toward "enrichment" activities like health and wellness education is minimal, and leaders instead prioritize services targeting academic proficiency (Kumanyika \& Grier, 2006). It is difficult to justify diverting already limited funds to activities that do not directly target academics. 
Finally, few school-based examples currently exist to model best practices related to health and wellness instruction. Schools modeling the efficacy of health and wellness instruction would offer guidance to all schools - lower-performing or otherwise - and validate the need for this beneficial method of reform. The current emphasis on academic accountability, a need for both monetary and human capital, and the absence of school and community models causes health and wellness programs to be less-prominent in communities with fewer resources.

Low-income students could arguably be most in need of school-based health and wellness support services. Currently, researchers and practitioners are unsure how to best implement an effective health and wellness program, and if the construct of such programs should be different for low-income and students of means. Schools often provide an array of programs and activities, and it is nearly impossible to link student outcomes directly to health and wellness activities taking place at school. Although the literature supports a need for physical and mental support services for children, little is known about the effect of comprehensive health and wellness programs at schools serving sizeable low-income student populations.

\section{Purpose of the Study}

Efforts have begun in select schools and districts to address chronic low performance in new, holistic ways. Some communities embrace health and wellness programs as a means to improve student well-being and, in turn, academic performance. Reform measures are currently most prominent in higher income communities, but select education practitioners are striving to provide services to low-income students because of the benefits such services are believed to provide. The purpose of this study is to 
understand the impact of health and wellness education on the physical and psychological well-being of kindergarten through sixth grade students, and additionally determine if students are affected by health and wellness interventions differently based on their socioeconomic status.

\section{Research Questions}

This study takes an in-depth look at the health and wellness programs within three Title 1 schools from a single California school district. Through a mixed-methodological analysis, a health and wellness program's impact on each school's student population was studied. Specifically, this study was conducted to answer the following three research questions:

1. How do low-income students' physical responses to health and wellness instruction differ from their non-low-income peers at these schools?

2. How do low-income students' psychological responses to health and wellness differ from their non-low-income peers at these schools?

3. In what ways do schools with large numbers of low-income students incorporate health and wellness instruction?

Physical and psychological responses are examined in this document through a review of the literature available in Chapter 2, the methodology used to identify such characteristics in Chapter 3, and the findings and discussion that resulted from the study provided respectively in Chapters 4 and 5. At this juncture, physical responses can be identified as lifestyle alterations that improve one's bodily health, or actions that elevate one's external quality of life. Psychological responses are identified as behaviors, 
sentiments, or emotional reactions that could be influenced by health and wellness support.

This mixed-methodological study will be the first of its kind to explore the health and wellness programs and activities schools serving large numbers of low-income students have chosen to integrate into their school community. Each school will be treated as an independent case study in order to understand the program's goals and potential impact on low-income students. Although an identical research design is intended for each school site, differences in health and wellness instruction were anticipated. For this reason, research question three was included to determine if differences among the schools' incorporation of health and wellness may account for variations in student response.

It is important to note that this study was designed to identify existing health and wellness components that the three participating Title I schools have incorporated into their health and wellness program and to understand how socioeconomically different students at each school have responded both physically and psychologically. Data are not sufficiently comprehensive to offer comparisons of the participating schools, nor can an evaluation of each program's effectiveness be made conclusively. However, as will be discussed in Chapter 5, the findings do offer some insight into the degree to which the health and wellness program at each of the schools relates to the ten components of emerging Whole School, Whole Community, Whole Child model (introduced in Chapter 2) and what future research is necessary in this context. 


\section{Limitations}

Although this study seeks to understand the impact of school-based health and wellness education, limitations should be noted that inhibit the generalizability of the findings presented. Limitations include the regional uniformity of participating schools, the study's focus on low-income students, and the prioritization of qualitative data.

Chapter 3 provides an overview of the sampling procedures and the final selection of the three participating schools. Purposeful and convenience sampling resulted in a crosscase analysis of three Title 1 schools within a single Southern California school district. Although these schools primarily support the community's lowest-income students, all three schools still reside within a region that does not emulate the nation's low-income student population at large. The uniqueness of this region and details about the participating schools is further delineated in the limitations section of Chapter 3.

Because this paper concentrates on the impact school-based health and wellness education may or may not have on low-income elementary students, literature about health and wellness in relation to the student population at large will not be included. The literature reviewed in Chapter 2 prioritizes studies whose participants are enrolled in primary K-6 public schools and, to the extent possible, low-income. This study was conducted in Title I kindergarten through $6^{\text {th }}$ grade schools, and the literature reviewed in Chapter 2 mirrors this work.

Although this study includes both quantitative and qualitative methods by design, limitations emerged compromising the quality of findings resulting from the quantitative data. Such limitations are explained in Chapter 3. Two that are significant are small 
sample sizes and the anonymity of certain data that inhibited the ability to discern which respondents were low-income. To compensate for the latter, focus groups were held with low-income and non-low-income students on separate occasions to uncover potential differences in their experiences and responses. Thus, findings from the study's qualitative methods took precedence in this context over quantitative methods. 


\section{CHAPTER TWO \\ REVIEW OF LITERATURE}

Research from scholars in countless fields affirm the benefits of a healthy lifestyle and advocate that healthy choices can be learned during childhood and maintained as an adult (Bates \& Eccles, 2008; CDC website, 2013c; Hoxie-Setterstrom \& Hoglund, 2011). According to the Centers for Disease Control and Prevention (CDC), "Establishing healthy behaviors during childhood is easier and more effective than trying to change unhealthy behaviors during adulthood. Schools play a critical role in promoting the health and safety of young people helping them establish lifelong healthy behavior patterns" (CDC website, 2013c). This fact is especially true for low-income children given the health and educational challenges they are more likely to experience (Aud, Fox, Kewal, \& Ramani, 2010; Braveman, Cubbin, Egerter, Williams \& Pamuk, 2010; Kumanyika \& Grier, 2006).

This section will include a review of the literature published after 2005 that identifies physical and psychological responses students are more likely to exhibit when health and wellness services are available at their school. The year 2005 was selected because No Child Left Behind (NCLB) legislation required all states to institute annual testing in grades three through eight by the 2005-2006 school year. (United States Department of Education, 2014). Four years following NCLB's adoption in 2001 additionally offered time for research to be generated in this reforming educational environment, making 2005 an ideal year. Classic literature related to health and wellness will also be presented through current literature reviews in order to uphold a representational sweep of all applicable research. 
A wealth of literature was available and reviewed from the medical, psychological, educational, and political arenas examining interventions that are found to affect students' physical and mental health. The literature most pertinent to students' physical and psychological responses to school-based health and wellness interventions is included. The review excludes health and wellness endeavors taking place at secondary schools as well as activities extending beyond the school-day environment, such as after school clubs or sports teams. To the extent possible, the chapter will prioritize and detail studies conducted within low-income schools, but studies with samples representative of the school or community population will be included.

Following an overview of student physical and psychological responses to various health and wellness interventions, this chapter will conclude by explaining two types of health and wellness programs introduced in schools: models, initiatives, or programs promoted at the federal level, and independent programs resulting from philanthropic or local community action. Both will be described, and to the extent possible, research evaluating their effectiveness will be provided.

\section{Students' Physical Response to Health and Wellness Instruction}

As schools implement programs to support the health and well-being of students, physical responses to a program are expected and may differ among subgroups like gender, race, age, or socioeconomic status. A review of the literature suggests that children have the ability to respond physically to health and wellness instruction in four ways: They could be more likely to eat healthier foods (Fung et al., 2012; Gibb et al., 2013; Graham \& Zidenberg-Cherr, 2005; McAlessee \& Rankin, 2007; Morris, \& Zidenberg-Cherr, 2009; Ozer, 2007; Robinson-O’Brien, Story, \& Heim, 2009; Sims, 
Bock, \& Hackett, 2013; Stewart, Purner, \& Guzman 2013), be more physically active (Carlson et al., 2013; Cradock et al., 2014; Dellert \& Johnson, 2013; Demetriou \& Honer, 2012; Eather, Morgan, \& Lubans, 2013; Fung et al., 2012; Hyndman, Benson, Ullah, \& Telford, 2014; McKenzie \& Kahan, 2008), have lower risk of obesity through weight loss and/or body mass index reduction (Dencker et al., 2006; Fairclough et al., 2013; Flynn et al., 2006; Fung et al., 2012; Gonzalez-Suarez, Worley, Grimmer-Somers, \& Dones, 2009; Hollar et al., 2010; Rito, Carvalho, Ramos, \& Breda, 2013; Siegrist et al., 2011; Veugelers \& Fitzgerald, 2005), or they could be less likely to engage in risky healthrelated behaviors (substance use, violence, and sexual activity) (Beets et al., 2009; Hahn, R., Fuqua-Whitley, D., Wethington, H., Lowy, J., Crosby, A., Fullilove, M...\& Chattopadhyay, S., 2007). Pertinent literature supporting each response will be shared in the subsequent sections.

\section{Healthy Diet}

Three applicable studies of physical activity intervention programs, five studies of garden science programs, and two comprehensive literature reviews were found to support the claim that school-based health and wellness interventions correlate to a healthier diet (Fung et al., 2012; Gibb et al., 2013; Graham \& Zidenberg-Cherr, 2005; McAlessee \& Rankin, 2007; Morris, \& Zidenberg-Cherr, 2009; Ozer, 2007; RobinsonO’Brien, Story, \& Heim, 2009; Sims, Bock, \& Hackett, 2013; Stewart, Purner, \& Guzman 2013). No studies were found to challenge that statement. The five studies of school garden-science programs each evaluated a different sample, region, and program, but all affirmed improvements in student eating habits when exposed to school-based gardens. 
Stewart et al. (2013) analyzed the presence and affect of school garden programs throughout Santa Clara County, California, explicitly targeting access within low-income communities. Although school gardens were found to improve children's willingness to try healthier foods and be more physically active, no school gardens within Santa Clara County were found in communities with $15 \%$ or more low-income families (Stewart et al., 2013). Such correlates suggest low-income students may have less access to gardenscience programs, which are found to improve nutritional habits.

Despite this inequality, school gardens have become a prominent addition to our nation's schools. California alone currently has over 3,000 school gardens (California Department of Education, 2014) yet the body of literature exploring their impact is minimal. In total, Ozer's (2007) review of the literature presented five appropriate research studies dated before 2005 . Though slightly dated, Ozer (2007) hypothesizes that school gardens are a worthwhile tool to promote health and wellness in multiple domains (self-esteem, responsibility, cooperation, etc.) and promote positive youth development. Of the five studies she reviewed, findings suggest students participating in school gardens have greater knowledge of- or preference toward- vegetables (Morris \& Zidenberg-Cherr, 2001), a willingness or more positive attitude toward eating fruits and vegetables (Lineberger \& Zajicek, 2000; Morris, Neustadter, \& Zidenberg-Cherr, 2001), and an increase in the consumption of fruits and vegetables in addition to physical activity (Twiss et al., 2003). One study reviewed by Ozer (2007) found school gardens to have positive effects for girls but not boys, but stressed concern surrounding the variation and infrequent exposure to the garden program (Waliczek, Bradley, \& Zajicek, 2001). Ozer 
(2007) also introduced a school garden science program, Berkeley, California's Edible Schoolyard, which will be introduced in the final section of this chapter.

\section{Increased Physical Activity}

The Department of Health and Human Services, the Institute of Medicine, and countless other highly-regarded organizations stress the importance of regular, rigorous physical activity while also identifying schools as the prime locale for children to become more physically active. Currently, however, two-thirds of United States' students fail to meet the minimum recommended amount of sixty minutes of daily physical activity in or outside the school day (Basch, 2010). When schools engage in methods to support the health and wellness of students, activities are implemented that initially increase the degree to which students engage in physical activity (Carlson et al., 2013; Cradock et al., 2014; Dellert \& Johnson, 2013; Demetriou \& Honer, 2012; Eather, Morgan, \& Lubans, 2013; Fung et al., 2012; Hyndman, Benson, Ullah, \& Telford, 2014; McKenzie \& Kahan, 2008). Although this immediate improvement is beneficial to student health and wellness, a large amount of this body of literature offers evidence to suggest physical activity levels may not change significantly as a result of an intervention (Elinder et al., 2012; Seigrist et al., 2011), or long-term improvements in physical activity are not sustained beyond the program's duration (Meyer et al., 2014; Puma et al., 2013).

Eight applicable studies and two literature reviews support the claim that schoolbased health and wellness interventions correlate to improvements in students' level of physical activity (Carlson et al., 2013; Cradock et al., 2014; Dellert \& Johnson, 2013;

Demetriou \& Honer, 2012; Eather, Morgan, \& Lubans, 2013; Fung et al., 2012; Hyndman et al., 2014; Long et al., 2013) while four studies challenge it (Elinder et al., 
2012; Meyer et al., 2014; Puma et al., 2013; Seigrist et al., 2011). Intervention durations ranged from eight weeks (Eather et al., 2013) to two years (Fung et al., 2012) and randomized control trial methodologies were dominant in eight of eleven relevant studies. Other designs, such as Long et al.'s (2013) study utilized National Health and Nutrition Examination survey data $(\mathrm{n}=2,548)$ to affirm each additional minute of moderate to vigorous physical activity (MVPA) within the school day is associated with an additional 1.14 minutes of total daily MVPA, or 0.14 additional minutes outside the school day, regardless of age, gender, or race.

Contention as to the effectiveness of a health and wellness intervention resides in the longevity of change in student physical activity. Meyer et al. (2014) and Puma et al. (2013) revisited the effects of health and wellness interventions three and six years, respectively, after the program's implementation. Although Meyer et al. (2014) detected short-term changes in physical activity initially after the intervention, neither Meyer et al. (2014) nor Puma et al. (2013) found them to be long-lasting. Findings of this nature suggest school leaders should be mindful of an intervention's quality and the sustainability of the program to influence long-term improvement in student wellness.

Successful improvements in physical activity were particularly evident from programs taking a coordinated approach to health and wellness. Fung et al.'s (2012) study and Dellert et al's (2013) literature review evaluated and overviewed health and wellness programs that extended to parents, school, and community members as well as students. While Fung et al.'s (2012) pre/post study found that children from ten schools in Alberta, Canada were more physically active two years after the intervention began, 
Dellert et al. (2013) found increased levels of student physical activity when parents and children were involved with the intervention together.

McKenzie and Kahan (2008) published an article arguing that schools are integral to increase physical activity. They stressed schools that create an enjoyable physical education experience provide students with the opportunity to "learn basic generalizable movement skills that can be integrated into multiple activities, sports, and games they engage in at school, in the community, and later in life" (p. 174). When schools incorporate a health-related curriculum, provide trained physical education personnel or teachers, and offer an environment suitable for regular physical education, long-lasting improvements in physical activity result (Dowda, Sallis, McKenzie, Rosengard, \& Kohl, 2005; McKenzie et al., 2003; McKenzie \& Kahan, 2008).

Without the support of schools, McKenzie and Kahan (2008) also stress children living in poverty are at increased risk of low levels of physical activity compared to children not living in poverty. This difference is due to restrictions in living conditions, safety concerns, or a lack of facilities. Recreational facilities consistently are found to be unequally distributed (Basch, 2010; Kumanyika \& Grier, 2006), and "Poor urban minority youth have less access to safe recreational facilities" (Basch, 2010, p. 40; Gordon-Larsen, Nelson, Page, \& Popkin, 2006; Moore, Deiz, Roux, Evenson, McGinn \& Brines, 2008). Carlson et al. (2014) affirms this disparity finding schools in lower socioeconomic communities to have less access to physical education teachers. As a result, students at schools within challenged communities had 4.4 fewer minutes of daily moderate to vigorous physical activity (MVPA) than schools in high socioeconomic regions (Carlson et al., 2014). 


\section{Changes in Weight Loss/Body Mass Index (BMI)}

In addition to advocating for regular school-based physical activity, McKenzie and Kahan (2008) offer evidence to suggest overweight children are statistically more likely to remain overweight into adulthood without experiencing an effective health and wellness intervention. Their paper cited a study by Datar and Sturm (2004) that projected increasing physical education by a minimum of one hour each week for kindergarten and first graders has the potential to reduce the number of overweight 5-6 year-old females by as much as ten percent across the country. When children regularly engage in physical activity, reductions in body fat are likely, resulting in a reduction of weight and BMI (Dencker et al., 2008; Eisenmann, Bartee, Schmidy, Welk, \& Fu, 2008; Katzmarzyk et al., 2008; Lohman et al., 2008; Ortega et al., 2007). School involvement is again seen as a conduit to reverse the current obesity statistics through healthful school meals and foods, physical education programs at recess, classroom health education, and school health services (Story, Kaphingst, \& French, 2006).

Seven applicable studies and two literature reviews support the claim that schoolbased health and wellness interventions correlate with improvements in student weightloss or changes to Body Mass Index (BMI) (Denckner et al., 2006; Fairclough et al., 2013; Flynn et al., 2006; Fung et al., 2012; Gonzalez-Suarez, Worley, Grimmer-Somers, \& Dones, 2009; Hollar et al., 2010; Rito, Carvalho, Ramos, \& Breda, 2013; Siegrist et al., 2011; Veugelers \& Fitzgerald, 2005) while two studies challenge it (Rappaport, Daskalakis, \& Sendecki, 2013; van Grieken et. al., 2014). All studies including a physical activity intervention component yielded favorable results, whereas those studies not including physical activity did not. Measurable change indicators presented in 
studies included waist circumference, BMI scores, accelerometers, student surveys, and routinely collected school data.

A two-year study conducted by van Grieken et al. (2014) measured the effectiveness of a parental healthy lifestyle counseling component of the 'Be active, eat right' intervention, finding the counseling component alone was not an effective method to influence student BMI. In contrast, Fairclough et al.'s (2013) randomized control study of the CHANGE program with a physical activity component yielded significant between group effects for waist circumference, and BMI. These findings were most apparent for overweight, obese, and students of lower socioeconomic status.

All studies yielding positive results followed a research design that included active data collection by researchers. Rappaport et al. (2013) adversely utilized two years of Body Mass Index (BMI) data to construct a cluster-randomized trial $(n=8,186)$ of a nutrition education intervention that provided no mention of a physical activity component. Using six years of height and weight data routinely collected each year by school personnel, all data were provided to, and analyzed by researchers. Findings indicate obesity levels within both the control and intervention groups increased by three percent, concluding the intervention had no effect.

This field of literature presents two important points that should be noted. First, positive effects in student weight loss and BMI are found when health and wellness interventions incorporate a physical activity component (Denckner et al., 2006; Fairclough et al., 2013; Flynn et al., 2006; Fung et al., 2012; Gonzalez-Suarez et al., 2009; Hollar et al., 2010; Rito et al., 2013; Siegrist et al., 2011; Veugelers \& Fitzgerald, 2005). Interventions omitting physical activity but solely targeting nutrition, counseling, 
or other interventions do not appear to significantly influence weight loss (Rappaport et al., 2013; van Grieken et al., 2014). Second, findings generated from the 173 studies compiled within the two applicable literature reviews stress long-term health and wellness interventions and adjoining studies are valuable compared with short interventions. The field is saturated with shorter term interventions and evaluations, but long term effects involving weight loss and BMI change are limited and of value (Flynn et al., 2006; Gonzalez-Suarez et al., 2009). Recommendations as to optimal intervention durations were not presented in the literature.

\section{Less-Risky Behavior}

The Centers for Disease Control and Prevention (CDC) identify the following six health-risk behaviors that are determined by the Youth Risk Behavior Surveillance System (YRBS) ${ }^{\prime}$ to be the leading causes of death and disability among youth and adults: (1) Behaviors that contribute to unintentional injuries and violence; (2) Sexual behaviors that contribute to unintended pregnancy and sexually transmitted diseases, including HIV infection; (3) Alcohol and other drug use; (4) Tobacco use; (5) Unhealthy dietary behaviors; and (6) Inadequate physical activity (CDC website, 2011). Since unhealthy dietary behaviors and inadequate physical activity have been discussed in the previous sections, the literature surrounding the remaining four health-risk behaviors will be addressed in this section.

Twenty-year trends in the CDC's Prevalence of Risky Behaviors show declines in alcohol consumption and instances of riding in cars with an intoxicated driver, but a rise in instances of marijuana use and attempted suicide was reported. No change in weapon

\footnotetext{
'More information about the CDC's Youth Risk behavior Surveillance System can be found at: http://www.cdc.gov/healthyyouth/yrbs/.
} 
concealment, smoking, or sexual-risk behavior have occurred since 1991 (CDC, 2011). Consistent with the accompanying body of literature, however, such health-risk behavior trends reported in the YRBS only encompass data from students at the secondary level.

Conversely, research indicates traumatic events occurring in early childhood contribute to the social dysfunction that is being studied with adolescents through the YRBS and other studies. Researchers have identified a relationship between social dysfunctional behaviors and evidence of neurological change resulting from early childhood trauma (Delima \& Vimpani, 2011). Understanding the long-term impact of childhood trauma is essential as practitioners advocate for and implement health and wellness support.

Considering the implications of early childhood trauma, studies of health and wellness interventions implemented at the secondary level have been found to diminish the prevalence of risky behaviors among adolescents (Botvin, Griffin, \& Nichols, 2006; Conrod, Stewart, Comeau, \& Maclean, 2010; Eaton, et al., 2012; Farhat, Iannotti, \& Simons-Morton, 2010; Jackson, Geddes, Haw, \& Frank, 2011; Patton et al., 2006). Given that this chapter is limited to studies with samples of elementary-age students, findings from studies conducted with adolescents will not be examined. They can, however, offer evidence to suggest health and wellness interventions may be equally beneficial to reduce risky behavior among elementary students, especially given the temporal proximity to potentially traumatic early childhood experiences.

Two applicable studies of elementary-age participants and one literature review support the claim that the incorporation of school-based health and wellness interventions are correlated to the reduction of risky behavior engagement (Beets et al., 2009; Coyle et 
al., 2004; Hahn et al., 2007). The study conducted by Coyle et al. (2004) falls outside of the 2005 timeframe leaving only Beet's (2009) study and Hahn et al.'s (2007) literature review applicable. Beets et al.'s (2009) matched-pair, cluster-randomized control trial study of 1,714 Hawaiian fifth graders evaluated a health and wellness program, Positive Action, over a five-year time period. Findings from student self-reports indicate that substance use, violence, and sexual activity were significantly lower at schools with the Positive Action intervention. A dose-response analysis ${ }^{2}$ was also conducted to find that students participating in the program for a minimum of five years were significantly less likely to exhibit such risky behaviors (Beets et al., 2009).

Hahn et al. (2007) reviewed the effectiveness of 65 pre-kindergarten through twelfth-grade wellness interventions to identify their impact on violence and other risky behaviors. Results from all 65 studies were summarized to find a $-15 \%$ total median effect indicating a reduction of disruptive/antisocial behavior, general violence, or bullying following the intervention. Studies conducted at the elementary $(K-5)$ level generated a more substantial $-18 \%$ median effect in comparison to the. $-7 \%$ median effect for middle school (6-8) suggesting the initiation of interventions earlier in a child's educational career could be advantageous.

Findings from Hahn et al.'s (2007) literature review and Beets et al.'s (2009) longitudinal study in conjunction with findings from secondary school studies provide evidence to suggest school-based health and wellness interventions are capable of

\footnotetext{
${ }^{2}$ A dose-response analysis, according to the World Health Organization, involves "the amount of an agent... administered to an experimental animal or human in a controlled experimental setting."(WHO, 2008, p. 3). This process provides the opportunity to understand the optimal duration or amount of a particular intervention in order to generate effects.
} 
supporting the reduction of risky behavior within elementary and secondary school environments (Beets et al., 2009; Farhat, Iannotti, \& Simons-Morton, 2010; Hahn et al., 2007; Jackson, Geddes, Haw, \& Frank, 2011; Patton et al., 2006). Available literature, however, exemplifies the scarcity of research conducted at the elementary level. Whether a lack of elementary school-based interventions or an absence of conjoining research, this body of literature demonstrates risky behavior is currently more of a public concern for adolescents and secondary school environments. Regardless, elementary students' engagement in risky behaviors could be reduced with the presence of appropriate interventions.

\section{Summary}

This section of Chapter 2 included a review of the literature published after 2005 that identified various physical responses students are more likely to exhibit when health and wellness services are available at their school site. Literature was available and reviewed from the medical, psychological, educational, and political arenas examining interventions that may affect the betterment of child physical health, and the previous four sections examined the most prominent research recently published outlining how students respond. The literature suggests children respond physically to health and wellness instruction in four ways: they could be more likely to eat healthier foods (Fung et al., 2012; Gibb et al., 2013; Graham \& Zidenberg-Cherr, 2005; McAlessee \& Rankin, 2007; Morris, \& Zidenberg-Cherr, 2009; Ozer, 2007; Robinson-O’Brien, Story, \& Heim, 2009; Sims, Bock, \& Hackett, 2013; Stewart et al., 2013), be more physically active (Carlson et al., 2013; Cradock et al., 2014; Dellert \& Johnson, 2013; Demetriou \& Honer, 2012; Eather et al., 2013; Fung et al., 2012; Hyndman et al., 2014; McKenzie \& Kahan, 
2008), have lower risk of obesity through weight loss and/or body mass index reduction (Denckner et al., 2006; Fairclough et al., 2013; Flynn et al., 2006; Fung et al., 2012; Gonzalez-Suarez, Worley, Grimmer-Somers, \& Dones, 2009; Hollar et al., 2010; Rito, Carvalho, Ramos, \& Breda, 2013; Siegrist et al., 2011; Veugelers \& Fitzgerald, 2005), or could be less likely to engage in risky health-related behaviors (substance use, violence, and sexual activity) (Beets et al., 2009; Hahn et al.,2007). The next section examines pertinent research identifying students' psychological responses to school-based health and wellness interventions.

\section{Students' Psychological Response to Health and Wellness Instruction}

As schools implement programs to support the health and wellness of students, behavioral, social, and psychological responses are expected and may differ among subgroups that include gender, race, age, or socio-economic status. As introduced in

Chapter 1, psychological responses are identified as behaviors, sentiments, or emotional reactions that could be influenced by health and wellness support. A review of the literature suggests children have the ability to psychologically respond to health and wellness instruction in three ways: They could enhance their mental wellness reducing instances of depression, anxiety, or other stressors (Beehler, Birman, \& Campbell, 2012; Collins, Woolfson, \& Durkin, 2014; Cuijpers, van Straten, Smits, \& Smit, 2006; Lee, Tiley, \& White, 2009; Ohl, Mitchell, Cassidy, \& Fox, 2008; Stallard, 2013; WebsterStratton, Reid, \& Stoolmiller, 2008); experience a change in attitude toward their self (self-concept, self-efficacy, or self-esteem)(Barry, Clarke, Jenkins, \& Patel, 2013;

Dalgas-Pelish, 2006; Durlak, Weissberg, Dymnicki, Taylor, \& Schellinger, 2011; Telles, Singh, Kumar, Kumar, \& Balkrishna, 2013); or experience a change in behavior and 
interaction with others (Bavarian et al., 2013; Chalmers-McDonald, 2006; Durlak et al., 2007; Durlak et al., 2011; Frey et al., 2005a; Frey, Nolen, Edstrom, \& Hirschstein, 2005b; Graham \& Zidenberg-Cherr, 2005; Hayes, Giallo, \& Richardson, 2010; Lewis et al., 2010; Munoz \& Vanderhaar, 2006; Snyder et al., 2012; Webster-Stratton, Reid, \& Stoolmiller, 2008; Wilson \& Lipsey, 2007). Pertinent literature supporting each response will be shared in the subsequent sections.

Unlike health and wellness programs that explicitly report potential changes in physical responses, many of the findings reporting psychological effects are grounded in behavioral changes as opposed to changes in elementary students' thoughts, feelings, or beliefs. This is likely due to age-related challenges impeding self-reporting, and therefore much of the evidence below is drawn from behavioral observations or the perception of parents and teachers as opposed to student introspective perceptions of self.

\section{Mental Wellness}

"Although mental health challenges experienced early in childhood tend to be stable and predictive of negative outcomes later in youth, early prevention and intervention has the potential to alter this negative trajectory" (Hill, Lochman, Coie, Greenberg, \& Conduct Problems Prevention Research Group [CPPRG], 2005). Although schools are beginning to play a larger role to support student mental wellness, select scholars in the field indicate that mental health remains outside of the mission of public education (Weist $\&$ Paternite, 2006) or interventions that have been introduced have limited effect on student mental wellness (Hoagwood et al., 2007; Spense, 2007). In a review of school-based interventions and their correlation with changes in mental wellness, five applicable studies and two literature reviews support the claim that health 
and wellness interventions enhance student emotional wellness (Beehler, Birman, \& Campbell, 2012; Collins, Woolfson, \& Durkin, 2014; Cuijpers, van Straten, Smits, \& Smit, 2006; Lee, Tiley, \& White, 2009; Ohl, Mitchell, Cassidy, \& Fox, 2008; Stallard, 2013; Webster-Stratton, Reid, \& Stoolmiller, 2008) while one meta-analysis challenges it (Spense \& Shortt, 2007).

Although countless organizations advocate to support the mental health of youth and identify schools as an ideal locale to do so, few school-based programs have surfaced to support mental health, and even fewer have been evaluated. Much of the literature on this topic is newly published indicating a present interest in the issue (Beehler et al., 2012; Collins et al., 2014; Stallard, 2013), and many interventions and accompanying studies originate in Europe (Collins et al., 2014; Lee et al., 2009; Ohl et al., 2008). Spence \& Shortt's critique of school-based mental health interventions in 2007 supports the absence of effective interventions in the United States at the time of publication. They identified and evaluated the effectiveness of universal school-based interventions designed to reduce instances of depression in children. Their findings show little programmatic evidence as to the efficacy and effectiveness to prevent depression. . Spence \& Shortt (2007) conclude by suggesting that schools in the United States should look to implement more credible and effective programs given their findings.

Counter to Spencer and Shortt's (2007) conclusion, Stallard's (2013) more recent review identifies fifty-five randomized control studies that claim interventions for depression to be effective. He states,

...[Cognitive Behavior Therapy] CBT interventions typically target factors to protect against the development of depression such as positive and enabling thinking styles, emotional recognition and regulation, coping and personal effectiveness skills. Compared to no-intervention both universal and targeted 
depression prevention programs reduced depressive symptoms at up to 12-month follow-up (p. 60).

Moreover, Stallard (2013) identified twenty-seven school-based anxiety prevention programs. Most interventions provided between eight and ten cognitive behavioral therapy sessions throughout the intervention, and Stallard (2013) explicitly referenced FRIENDS as a particularly effective program to aid children in the identification and management of anxious thoughts and feelings through age-appropriate stories, quizzes, role-plays, and games. A recent search for the FRIENDS program to learn more about its construct, however, yielded no results.

Studies conducted by Beehler et al. (2012), Ohl et al. (2008), Lee et al. (2009), and Collins et al. (2014) each evaluated separate interventions designed to promote mental wellness finding significant improvement in participating children. While Beehler et al., (2012) specifically assessed the presence of post-traumatic stress disorder symptoms in traumatized immigrant children, all other researchers utilized Goodman's strengths and difficulties questionnaire to identify improvements in student well-being.

Programmatic improvements over the course of six years noted in both Spencer and Shortt (2007) and Stallard's (2013) reviews indicate more effective health and wellness programs have entered the public school arena in large numbers. That growth, in conjunction with the findings from Beehler et al. (2012), Ohl et al. (2008), Lee et al. (2009), and Collins et al. (2014), suggest mental wellness has grown in prominence in recent years. Although there is still much we can learn about the programmatic effects on student emotional wellness, current literature indicates that select children are experiencing the benefits of school-based interventions (Beehler et al., 2012; Collins et 
al., 2014; Cuijpers et al., 2006; Lee et al., 2009; Ohl et al., 2008; Stallard, 2013; WebsterStratton et al., 2008).

\section{Attitude Toward Self}

In a large-scale kindergarten through twelfth grade meta-analysis of 213 schoolbased social and emotional learning (SEL) programs, Durlak et al. (2011) outlined the Collaborative for Academic, Social, and Emotional Learning's (CASEL's) (2005) goals of SEL to foster the following cognitive, affective, and behavioral competencies: selfawareness, self-management, social awareness, relationship skills, and responsible decision making (p. 406). Although findings from Durlak et al.'s (2011) meta-analysis demonstrate significant improvement in kindergarten through twelfth-grade student attitudes aligned to CASEL's goals, a closer analysis of the referenced studies and papers indicate a change in student attitude was documented only at the secondary level. No studies at the elementary level are cited to support this finding.

The lack of evidence to support Durlak et al.'s (2011) finding remains consistent throughout a review of this vast body of literature. Although the betterment of student attitude has been associated with health and wellness interventions, they are primarily being implemented and/or evaluated at the secondary level. Barry, Clarke, Jenkins, and Patel (2013) were commissioned by the World Health Organization to review the presence and effectiveness of mental health promotion interventions within low and middle-income countries. Although they too found positive effects on students' selfesteem, motivation, and self-efficacy, their basis for this finding relied largely on interventions and research with secondary-age students. Barry et al. (2013) explicitly call 
for a need to ensure implementation research is conducted with younger primary schoolage children alongside the work being done at the secondary level (p. 17).

Two applicable studies support the enhancement of student self-attitude in conjunction with an elementary school-based intervention. Telles et al. (2013) and Dalgas-Pelish (2006) respectively evaluated yoga and self-esteem enhancement programs finding change in students' attitude of self. Telles (2013) found a greater improvement in student self-esteem with children who participated in the control physical activity program as opposed to the intervening yoga program, and Dalgas-Pelish's (2006) utilization of the Coopersmith Self-Esteem Inventory indicated improvements in general and social areas of self-esteem develop over time. Dalgas-Pelish (2006) also found children of lower socioeconomic status had lower self-esteem scores at the pre- and posttesting periods compared with the sample at large. Limitations are apparent with both studies given that both samples contained fewer than 100 students.

Studies or evaluations of the effects of health and wellness interventions on elementary students' self-perception, self-esteem, or other change in attitude are limited. Although this may currently be the case, the presence of secondary interventions and the accompanying research and evaluations indicate school-based interventions can be beneficial to student attitudes of self (Barry et al., 2013; Dalgas-Pelish, 2006; Durlak et al., 2011; Telles, 2013;). These present day findings are consistent with trends in dated psychological literature (Durlak \& Wells, 1997; Larkin \& Thyer, 1999). A lack of evidence at the elementary school level may, in part, be due to young students' developmental inability to introspectively discuss or evaluate their feelings or perspectives. Perhaps as more primary schools acquire health and wellness programs to 
support mental wellness, more research will surface allowing scholars to study their effectiveness and learn how to better support the mental health of young students.

\section{Social Behavior and Interaction}

As mentioned in the section's introduction, much of the literature reporting psychological responses share behavioral findings as opposed to self-reported changes in thoughts, feelings, or beliefs at the elementary school level. This is evidenced by the limited body of literature in the previous section. As such, a wealth of rigorous research and syntheses of the literature has been conducted to showcase how student behavior and interaction is affected by the presence of school-based health and wellness interventions targeting psychological responses. A review of this body of literature reveals studies that identified student behavior changed in the following three ways: (1) Researchers witnessed a reduction in aggression and/or bullying (Frey et al., 2005a; Frey, Nolen, Edstrom, \& Hirschstein, 2005b; Hayes, Giallo, \& Richardson, 2010; Lewis et al., 2010; Wilson \& Lipsey, 2007); (2) An increase in pro-social behavior (Chalmers-McDonald, 2006; Durlak et al., 2007; Frey et al., 2005b; Hayes, et al., 2010; Snyder, et al., 2012; Webster-Stratton, Reid, \& Stoolmiller, 2008); and (3) Better academic engagement and/or performance (Bavarian et al., 2013; Durlak et al., 2011; Graham \& ZidenbergCherr, 2005; Munoz \& Vanderhaar, 2006). In total, thirteen applicable studies support the claim that health and wellness interventions enhance positive changes in behavior and interaction (Bavarian et al., 2013; Chalmers-McDonald, 2006; Durlak et al., 2007; Durlak et al., 2011; Frey et al., 2005a; Frey, Nolen, Edstrom, \& Hirschstein, 2005b; Graham \& Zidenberg-Cherr, 2005; Hayes, Giallo, \& Richardson, 2010; Lewis et al., 2010; Snyder, et al., 2012; Munoz \& Vanderhaar, 2006; Webster-Stratton, Reid, \& Stoolmiller, 2008; 
Wilson \& Lipsey, 2007) while one study solely challenges the impact on child aggression (Boxer, Guerra, Huesmann, \& Morales, 2005).

While three studies and one literature review of 249 studies of school-based programs found overall intervention effects on student aggression or disruptive behavior, Boxer et al.'s (2005) mixed findings present an interesting hypothesis worthy of consideration. His study of approximately 500 urban youth examined an intervention that grouped kids with four to ten peers and two facilitators consistently over the course of a year. Through a composite measure of students' aggressive behavioral tendencies, Boxer et al. (2005) found the intervention to lessen aggressive actions for those students identified as high-aggressors, while expanding aggressive actions for those identified as low-aggressors. In sum, Boxer et al. (2005) hypothesized, "the more discrepant is a target child's behavior from that of his or her peers, the more that child's behavior will change in the direction of the peer group's average (pgs. 334-335).

Counter to Boxer et al.'s (2005) argument, a classic prominent study argues that Social Group Identity is most favorable when a lack of clear differentiation in roles is absent (Brown \& Wade, 1987). When groups and their individuals lack a clearly defined identity, friendliness toward others and within group productivity improved. Given Boxer et al.'s study took place within a single urban school, it is likely to assume participants entered the environment with preexisting biases and interpersonal relationships that influenced the aggressive tendencies observed. Aside from Boxer et al.'s (2005) intervention evaluation, all other applicable studies identified favorable change in the lessening of aggression (Frey et al., 2005a; Frey, Nolen, Edstrom, \& 
Hirschstein, 2005b; Hayes, Giallo, \& Richardson, 2010; Lewis et al., 2010; Wilson \& Lipsey, 2007).

A higher prevalence of pro-social behavior was also presented when health and wellness interventions were introduced into the school environment (ChalmersMcDonald, 2006; Durlak et al., 2007; Frey et al., 2005b; Hayes, et al., 2010; Snyder, et al., 2012; Webster-Stratton, Reid, \& Stoolmiller, 2008). Five studies and a synthesis of 526 positive youth development programs showcase interventions that are found to correlate to the exhibition of the following pro-social behaviors: coordinated teamwork, global conduct, social competencies, and egalitarian reasoning for satisfaction. Although studies were conducted in various regions, with differing methodologies, and varying sample sizes, all studies included a baseline and post-intervention component and most were randomized control studies by design.

Finally, three applicable studies and one synthesis of 213 school-based social and emotional learning programs indicate students may interact differently with school when health and wellness interventions are available during the school day (Bavarian et al., 2013; Durlak et al., 2011; Graham \& Zidenberg-Cherr, 2005; Munoz \& Vanderhaar, 2006). Where Munoz's (2007) quasi-experimental matched comparison study of eight schools participating in the Child Development Project showed significant improvement in the liking of, respect, and appreciation for school and their teacher, the remaining three researcher teams specifically targeted academic outcomes. Durlak et al., (2011) and Graham \& Zidenberg-Cherr (2005) presented improvements in academic performance respectively through achievement tests/grades and teacher perspective when school-based interventions were present. Bavarian et al.'s (2013) evaluation of Positive Action, a 
multi-year program found in Chicago Public Schools, found both students and teachers to report a growth in academic motivation as students were exposed to the program. No studies or evaluations of health and wellness interventions were found to hinder academic engagement or performance.

\section{Summary}

This section of Chapter 2 included a review of the literature published after 2005 that identified psychological responses students are more likely to exhibit when health and wellness services are available at their school site. Literature was available and reviewed from the medical, psychological, educational, and political arenas examining interventions that may affect the betterment of child mental health, and the previous three sections examined the most prominent research recently published outlining how students respond. The literature suggests children respond psychologically to health and wellness instruction in three ways: They could enhance their mental wellness reducing instances of depression, anxiety, or other stressors (Beehler, Birman, \& Campbell, 2012; Collins, Woolfson, \& Durkin, 2014; Cuijpers, van Straten, Smits, \& Smit, 2006; Lee, Tiley, \& White, 2009; Ohl, Mitchell, Cassidy, \& Fox, 2008; Stallard, 2013; Webster-Stratton, Reid, \& Stoolmiller, 2008); experience a change in attitude toward their self (selfconcept, self-efficacy, or self-esteem)(Barry, Clarke, Jenkins, \& Patel, 2013; DalgasPelish, 2006; Durlak, Weissberg, Dymnicki, Taylor, \& Schellinger, 2011; Telles, Singh, Kumar, Kumar, \& Balkrishna, 2013); and experience a change in behavior and interaction with others (Bavarian et al., 2013; Chalmers-McDonald, 2006; Durlak et al., 2007; Durlak et al., 2011; Frey et al., 2005a; Frey, Nolen, Edstrom, \& Hirschstein, 2005b; Graham \& Zidenberg-Cherr, 2005; Hayes, Giallo, \& Richardson, 2010; Lewis et 
al., 2010; Munoz \& Vanderhaar, 2006; Snyder et al., 2012; Webster-Stratton, Reid, \& Stoolmiller, 2008; Wilson \& Lipsey, 2007).

In the final section of this chapter, an explanation of the following two types of health and wellness programs found to have been introduced in schools will be presented: models, initiatives, or programs promoted at the federal level, and independent programs resulting from philanthropic or local community action. An overview of each type of health and wellness program will be offered, and to the extent possible, research evaluating their effectiveness will be provided.

\section{Health and Wellness Programs}

The literature detailing physical and psychological factors resulting from schoolbased health and wellness programs exhibited two types of programs that can be found in today's schools. The first collection of school-based health and wellness activity overviews programs implemented either voluntarily or mandatorily from federal models, programs, or policies. The second collection reviews independent and comprehensive health and wellness programs that have been strategically created and implemented as a result of grants or private dollars. Research and evaluation studies about these programs will be addressed to the degree they are available. To the extent possible, studies conducted within low-income schools will prioritized, but studies with samples representative of the school or community population will be included.

\section{Federal Health and Wellness Initiatives}

The national health and wellness landscape is propelled by two overarching federal foci: the Centers for Disease Control and Prevention's Coordinated School Health Program (CSH) and Local School Wellness Policy (LWP) stemming from the Child 
Nutrition and Reauthorization Act of 2004. The purpose and background of both efforts will be provided followed by an overview of existing research about their effectiveness. Finally, a forthcoming holistic model adopted to enhance the CSH will be introduced.

Coordinated School Health. Introduced in Chapter 1, the Coordinated School Health Program was an idea shared with the Centers for Disease Control and Prevention (CDC) in 1987 by Diane Allensworth and Llyod Kolbe to "promote the optimal physical, emotional, social, and educational development of students" (Allensworth \& Kobe, 1987). The CDC took Allensworth and Koble's initial three-component model alongside their proposed need for expansion and assembled an expert panel to approve an eightcomponent model displayed in Table 2. In 2007, the Coordinate School Health Program was nationally introduced by the CDC. ${ }^{3}$

Table 1

The Development of the Coordinated School Health Program

\begin{tabular}{|l|l|}
\hline $\begin{array}{l}\text { Kobe \& Allensworth } \\
1987 \text { Components }\end{array}$ & $\begin{array}{l}\text { Centers for Disease Control \& Prevention } \\
\text { 2007 Components }\end{array}$ \\
\hline School Health Services & Health Services \\
\hline School Health Education & Health Education \\
\hline School Health Environment & Healthy Environment \\
\hline & Physical Education \\
\hline & Nutrition Services \\
\hline & Counseling, Psychological, \& Social Services \\
\hline & Staff Health Promotion \\
\hline & Family \& Community Involvement \\
\hline
\end{tabular}

3 Visit http://www.cdc.gov/healthyyouth/schoolhealth/index.htm for additional information about Coordinated School Health. 
Today, several definitions of $\mathrm{CSH}$ are available due to the personalization CSH endorses. The Institute of Medicine (1997) offers the following definition for Coordinated School Health:

A (comprehensive) school health program is an integrated set of planned, sequential, school-affiliated strategies, activities, and services designed to promote the optimal physical, emotional, social, and educational development of students. The program involves and is supportive of families and is determined by the local community based on community needs, resources, standards, and requirements. It is coordinated by a multidisciplinary team and accountable to the community for program quality and effectiveness (CDC, 2013b).

The CDC encourages each state, school, or Local Education Association to tailor their program to meet the needs of their student population. Although there is no program districts can purchase to introduce $\mathrm{CSH}$, the $\mathrm{CDC}$ offers many resources and models educational organizations can reference to design their own program. Resources include access to funding opportunities and linkages to other federal initiatives related to $\mathrm{CSH}$. With these resources, 46 states in the United States and communities throughout Mexico, Canada, Egypt, Saudi Arabia, Oman, and West Africa have adopted the coordinated school health approach within various educational environments (Valois, 2011).

Given the variation in construct of $\mathrm{CSH}$ from one region to the next, it is impossible for researchers to study or evaluate the effectiveness of the CHS model, but they can evaluate the model a Local Education Agency designs and implements. An exploratory study by Cornwell, Hawley, \& Roman (2007), for example, evaluated the early stages of a multiyear CSH program in a rural Kansas school district. Using the eight focus areas of $\mathrm{CSH}$, school health index data revealed that the district scored high in the prevalence of health services, psychological, counseling, and social services, and physical education. However, they scored lower in family and community involvement, 
nutritional services, health education, and employee health promotion (Cornwell, Hawley, \& Roman, 2007).

Despite the variation of CHS program design, the CDC's Division of Adolescent and School Health has partnered with three school districts in 2010 to study the CSH programs embedded within their schools to identify strong systematic approaches and an understanding as to how those approaches have become successful. These data are currently being analyzed.

Local school wellness policy. The Child Nutrition and Reauthorization Act of 2004 (CNRA) made nutritious meals and snacks available to low-income children in and out of school hours (Food Research Action Council, 2013). As a component of this policy, school districts are required to develop and uphold a Local Wellness Policy (LWP) that supports improvement in nutrition and physical activity. Moreover, Congress passed the Healthy, Hunger-Free Kids Act (Sec. 204 of P.L.111-296) in 2010 to extend the provisions for LWPs related to implementation, evaluation, and publicly reporting the progress of the policy's effectiveness (CDC, 2014). According to the Center for Disease Control and Prevention:

Each local education agency that participates in the National School Lunch Program or other child nutrition program is required by law to establish a local school wellness policy for all schools under its jurisdiction. [These] local school wellness policies are designed to promote student health and reduce childhood obesity" (CDC, 2014).

In order to comply with CRNA and the Healthy, Hunger-Free Kids Act, a LWP must achieve the following five components: (1) Include goals for nutrition promotion and education, physical activity, and other school-based activities that promote student wellness; (2) include nutrition guidelines to promote student health and reduce childhood 
obesity for all foods available in each school district; (3) permit parents, students, representatives of the school food authority, teachers of physical education, school health professionals, the school board, school administrators, and the general public to participate in the development, implementation, and review and update of the local wellness policy; (4) inform and update the public (including parents, students, and others in the community) about the content and implementation of the local wellness policies; and (5) be measured periodically on the extent to which schools are in compliance with the local wellness policy, the extent to which the local education agency's local wellness policy compares to model local school wellness policies, the progress made in attaining the goals of the local wellness policy, and make the assessment available to the public (CDC, 2014). To support local education agencies in the creation and implementation of effective LWPs, federal and nonfederal agencies including the Department of Agriculture, United States Department of Education, and the United States Department of Health and Human Service (through the Center for Disease Control and Prevention) are tasked to provide information and assistance (CDC, 2014).

A review of the literature produced five evaluations of LWPs in low-income regions of Colorado, Georgia, Minnesota, Pennsylvania, and Utah. An evaluation of districts in Connecticut was excluded as it was not published or peer-reviewed. Studies in the other five states spanned as few as nine and as many as 499 school districts throughout each state. Although most participating districts within each state met the physical activity and nutritional mandates of the CRNA, the comprehensiveness and the implementation of evidence-based practices within districts is questionable (Belansky, Cutforth, Delong, Litt, Gilbert, Scarbro, S., Marshall, 2010; Hoxie-Setterstrom \& 
Hoglund, 2011; Lyn, O’Meara, Hepburn, \& Potter, 2012; Probart, McDonnell, Weirch, Schilling, \& Fekete 2008).

With the exception of the evaluation in Colorado, all studies included an analysis of each district's LWP. Comparisons against the six federal minimum requirements were assessed, and the strength and comprehensiveness of each LWP were analyzed.

Although adherence to federal requirements differed by district and region, most district LWPs contained language upholding minimum requirements but failed to articulate specific accountability measures to ensure schools carried out such mandates (HoxieSetterstrom \& Hoglund, 201 1; Lyn et al., 2012; Probart et al., 2008). Belansky's survey of 45 elementary school principals and food service managers in Colorado, for example, found small changes related to healthy alternatives for class parties or daily fresh fruit offerings, but participants reported little evidence-based change in lunchroom practice (Belansky et al., 2010). Lyn et al. (2012) expanded their analysis of 176 districts in Georgia to compare the strength of each LWP's goals to performance data. Although they, too, found accountability measures to be lacking within participating districts, a significant positive association was found between the strength of a district's LWP and its academic performance (Lyn et al., 2012).

Whole School, Whole Community, Whole Child model. Although the Coordinated School Health ( $\mathrm{CSH})$ initiative was formally introduced by the Centers for Disease Control and Prevention (CDC) in 2007, little has changed in the way of the CSH model since Allensworth and Kolbe called for a need for reform in 1987. In 2013, the 
$\mathrm{ASCD}^{4}$ and the CDC convened leaders of health, public health, education, and school health to evolve the CSH to "ensure that the health of the student, the teacher, and the school are taken seriously by educators and, in particular, by those involved in the school improvement process" (ASCD, 2014). The result was the Whole School, Whole Community, Whole Child (WSCC) model that was launched in 2014.

Figure 1

Whole School, Whole Community, Whole Child Model 2014

WHOLE SCHOOL,

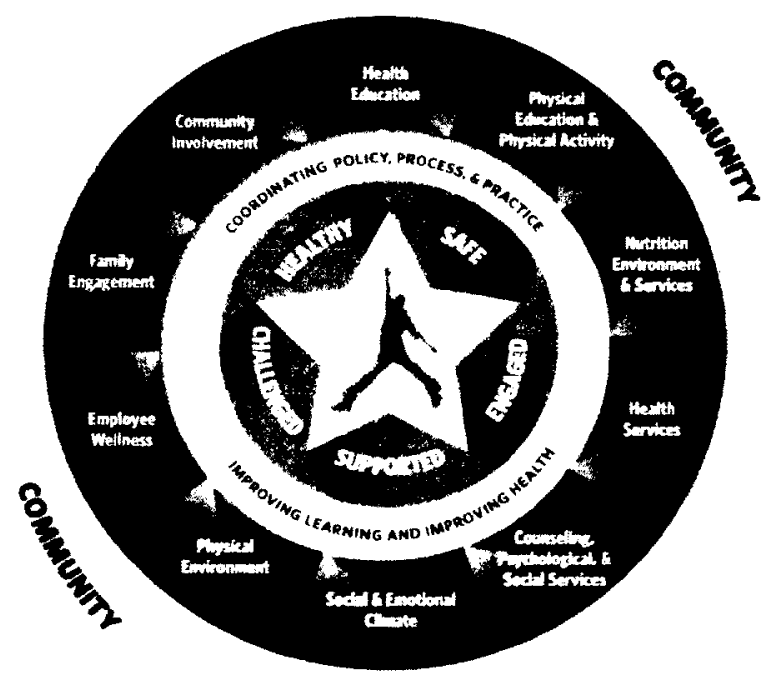

At this juncture, the $\mathrm{CDC}$ website still promotes the $\mathrm{CSH}$ as their recommended course of action concerning school health reform, but this literature review was generated at a time of political and educational change surrounding school health. The WSCC model, with the support of the $\mathrm{CDC}$, is likely to replace the $\mathrm{CSH}$ with the modifications outlined below.

${ }^{4}$ Formerly named the Association for Supervision and Curriculum Development, visit http://www.ascd.org to learn more about ASCD. 
WSCC expands the CSH model from eight to ten components urging "greater alignment, integration, and collaboration between education and health to improve each child's cognitive, physical, social, and emotional development" (ASCD, 2014). The expansion takes the CSH's Healthy and Safe School Environment element as well as the Family and Community Involvement elements into four components, bringing added attention to the social and emotional climate and the physical environment (ASCD, 2014). Table 2 below shows the progression from Allensworth and Kolbe's 1987 threecomponent model to the present-day WSCC.

Table 2

The Development of the Whole School, Whole Community, Whole Child Model

\begin{tabular}{|c|c|c|}
\hline $\begin{array}{l}\text { Kobe \& Allensworth } \\
1987 \text { Components }\end{array}$ & $\begin{array}{l}\text { Centers for Disease Control } \\
\text { \& Prevention } \mathbf{2 0 0 7} \\
\text { Components }\end{array}$ & $\begin{array}{l}\text { Whole School, Whole } \\
\text { Community, Whole Child } \\
2014 \text { Components }\end{array}$ \\
\hline School Health Services & Health Services & Health Services \\
\hline School Health Education & Health Education & Health Education \\
\hline \multirow{8}{*}{$\begin{array}{l}\text { School Health } \\
\text { Environment }\end{array}$} & Healthy Environment & Physical Environment \\
\hline & Physical Education & $\begin{array}{l}\text { Physical Education \& } \\
\text { Physical Activity }\end{array}$ \\
\hline & Nutrition Services & $\begin{array}{l}\text { Nutrition Environment \& } \\
\text { Services }\end{array}$ \\
\hline & $\begin{array}{l}\text { Counseling, Psychological, \& } \\
\text { Social Services }\end{array}$ & $\begin{array}{l}\text { Counseling, Psychological, } \\
\& \text { Social Services }\end{array}$ \\
\hline & Staff Health Promotion & Employee Wellness \\
\hline & $\begin{array}{l}\text { Family \& Community } \\
\text { Involvement }\end{array}$ & Family Engagement \\
\hline & & Community Involvement \\
\hline & & $\begin{array}{l}\text { Social \& Emotional } \\
\text { Climate }\end{array}$ \\
\hline
\end{tabular}

A significant difference between CSH and WSCC is the holistic call to action the WSCC makes to the school and community at large. The ASCD accuses society of placing student health and education into separate silos when a joined emphasis on both 
is vital to academic success. WSCC places the ownership of both student health and education on every adult and student who "...[plays] a role in the growth and development of self, peers, and the school overall" (ASCD, 2014). The child and school system are seen to extend into the community at large urging the interconnected system to play a role in the betterment of the whole child.

\section{Independent Health and Wellness Programs}

Given the wealth of research studies, evaluations, and literature reviews examining physical and psychological responses of elementary students, there has been a proliferation of various physical and mental health interventions that have made their way into public education since 2005. The requirements presented for LWPs and the flexibility of $\mathrm{CSH}$ leaves school and district leaders free to integrate programs they feel benefit their student population. Given this variation, only those independent health and wellness programs repeatedly referenced as effective in the literature, those resembling the CSH model, or those that have accompanying research will be introduced.

Project FIT. Project FIT invests public school systems, local health agencies, physicians, businesses, and university researchers in the implementation of physical activity and nutritional opportunities to reduce obesity. All stakeholders engage in a myriad of initiatives for healthy activities influencing all aspects of the child's school, home, and community. In 2011, Eisenman et al. reported baseline findings from their ongoing evaluation of Project FIT in Grand Rapids, Michigan. Initial findings show 70\% of children did not meet minimum physical activity recommendations. They also reported a low intake of vegetables and whole grains and a high intake of sugarsweetened beverages, fatty foods, and desserts. As a result, $48.5 \%$ of participants were 
overweight or obese and $6 \%$ were severely obese at baseline. Findings of programmatic results have yet to be released.

Positive Action. Positive Action is a socio-emotional and character development program (SECD) designed for $3^{\text {rd }}-8^{\text {th }}$ grade. The school-based curriculum proposes "positive feelings, thoughts, and actions result in fewer negative behaviors and an enhanced motivation to learn" (Bavarian, 2013, p. 772). The curriculum is composed of the following six core units taught four days per week for grades kindergarten through sixth grade: self-concept, positive actions for mind and body, positive social-emotional actions to get along with others, and managing, being honest with, and continually improving oneself (p. 772). Bavarian (2013) evaluated the effectiveness of Positive Action with a sample of students in Chicago Public Schools. This longitudinal study explicitly sought to understand the program's influence on low-income children from seven Chicago Public Schools. Data from students and teachers were collected over a six-year period. Findings suggest the program resulted in significant growth in academic motivation, enhanced students' desire to learn, and positively impacted absenteeism (Bavarian et al., 2013).

As mentioned in the less-risky behavior section of this chapter, Beets et al. (2009) also evaluated the Positive Action program with a sample of fifth graders in Hawaii. Through their matched-pair, cluster-randomized control trial study of 1,714 participants over a five-year time period, they found students to report fewer instances of substance use, violence, and sexual activity in schools where the Positive Action intervention took place. Both Beets et al. (2009) and Bavarian et al. (2013) measured different student 
outcomes, and the implementation of Positive Action was correlated to positive changes in student outcomes.

The Edible Schoolyard project. Founded by Alice Waters in 1995, the Edible Schoolyard Project ${ }^{5}$ integrates school gardens and kitchens into the K-12 public school environment to build and share an edible education curriculum. They aim to be a hub for edible education programs worldwide, offering a network of resources to educators, parents, and advocates to incorporate garden-based education within the context of their school environment. The organization is centered in Berkeley, California, where a oneacre organic garden and kitchen classroom are housed at King Middle School. Activities during the school day, after the school day, and on weekends allow students and members of the community to engage in the process of learning in the garden and preparing fresh meals alongside classmates or family members.

Healthier Options for Public Schoolchildren (HOPS). HOPS was an experimental elementary school-based obesity prevention intervention designed to test the feasibility of incorporating holistic nutrition and healthy life skills into the public school environment. Although funded by the Agatston Research Foundation to identify programmatic effects, HOPS integrated healthy foods, nutrition and lifestyle curriculum and instruction, increased levels of physical activity, school gardens, and other schoolbased projects that are conducive to and replicable in other public school settings. Thirteen thousand five hundred children from 23 elementary schools in central Florida and Buffalo, New York received the intervention.

\footnotetext{
${ }^{5}$ See http://edibleschoolyard.org for more information about the Edible Schoolyard Project.
} 
Hollar et al.'s (2010a) randomized control trial of six elementary schools in Florida evaluated the effectiveness of HOPS. Findings indicate that significantly more intervention schools enrolled students who maintained a normal BMI range, and more students at these schools decreased their BMI percentile range overall (Hollar et al., 2010). A second paper released by Hollar et al. (2010b) compared four intervention schools to one control school students' Body Mass Index, blood pressure, and academic data $(n=3,769)$. One specific analysis focused only on children qualifying for free or reduced priced meals. Researchers found statistically significant improvements in all measurements compared to the control school, particularly among students qualifying for free or reduced cost meals. Their findings suggest holistic interventions, like HOPS, can improve health outcomes and academic performances (Hollar, et al., 2010b).

\section{Summary}

A review of the literature of school-based health and wellness programs identified four physical and three psychological factors that correlate to the implementation of school-based health and wellness programs. Physically, health and wellness programs could influence students to eat healthier foods, be more physically active, have lower risk of obesity through weight loss and/or body mass index reduction, and be less likely to engage in risky health-related behaviors. Psychologically, students could enhance their mental wellness reducing instances of depression, anxiety, or other stressors, experience a change in attitude toward their self (self-concept, self-efficacy, or self-esteem), and experience a change in behavior and interaction with others through their participation in health and wellness instruction. Although a review of the literature identified few studies that explicitly targeted the response of low-income students, the literature highlighting 
the impact of school-based health and wellness interventions suggests positive changes can emerge. The questions this study seeks to answer will contribute to the field offering findings specifically related to low-income students.

Two types of health and wellness programs were presented in the literature: models, initiatives, or programs promoted at the federal level, and independent programs that have resulted from philanthropic or local community action. Regional and programmatic differences yield different findings, and each student population could respond differently. Given that this study seeks to understand the nuances of three independent health and wellness programs and their impact on low-income and non-lowincome students, the findings presented in Chapter 4 have the potential to enhance this area of the research literature. 


\section{CHAPTER THREE}

\section{METHODOLOGY}

This study sought to understand the impact of health and wellness education on the physical and psychological well-being of kindergarten through sixth grade students, and additionally determine if students are affected by health and wellness interventions differently based on their socioeconomic status. This study focused on specific schools in a preselected southern California district due to the district's progressive attitude toward health and wellness education. The study sought to answer three research questions:

1. How do low-income students' physical responses to health and wellness instruction differ from their non-low-income peers at these schools?

2. How do low-income students' psychological responses to health and wellness differ from their non-low-income peers at these schools?

3. In what ways do schools with large numbers of low-income students incorporate health and wellness instruction?

The chapter first overviews the research methods used in this study throughout the 2013-2014 school year. Sampling procedures are next introduced to explain how three schools within the district were ultimately selected as participants to answer the aforementioned research questions. WestED's California Healthy Kids Survey (CHKS) instrument utilized in this study is then introduced and the evidence validating its application to the study is presented. Elaboration on the methodology follows to explain how quantitative and qualitative methods converged to collect data throughout the spring 
semester. The process to analyze data and generate findings is offered before concluding with the studies' limitations and significance.

\section{Research Methods}

This study employed a convergent parallel mixed methods research design to understand the development of the health and wellness program at each school and then to identify how the programs may have affected low-income and non-low-income students in different ways. A document analysis of external reports preceded the analysis process to understand the health and wellness context of each school within one district. Through purposeful sampling, schools within that district meeting a pre-established criterion were included in the study. A pre/post quantitative analysis of the CHKS data followed to understand students' perspective of health and wellness and their experience with their school's program. Concurrently, qualitative data from numerous district and school personnel were collected in order to triangulate and validate findings.

Qualitative research was prominent throughout the study given challenges with the CHKS data described later in the chapter. Throughout the spring of the 2013-2014 school year, health and wellness program components were observed, and participants at each school and the district level were queried based on their involvement in a variety of health and wellness components. Observations, interviews, and focus groups were conducted with select participants to understand the context surrounding each school's health and wellness program and how each has evolved over time. Given that each school in the district has a unique health and wellness program, a cross-case analysis of each school's program was conducted to understand the nuances of each school's program and how these may relate to differences in health and wellness findings at the 
schools. Student focus groups concluded the data collection process to understand if trends exist among low-income and more affluent students across participating schools.

\section{Site and Sample Selection}

All participating schools were selected from one California school district resulting from both purposeful and convenience sampling. Purposeful sampling, according to Patton (2002), allows for "Cases of study... [to be] selected because they are "information rich" and illuminative... They offer useful manifestations of the phenomenon of interest; sampling, then, is aimed at insight about the phenomenon, not empirical generalization from a sample to a population" (p. 40). For this study, the Surfside Union School District (SUSD) ${ }^{6}$ was purposefully selected because its commitment to health and wellness education is information rich, illuminative and unique to the greater educational arena.

SUSD serves two cities in the coastal region of North San Diego County. Nine elementary schools enroll approximately 5,500 kindergarten through sixth grade students. The student population is approximately $20 \%$ Hispanic, $70 \%$ Caucasian, and $10 \%$ other ethnicities (California Department of Education Dataquest, 2013a). Four of the nine SUSD schools qualify to receive Title I funding to support their English learners and/or students from low-income families (National Center for Education Statistics, 2014). All SUSD schools have earned the California Distinguished School Award, four schools are National Blue Ribbon Schools (Surfside Union School District website, 2014), and the district itself has been nominated by the United States Department of Education as a national green ribbon school district (Breier, 2014). SUSD has allocated resources to

\footnotetext{
${ }^{6}$ Surfside Union School District and the forthcoming school names are pseudonyms to protect the privacy of each school and all participating staff and students.
} 
integrate certain health and wellness programs systematically at all schools, and the district encourages individual schools to implement additional health and wellness components to cater to the needs of that school's population. As a result, variations in health and wellness programs exist within each of the nine kindergarten through sixth grade SUSD schools.

In addition to purposefully sampling SUSD for this study, it is important to note that SUSD was also selected as a result of convenience sampling. Past professional interaction with SUSD stakeholders surrounding a separate yoga research study provided the opportunity to understand the district's stance on health and wellness education and ultimately gain access to school and district data. Through both purposeful and convenience sampling, SUSD was chosen for this study, and specific SUSD schools were invited to participate based on a pre-established criterion.

For the purpose of this study, schools within SUSD enrolling twenty percent or more low-income students were ultimately selected for participation. Free and Reduced Price Meal data available through the California Department of Education website were utilized as it serves as the best available proxy for a student's socioeconomic status (California Department of Education, 2013b). Those schools with twenty percent or more students receiving free or reduced price meals were invited to participate. Table 4 on the following page depicts Free or Reduced Price Meal eligibility data for the 20112012 school year ${ }^{7}$ for all nine SUSD schools.

\footnotetext{
${ }^{7} 2011-2012$ school year data are the most recent that is available as of October 30, 2013, which was the time period that schools were identified and invited to participate in the study.
} 


\begin{tabular}{|c|c|c|c|}
\hline $\begin{array}{l}\text { Table } 3 \\
\text { Free or }\end{array}$ & Meal Eligibility for Su & & \\
\hline \multicolumn{4}{|c|}{$\begin{array}{l}\text { Free or Reduced Price Meal Eligibility for Surfside Union School District by School } \\
2011-2012 \text { School Year }\end{array}$} \\
\hline School & $\begin{array}{l}\text { \# Students Eligible } \\
\text { for Free or Reduced } \\
\text { Price Meals }\end{array}$ & $\begin{array}{l}\text { Total Student } \\
\text { Enrollment }\end{array}$ & $\begin{array}{l}\% \text { Students Eligible } \\
\text { for Free or Reduced } \\
\text { Price Meals }\end{array}$ \\
\hline I & 9 & 843 & $1.1 \%$ \\
\hline $\mathrm{H}$ & 19 & 658 & $2.9 \%$ \\
\hline $\mathrm{G}$ & 27 & 591 & $4.6 \%$ \\
\hline$F$ & 28 & 461 & $6.1 \%$ \\
\hline$E$ & 31 & 656 & $4.7 \%$ \\
\hline $\mathrm{D}^{*}$ & 104 & 587 & $17.7 \%$ \\
\hline $\mathrm{C}^{*}$ & 116 & 476 & $24.4 \%$ \\
\hline B * & 186 & 646 & $28.8 \%$ \\
\hline $\mathrm{A}^{*}$ & 196 & 478 & $41.0 \%$ \\
\hline
\end{tabular}

*Designated Title I schools

Given the variation in Free or Reduced Price Meal Eligibility throughout the district, three schools, A, B, and C, enroll a population of at least twenty percent lowincome students. This differential distinguishes them from the rest of the SUSD schools making them ideal participants. The school serving the fourth largest population of lowincome students, School D, served as an alternate in the event that Schools A, B, or C were unable or unwilling to participate in this study. Ultimately, schools with a minimum low-income population of twenty percent were included and Schools A, B, and C agreed to participate for the duration of the study.

\section{Survey Instrument}

The California Healthy Kids Survey (CHKS) is a 65-question instrument recognized as the largest statewide survey of "resiliency, protective factors, and risk behaviors" in the nation (WestEd, 2013). CHKS is created, distributed, and analyzed by WestEd, and this organization generates reports from CHKS data for all California school 
districts approximately every other school year. Findings from these reports are said to guide reform efforts to improve student engagement and school climate while enhancing "the quality of health, prevention, and youth development programs" (WestEd, 2013). WestEd provides evidence that the CHKS instrument is valid and meets the anonymity criterion to secure valid responses from participating students ${ }^{8}$ (WestEd, 2013). Schools throughout California and other states across the country have adopted this instrument, the accompanying California School Climate Survey, and the California School Parent Survey. Traditionally in California, students in grades 5, 7, 9, and 11 are reported to complete the California Healthy Kids Survey once every other school year.

Through initial conversations with SUSD personnel, CHKS survey data were to be provided by the district allowing for student demographic information to accompany the CHKS data set. The intention was for CHKS data to be compared both at the school level, and by various subgroups like gender, race, and Free or Reduced Priced Meal eligibility. Following Institutional Review Board approval from the University of San Diego ${ }^{9}$, it was learned that CHKS raw data were not stored at the SUSD office and instead accessible only through WestEd, which anonymously collects and analyzes data at the school and district level. As a result, any potential linkage of desired demographic and socioeconomic data to CHKS information was eliminated.

\footnotetext{
${ }^{8}$ To learn more about the validity of the California Health Kids Survey, visit chks.wested.org.

${ }^{9}$ The Institutional Review Board (IRB) approval process is required in social science research in order to interact with participants and review pre-collected data. University personnel review the methodology of the intended study to ensure it meets all ethical and confidentiality requirements.
} 


\section{Data Collection Procedures}

Each participating school experienced an identical mixed methodological research design in order to conduct a cross-case analysis of each of the three health and wellness programs. Obtaining background knowledge of participating schools was important to understand the context of the health and wellness agenda within SUSD and the three participating schools. To do this, the data collection process was initiated with a document analysis of CHKS reports, school websites, district policy manuals, social media pages, and privately funded reports. Dated reports were also analyzed to understand changes over time.

\section{Background}

It is important to note that the methodological design for this study had to adjust from the manner in which it was initially intended. Originally, an explanatory sequential research design was proposed. Defined by Creswell and Plano-Clark (2011):

The explanatory design is implemented in two distinct phases. The first phase involves collecting and analyzing quantitative data. Based on a need to further understand the quantitative results, the researcher implements a second, qualitative phase that is designed to help explain the initial quantitative results.

It was the researcher's intent to utilize findings from the quantitative analysis of CHKS data to answer research questions one and two discerning how low-income and non-lowincome students responded physically and psychologically to their school's health and wellness programs. Such quantitative findings would then guide the creation of interview protocols and other qualitative efforts at each of the school sites to expand upon findings for questions one and two and additionally answer research question three. Qualitative findings would support the sub-group differences that may have emerged from the quantitative analysis of CHKS data. 
The delayed timeline to receive CHKS data from WestEd, in conjunction with CHKS data being unavailable at the district level to link to student demographic data, prevented the researcher from carrying out the explanatory design initially proposed. As an equally credible alternative, the design was modified to a convergent parallel design. Through this method, quantitative and qualitative data are collected and analyzed through two independent strands in a single phase. The researcher then, “...merges the results of the two strands; and then [looks] for convergence, divergence, contradictions, or relationships between the two databases" (Griswell \& Plano-Clark, 2011, p. 116).

As quantitative and qualitative procedures are explained in the sections below, this alternative design meets the rationale Griswell and Plano-Clark (2011) offer as justification to select a parallel convergent design. First, data collection needed to take place over a short time frame. January through June of 2014 provided only six months for the researcher to obtain sufficient qualitative data at each participating school to generate credible findings. Second, the researcher sees equal value in both quantitative and qualitative data and has the skills to collect and analyze both strands. In sum, utilizing a parallel convergent design proved effective to triangulate quantitative and qualitative results to validate findings and “...develop a more complete understanding of phenomenon, and [compare] multiple levels within [the] system" (Griswell \& PlanoClark, 2011, p. 77).

\section{Quantitative Strand}

This strand sought to discern how students at each school responded to questions about their physical and psychological health and wellness before and after the start of the SUSD health and wellness reform. As CHKS survey data was unavailable from 
SUSD, the researcher submitted the Application for Obtaining a CHKS Data Set accompanied with the necessary application fee to WestEd as the appropriate alternative. SUSD data were provided to the researcher on February 10, 2014.

Data from two administrations of the California Healthy Kids Survey (CHKS) were utilized to understand student experiences in 2008-2009 before SUSD embarked on their health and wellness reform efforts, and in 2011-2012, once the program was underway. This time period is significant in SUSD because the 2010-11 school year introduced the district-wide health and wellness reform movement. Survey data from before and after the start of health and wellness instruction were originally hypothesized to yield different results. Available data from consented fifth graders in the 2008-2009 and the 2011-2012 school years were included in the study. CHKS data for 276 fifth graders (119 students in 2009 and 157 students in 2012) from all three schools were analyzed over the three-year time period. Although data were analyzed at the student level, student identity was kept confidential through the procedures upheld by WestEd. ${ }^{10}$

\section{Qualitative strand}

To understand the nuances of each health and wellness program and ultimately validate quantitative findings, observations were conducted and participants were selected to participate in focus groups and interviews. An initial 90-minute interview with the SUSD Health and Wellness Coordinator offered background knowledge about the district-wide health and wellness movement, her perspective of each school's present day health and wellness program, and finally suggestions of individuals to contact to further clarify how each school supports its students.

${ }^{10}$ To learn more about WestEd's confidentiality procedures for the California Health Kids Survey, visit: https://chks.wested.org/about/faq_fees. 
Following that initial interview, eight full-day observations were conducted at school A, five at school B, and seven at school C. Field notes were collected during all health and wellness activities as well as other activities taking place at each school throughout the school day. Particular attention was paid to indicators such as student, staff, and community interaction; behavior; engagement; physical activity; diet; and nutritional opportunities for students. Activities specifically targeting fifth grade students were closely observed, given the quantitative component of this study, but all indicators were observed among students, teachers, staff, and parents alike. A list of observed activities is available in Table 4 below.

\begin{tabular}{|c|c|c|}
\hline \multicolumn{3}{|c|}{$\begin{array}{l}\text { Table } 4 \\
\text { Observed Activities by Surfside Union School District School }\end{array}$} \\
\hline \multicolumn{3}{|c|}{ 2013-2014 School Year } \\
\hline School A & School B & School C \\
\hline Recess & Recess & Recess \\
\hline Lunch & Lunch & Lunch \\
\hline Physical Education & Physical Education & Physical Education \\
\hline $\begin{array}{l}3^{\text {rd }} \& 5^{\text {th }} \text { grade Classroom } \\
\text { Instruction }\end{array}$ & $\begin{array}{l}3^{\text {rd }} \& 5^{\text {th }} \text { Classroom } \\
\text { Instruction }\end{array}$ & $\begin{array}{l}3^{\text {rd }} \& 5^{\text {th }} \text { Classroom } \\
\text { Instruction }\end{array}$ \\
\hline $\begin{array}{l}3^{\text {rd }} \& 5^{\text {th }} \text { grade Yoga } \\
\text { Instruction }\end{array}$ & $\begin{array}{l}3^{\text {rd }} \& 5^{\text {th }} \text { grade Yoga } \\
\text { Instruction }\end{array}$ & $\begin{array}{l}3^{\text {rd }} \& 5^{\text {th }} \text { grade Yoga } \\
\text { Instruction }\end{array}$ \\
\hline $\begin{array}{l}\text { Student transition/out of } \\
\text { class interaction }\end{array}$ & $\begin{array}{l}\text { Student transition/out of } \\
\text { class interaction }\end{array}$ & $\begin{array}{l}\text { Student transition/out of } \\
\text { class interaction }\end{array}$ \\
\hline Garden & & Garden science lesson \\
\hline $\begin{array}{l}\text { Happenings in Main office, } \\
\text { before, \& after school w/ } \\
\text { parents }\end{array}$ & $\begin{array}{l}\text { Happenings in Main office, } \\
\text { before, } \& \text { after school w/ } \\
\text { parents }\end{array}$ & $\begin{array}{l}\text { Happenings in Main office, } \\
\text { before, \& after school w/ } \\
\text { parents }\end{array}$ \\
\hline Cooking Class & & Outdoor kitchen tour \\
\hline PTA Meeting & PTA Meeting & $\begin{array}{l}\text { Correspondence with } \\
\text { ELAC personnel }\end{array}$ \\
\hline $\begin{array}{l}\text { Morning Family Wellness } \\
\text { Program }\end{array}$ & Student drop-off/pick-up & Student drop-off/pick-up \\
\hline
\end{tabular}


In conjunction with observations, interviews and focus groups were conducted throughout spring, 2014. To the extent they were available, same school personnel were interviewed at each school using an identical interview protocol ${ }^{\prime \prime}$. Adult interviews and focus groups were 60-minutes in length at various times throughout the school day, and student focus groups occurred during the students' 40-minute lunch period. Participants from each school are included in Table 5 below. Unless noted in the table, representatives from all three schools were interviewed.

\begin{tabular}{|l|}
\hline Table 5 \\
Participating Surfside Union School District \\
Stakeholders \& Community Personnel \\
\hline 2013-2014 School Year \\
\hline SUSD Superintendent \\
\hline Assistant Superintendent \\
\hline Health and Wellness Coordinator \\
\hline Director of Food Services \\
\hline Mental Health Teacher on Special Assignment \\
\hline Administrator of Support Services (DELAC) \\
\hline Non-Profit SUSD Affiliate (Healthy Day Partners) \\
\hline Principals \\
\hline Health and Wellness Instructors \\
\hline School Psychologist (School B) \\
\hline Garden Instructors (Schools A \& C) \\
\hline Classroom Teachers \\
\hline Parent Volunteers \\
\hline Students \\
\hline
\end{tabular}

Participants were sampled purposefully through Critical Case, Opportunistic, and Snowball sampling. SUSD's superintendent, the Health and Wellness Coordinator, principals, Health and Wellness Instructors, Garden Science Instructors, and students

"School faculty and staff holding the same title were interviewed in an identical manner in order for similarities and differences between schools to emerge. An interview protocol for principals varied slightly from the protocol used with classroom teachers, but principal interviews adhered to the same interview protocol across all three schools. 
were selected through Critical Case sampling. This strategy allowed the researcher to “...pick the [participant] that [yielded] the most information and [had] the greatest impact on the development of knowledge" (Patton, 2006, p. 236). Within each of these interviews, the researcher inquired as to other school or district personnel who would hold valuable information to contribute to this study. Participants identified the Mental Health Teacher on Special Assignment, Administrator of Support Services (DELAC), parent volunteers, the coordinators of the affiliated non-profit, Healthy Day Partners, and select classroom teachers through Snowball sampling.

Opportunistic sampling generated interviews with the Director of Food Services, a School Psychologist, and the Assistant Superintendent. A need to interview these participants “...emerged during fieldwork” (Patton, 2006, p. 240) presenting an opportunity to take advantage of the information they provided to the study. In total, 19 formal interviews and one focus group were conducted with school or district stakeholders or parent volunteers. Interview protocols are available in Appendices A through F. Informal conversations with school lunch personnel, classroom teachers, parents, students, and other individuals also transpired during fieldwork. Data from those conversations were captured within field notes.

Student focus groups. Student focus groups were intentionally left as the final component of the data collection phase. When complications with the CHKS data surfaced, it became apparent that research questions one and two could no longer be answered quantitatively though CHKS data. To still determine if low-income students respond physically or psychologically different from non-low-income students, focus groups with randomly selected fifth grade students served as the alternative. 
Convenience sampling resulting from professional relationships with teachers generated one class of students from Schools A, B, and C from which the focus groups would result. Teachers supported the researcher by managing the parental consent process, and teachers worked with district officials to randomly sample consented students to construct two focus groups at each site. As a result, one group was comprised of students eligible for Free or Reduced Price Meals, and the other included students not eligible for this program. Six student focus groups occurred in May and June of 2014

Student focus groups were held during 40-minute lunch breaks allowing students to eat while participating in the conversation. To uphold participant confidentiality, student names were unknown to the researcher. Teachers and district personnel identified which group of students comprised a focus group on a particular day for the researcher, but student names were not provided to ensure confidentiality. Additional privacy measures were taken by not holding focus groups on consecutive days in an effort to inhibit students from perceiving between-group differences, but no more than four days passed between focus groups at each school. The classroom teachers determined which student group would be interviewed first and second based on student attendance that particular day. Students in either group at all schools were exposed to an identical interview protocol available in Appendix E.

Leaving this component for the end of the data collection process allowed for an understanding of the school's health and wellness program to be established. As a component of the focus group, the researcher provided each student with a list of health and wellness components adult participants had referenced as a component of the school's health and wellness program. Students were asked to engage with this list in the 
following ways: describe each activity, elaborate whether or not they believed the activity supported health and wellness, identify desirable and less-desirable activities, list the activities they'd experienced, how often they participated, expand upon the list if schools offered other health and wellness activities, and revisit the list when sharing how various activities made them feel physically and psychologically.

\section{Data Analysis}

Being a mixed methodological study, data were analyzed both quantitatively and qualitatively to effectively answer the study's three research questions. The convergent parallel design called for each strand to be analyzed independently of the other to ultimately synthesize "...complementary, qualitative, and qualitative results to develop a more complete understanding of a phenomenon, and compare multiple levels within a system (Griswell \& Plano-Clark, 201 1, p. 77). With this research design, a clear understanding of student-level quantitative and qualitative data from a myriad of SUSD personnel provided meaningful information about each school's health and wellness program, which was critical to answering research question three.

\section{Quantitative Strand}

To obtain a clear understanding of each school's health and wellness program, student-level data from CHKS were analyzed using SPSS software. To compare student physical and psychological sentiments from one school to the next, various descriptive statistical analyses were conducted. Potential changes in 2008-2009 and 2011-2012 CHKS responses were also compared using descriptive statistics. Methods will be expanded in the subsequent section. 
Physical response. Austin, Bates, and Duerr's (2013) Guidebook to the California Healthy Kids Survey: Part II: Survey Content- Core Module, provides an overview of the expert panel that was constructed to create the CHKS instrument as well as offer an in depth review of the rationale behind each of the 65 questions posed to fifthgrade students. Austin et al., (2013) identified eight questions the panel classifies as physical wellness questions: (6) Did you eat breakfast this morning; (48) Do you think you are too skinny, about right, or too fat; (49) Are you doing anything to try to lose weight; (50) Have other kids at school teased you about what your body looks like; (51) How many days each week do you exercise, dance, or play sports; (52) When not exercising, do you ever have trouble breathing; (53) Has a parent or some other adult ever told you that you have asthma. (54) Yesterday, how many hours did you spend watching TV or playing video games? Positive healthy responses were coded as " 1 " and unhealthy responses were coded as " 0 ". For scaled questions such as numbers 51 (days per week of exercise) and 54 (daily hours of television viewing), recommended values form the American Academy of Pediatrics ${ }^{12}$ and the Mayo $\mathrm{Clinic}^{13}$ were utilized to generate "0" and " 1 " delineations. Although descriptive statistics were separately run and analyzed for each physical wellness question, responses were also grouped with the risky behavior engagement questions, which are described below.

A review of the literature presented in Chapter 2 identified a change in risky behavior avoidance as an additional physical response to health and wellness

\footnotetext{
${ }^{12}$ For more information about recommendations for child weekly exercise, visit: http://www.cdc.gov/physicalactivity/everyone/guidelines/children.html.

${ }_{13}$ For more information about recommendations for daily hours of child television viewing, visit: http://www.mayoclinic.org/healthy-living/childrens-health/indepth/children-and-tv/art-20047952
} 
interventions. Austin et al. (2013) present eight questions in the Guidebook to the California Healthy Kids Survey: Part II: Survey Content-Core Module, that would indicate a student's degree of avoiding risky behaviors: (7) When you ride in a car, do you wear a seat belt; (8) When you ride a bicycle, do you wear a helmet; (26) During the past year, did you ever bring a gun or knife to school; (31) Have you ever smoked a cigarette; (32) Have you ever chewed tobacco or snuff; (35) Have you ever used alcohol or an illegal drug like marijuana before school or at school; (40) In the past month, did you drink any beer, wine, or other alcohol; (41) In the past month, did you smoke a cigarette? Although descriptive statistics were separately run and analyzed for each risky behavior avoidance question, responses were also grouped to create a risky behavior avoidance score to identify possible between-school differences and change over time in student risky behavior avoidance. Positive behaviors were coded as "l" and risky behavior responses were coded as " 0 ". Responses for all eight questions were averaged to provide a risky behavior avoidance score ranging from zero to one for each school.

Finally, Austin et al.'s (2013) physical wellness questions were joined with the risky behavior avoidance questions to create an overarching total Physical Health score that is supported by the literature. See Appendix $G$ for more information about how CHKS physical health questions were compiled to generate scores for physical wellness, risky behavior avoidance, and the total Physical Health score. Descriptive statistical analyses of possible between-school differences and changes over time in the Physical Health score concluded the analysis of the questions related to students' physical response. 
Psychological response. A similar analysis process was undertaken with questions targeting student psychological well-being. In this instance, Austin et al. (2013) did not specify which questions target psychological wellness leaving the researcher to compile the list using evidence available from the literature discussed in Chapter 2. With a larger sample, a factor analysis could be utilized to identify and compile appropriate questions into psychological wellness categories and subcategories, but this study offered a limited number of student participants restricting its utility. With this dataset, using evidence from the literature proved most valuable. From the literature, questions addressing students' connection to school, experience with bullying, and perception of self were identified. The following six questions were compiled to create the students' connection to school subcategory: (9) Do you feel close to people at school; (10) Are you happy to be at this school; (11) Do you feel like you are part of this school; (16) How well do you do in your schoolwork; (29) Do you feel safe at school; and (46) Do you try to do your best?

The following six questions were compiled to create the students' experience with bullying subcategory: (21) During the past year how many times have you hit or pushed other kids at school when you weren't playing around; (22) During the past year how many times have you spread mean rumors or lies about other kids at school; (23) Do other kids hit or push you at school when they are not just playing around; (24) Do other kids spread mean rumors or lies about you; (25) Do other kids at school spread mean rumors or lies about you on the internet (i.e. Facebook, MySpace, email, Instant message); (50) Have other kids at school ever teased you about what your body looks like? 
The following five questions were compiled to create the students' perception of self subcategory: (12) Do teachers treat students fairly at school (14) Do the teachers and other grown-ups at school care about you; (15) At school, do teachers and other adults tell you when you do a good job; (17) At school do the teachers and other adults listen to you when you have something to say (18) Do the teachers and other grown-ups at school believe that you can do a good job? Although descriptive statistics were separately run and analyzed for each psychological health question and for each of the three subcategories (connection to school, experience with bullying, and perception of self), responses were also grouped to create a total Psychological Health score to identify possible between-school differences and change over time in student psychological health. Positive healthy responses for all questions and groupings were coded as " 1 " and unhealthy responses were coded as "0". Responses for all 17 questions were averaged to provide a total Psychological Health score ranging from zero to one for each school. See Appendix $\mathrm{H}$ for more information about how CHKS psychological health questions were compiled.

Descriptive statistics were used to ultimately analyze 33 of the CHKS questions to quantitatively discern how students at each school rated their physical and psychological well-being in 2008-2009 and 2011-2012. . Descriptive statistics were used to compare responses in 2009 , before the district's health and wellness initiative, to responses in 2012, once children experienced health and wellness interventions. Findings were generated to ultimately compare to the qualitative findings that emerged from the analysis described below. 


\section{Qualitative Strand}

While school-level physical and psychological differences were revealed and changes over time were detected, observation guides, interview, and focus group protocols were utilized to understand each school's health and wellness program.

Observation and interview data from each school were analyzed using Polkinghorne's (1995) analysis of narrative approach to qualitative research. According to Polkinghorne, "This paradigmatic analysis results in descriptions of themes that hold across the stories or in taxonomies of types of stories, characters, or settings" (p. 12). To proceed in this manner, the researcher utilized the ten components depicted in the Whole School, Whole Community, Whole Child Model (See Chapter 2, Figure 1) to determine the extent to which these concepts have taken shape at participating schools.

Using this pre-established model to locate common themes across various stories is advantageous given the federal recognition of Coordinated School Health. Using the Whole School, Whole Community, Whole Child Model in place of the Centers for Disease Control and Prevention's traditional Coordinated School Health framework is advantageous given the extension from 8 to 10 components detailed in Chapter 2 . As such, a database was created that contains the many narratives, or stories, taking place within the health and wellness program at each school, and the presence of the following ten Whole School, Whole Community, Whole Child Model components were utilized in the coding process: health services, health education, physical environment, physical education \& physical activity, nutrition environment \& services, counseling, 
psychological, \& social services, employee wellness, family engagement, community involvement, and social \& emotional climate.

Narratives were generated from the compiled field notes from school observations presented in Table 5 and from transcribed interviews with the participants presented in Table 6. Each was analyzed using HyperRESEARCH qualitative data management software to identify prominent themes happening throughout each case. Using Polkinghorne's method of the paradigmatic analysis of narrative, common themes sourced from the Whole School, Whole Community, Whole Child Model were collected from the stories each observation, interview, and focus group produced. Commonalities were detected across stories to generate findings to ultimately compare to findings resulting from the quantitative analysis.

\section{Limitations of the Study}

Although this study answers important questions about how select health and wellness programs affect low-income students, limitations exist that hinder the generalizability of findings. The homogeneity of participating schools from the same district, regional affluence, and methodological limitations including a small quantitative sample sizes of fifth grade students limit the study's ability to generalize findings to the population. Additional research beyond the constraints of this dissertation will be necessary. Personal biases related to this study should also be noted, and efforts that were made to control them are presented.

Although the cross-case analysis of each school's health and wellness program provided a foundation to begin understanding how schools implement holistic educational programs, findings are not scientifically generalizable to draw definitive 
conclusions about the observed effects in other schools and in other districts. Schools within other districts and communities choosing to implement health and wellness education will need to be studied to support the findings from this research study. Dynamics related to school leadership, school culture, teacher buy-in, and community involvement all influence a health and wellness program and need to be considered. Thick description that resulted from this cross-case analysis provides the groundwork and preliminary findings necessary for more research to expand this educational field (Patton, 2002, p. 437-438).

Generalizability was further hindered by the socioeconomic distribution represented in this district. Although each participating school educated $20 \%$ or more low-income students, many schools throughout the nation serve communities with a substantially larger low-income population. Despite each participating school's commitment to its low-income students, the successes and challenges at these participating schools are likely to be far different from schools that serve an entirely lowincome population. Potential findings from low-income students in this study cannot transfer to other low-income populations. Moreover, Chapter 4 will indicate intra-district transfer rates are substantial across all SUSD schools including Schools A, B, and C. School choice is an opportunity SUSD offers to community members allowing families to choose the district school that best meets their needs. This fluidity of enrollment is unique to traditional public schools and impacts the student enrollment at participating schools.

Quantitatively, small sample sizes of fifth grade students during each school year and at each school are a limiting factor of this study. Although 276 California Healthy 
Kids Survey (CHKS) data points were analyzed to generate findings, samples span a three-year period at three schools. Approximately 100 fifth graders within a given school year are exposed to each school's health and wellness program. Small samples limit the generalizability of findings. Moreover, the 2009 fifth-grade California Healthy Kids Survey respondents are a different group of students than those responding in 2012 . Individual student differences may contribute to any variation identified through the analysis process.

Finally, researcher biases should be noted. As a former university athletic coach and elementary teacher from a low-income community, personal biases about the importance of health and wellness instruction for low-income children exist. To control for this, the researcher committed to keeping a personal journal throughout the data collection and analysis process. Additionally, member checking took place through the support of a university colleague and mentor. The Director of Research for the Center for Education Policy and Law has a deep understanding of quantitative and qualitative research in addition to a familiarity with the Surfside Union School District. He was provided with the study's findings, and several transcripts to ensure the findings contained in the following chapter are valid and free from researcher bias.

\section{Significance of the Study}

Despite the limitations addressed in the previous section, the significance of this study enhances the body of research about the effects of health and wellness instruction in the school environment. To date, there have been no studies uncovered that quantitatively or qualitatively examine the effects of holistic health and wellness instruction on low-income students. Moreover, this study contributes to the field by 
identifying key factors that are necessary to incorporate within a school-based health and wellness program. Further research will be necessary within this school district and elsewhere where formal health and wellness instruction is taking place as more and more schools and districts institute programs to support the health and well-being of their students. 


\section{CHAPTER FOUR}

\section{FINDINGS}

Through a mix-methodological research design, this study sought to understand the impact of health and wellness education on the physical and psychological well-being of kindergarten through sixth grade students, and additionally determine if students are affected by health and wellness interventions differently based on their socioeconomic status. Given that health and wellness endeavors are sporadically present within public elementary schools at this juncture, knowledge of effective health and wellness educational components were also uncovered and are shared in this chapter.

Chapter 4 reports findings related to health and wellness programs present at three kindergarten through sixth grade Title I schools in the Surfside Union School District ${ }^{14}$ (SUSD) during the 2013-14 school year. An overview of each school will initiate the chapter reporting findings about school vision, staffing, leadership, and enrollment. Included in the overview are themes from SUSD stakeholder interviews reporting perspectives of the present day health and wellness programmatic construct at each school. This overview will also introduce findings from the California Healthy Kids Survey (CHKS) that reports the school-wide impact of health and wellness efforts. Following this overview, findings will be presented in the order in which the following three research questions below are listed:

1. How do low-income students' physical responses to health and wellness instruction differ from their non-low-income peers at these schools?

\footnotetext{
${ }^{14}$ Surfside Union School District and the forthcoming school identifiers are pseudonyms to protect the privacy of each school and all participating staff and students.
} 
2. How do low-income students' psychological responses to health and wellness differ from their non-low-income peers at these schools?

3. In what ways do schools with large numbers of low-income students incorporate health and wellness instruction?

As noted in Chapter 3, data are analyzed in this chapter to determine how students' physically and psychologically respond when a school strives to educate the whole child and tend to their health and wellness needs. Changes over time in school-wide physical and psychological health scores are included in both the physical and psychological response sections of this chapter. Next, socioeconomically relevant findings for both physical and psychological responses will be presented, first at the school level and then for SUSD at large.

Findings from research question three will then be presented. After discussing what stakeholders say regarding the school's commitment to health and wellness, specific health and wellness components identified during the 2013-14 school year will be set forth. This chapter will conclude by presenting the prominent findings relevant to each school's health and wellness program presented through observations, interviews, and focus groups. School information identified quantitatively through the California Healthy Kids Survey (CHKS) will be revisited to provide additional context about the students' health and wellness experiences in SUSD and ultimately offer general conclusions about each school's health and wellness program and its physical and psychological impact on the student population. It is important to note that this study was designed to identify existing health and wellness components that the three participating Title I schools have incorporated into their health and wellness program and 
to understand how socioeconomically different students at each school have responded both physically and psychologically. Data are not sufficiently comprehensive to offer comparisons of the participating schools, nor can an evaluation of each program's effectiveness be made conclusively. However, as will be discussed in Chapter 5, the findings do offer some insight into the degree to which the health and wellness program at each of the schools relates to the ten components of emerging Whole School, Whole Community, Whole Child model (See Figure 1) and what future research is necessary in this context.

\section{Overview of School Context}

As discussed in Chapter 3, Surfside Union School District supports nine kindergarten through sixth grade schools in the northern coast of San Diego County. The 2010-2011 school year brought forth a district-wide emphasis on health and wellness reform, where schools and the district at large were taking strides to attend to the health and wellness needs of their student population. SUSD provides families living within the SUSD boundary the option to enroll their child at any of the nine SUSD schools rather than be restricted to the neighborhood school. Regardless of this intra-district transfer option, four of nine SUSD schools are classified as Title I, and three educate a lowincome student population greater than $20 \%$. Each of the three participating Title I schools has taken a different approach to health and wellness education by implementing different components and enrichment opportunities for its students and school community. Information obtained through document analyses, stakeholder interviews, and focus groups provide context for each school's construct, goals, and unique position within SUSD. 


\section{Overview of School A}

Located in the heart of the region's lower-income housing neighborhood, School A serves the community's largest population of students receiving free or reduced-priced meals. Seven years prior, School A was SUSD's lowest performing school. The term "white flight" was referenced by many stakeholders to recount that period of School A's history indicating many of the community's white families sent their children to other SUSD schools. Currently, the school is on par with other SUSD schools in terms of academic excellence and educates a nearly equivalent proportion of white students and students of color. Stakeholders describe School A's niche as being the school with the International Baccalaureate (IB) program and a commitment to health and wellness. While recounting the school's goals and vision, a School A teacher and parent emotionally stated, "When I think about all the terrific things we're doing for our kids, I just start getting so proud of what we do here." Embodied in its mission statement, School A is committed to "create culturally proficient, lifelong learners who inquire and think critically about the world around them."

Sixty-one administrators, teachers, and staff are listed within School A's directory. A list of staff positions include: school nurse, health technician, food services personnel, health and wellness instructor, garden instructor, custodian, speech therapist, school psychologist, learning resource center aide, team time teacher, instructional assistant, science enrichment, music enrichment, media center aide, and an International Baccalaureate coordinator. Three credentialed teachers are generally placed within each grade level and few combination classes of students from two different grades exist. A principal, office manager, and secretary round out this administration staff. 
School A is the first and only SUSD school to offer an International Baccalaureate (IB) program, and it concluded its first year as an accredited IB school in 2014. Schools earning IB recognition are said to "develop the intellectual, personal, and emotional skills to live, learn and work in a rapidly globalizing world" (International Baccalaureate, 2014). When describing the components of School A's IB program, one teacher stated, "I feel like IB is the essence of what a teacher tries to instill in their students, or the type of classroom she hopes to run. And the whole campus is IB so it's engrained in everything campus-wide". School A also offers PTA and grant-funded enrichment opportunities that students experience weekly. All students attend music, garden/cooking, and yoga, and K-2nd grade students attend the hands-on science "Exploratorium" while teachers collaborate as a grade level.

January of 2014 presented School A with its first new principal in seven years. Although the recently promoted former principal maintains a constant presence on the school campus at this juncture, a new principal was hired mid-year with experience in IB leadership. Comments about the new principal were positive, but School A's former principal was identified by the SUSD Superintendent as "exactly the right leader for that school". Priding herself on her ambition to emphasize academic achievement and turn School $\mathrm{A}$ around, this veteran principal was described by district personnel to be, “...literally the queen of, 'if there's a resource out there, I am going to get it'." She attended SUSD School B as a child, taught at School B as an adult, and ultimately took on her first position as principal at School A. Latina by decent, she utilizes her Spanishspeaking ability to communicate in Spanish and English throughout her school 
community, and is additionally embraced by her teaching staff as a driven leader. Both the current and former principal at School A have children attending School A.

Approximately 554 students are enrolled at School A. ${ }^{15}$ The ethnic compilation of School A is: Hispanic/Latino (47\%), White (47\%), other (4\%), Asian ( $1 \%$ ), and African American $(>1 \%)$. School A has experienced a six percent increase in intra-district transfers since the onset of the district health and wellness initiative. During the 20132014 school year, thirteen percent of School A students chose to attend School A as opposed to their neighborhood school. As with all fifth grade students in California, students whose parents have consented at School A complete the California Healthy Kids Survey (CHKS) anonymously responding to questions that address their physical and mental well-being. An analysis of 2012 CHKS data ${ }^{16}$ provides both a physical and psychological health score residing on a zero to one scale for each participating school.

Scores closer to one reflect more positive responses to survey questions, and scores closer to zero reflect negative responses. School A received a Physical Health score of .82 and a Psychological Health score of .80 .

\section{Overview of School B}

Located in the northern part of SUSD, School B was described in interviews with stakeholders as diverse in terms of its socioeconomic distribution serving many of the community's most and least wealthy families. Comments such as, "You really have both ends of the spectrum at [School B]" were repeatedly expressed. School B's principal described her school as "a school of languages" in that they strive to ensure students are

15 Data were derived for the 2013-14 school year from http://datal .cde.ca.gov.

${ }^{16}$ 2011-2012 California Healthy Kids Survey (CHKS) data were utilized to generate Physical Response and Psychological Response values. At the time of this study, 2011 2012 CHKS data are the most current. 
proficient in the languages of science, music, and the language of computer coding and programming. Embodied in their mission statement, School B “...facilitates learning in harmony with a community of differing abilities and talents. [School B] meets the needs of the diverse multicultural, ethnic, and socioeconomic community through ongoing evaluation, modification, and improvement of instructional strategies."

Fifty-five administrators, teachers, and staff are listed within School B's staff directory. A list of positions include: school nurse, occupational therapist, speech therapist, reading specialist, learning instructional aide, resource aide, science enrichment, music enrichment, media center aide, custodian, and a PE consultant. Although not listed on the school's website, two health and wellness instructors are also present at School B. Three credentialed teachers are generally placed within each grade level and few combination classes exist. A principal, office manager, and secretary round out this administration staff.

School B was SUSD's first school to offer the Dual Language Immersion (DLI) program to a select number of interested students determined through an annual lottery. Participating students are educated and interact in both Spanish and English throughout the school day. Students in the DLI program often progress from grade-to-grade as a cohort, building their language skills in addition to their academic content knowledge. Recent tension was reported at School B around a district proposal to collapse School C and B's DLI program and host it only at School C. Parents of School B students advocated to uphold DLI at their site and were successful in their efforts.

School B's principal validated the school community's commitment to diversity and upheld it in her actions. "I'll do my call-outs in both languages when I'm inviting 
people" she said during the interview. "That's a passion for me, to ensure [all parents] feel included. [English learners] are a lower percentage of our school makeup, but I think it's important and I've been able to bridge that gap." School B also offers PTA and grant-funded enrichment opportunities that students rotate through weekly. While classroom teachers collaborate at this site, all students attend music, science/technology, yoga, and physical education as teachers collaborate as a grade level.

The past seven years have presented School B with four new principals. Messages were mixed regarding the leadership style of School B's current principal who was concluding her second year at the time this study was being conducted. Sentiments such as, "Her emphasis on coding communication has really brought the school together" were heard throughout interviews, as were statements like, "I don't see [principal B] being quite as assertive... My perception is it's taking her a little longer to get her feet on the ground." Though promising in her role as principal, evidence indicates this principal continues to refine her leadership skills to lead a veteran and established team of teachers at this early juncture. Bi-racial by descent, she also utilizes her Spanish-speaking ability to communicate throughout her school community. Her own children, although SUSD students, attend another SUSD school.

Approximately 675 students are enrolled at School $\mathrm{C}^{17}$ The ethnic compilation of School B is: White (57\%), Hispanic/Latino (35\%), other (5\%), Asian (2\%), and African American (>1\%). School B has experienced a five percent increase in intra-district transfers since the onset of the district health and wellness initiative. During the 20132014 school year, 25 percent of School B students chose to attend School B as opposed to

${ }^{17}$ Data were derived for the 2013-14 school year from http://datal lcde.ca.gov. 
their neighborhood school. As with School A, students whose parents have consented at School B complete the California Healthy Kids Survey (CHKS) anonymously responding to questions that address their physical and mental well-being. An analysis of 2012 CHKS data ${ }^{18}$ provides both a physical and psychological health score residing on a zero to one scale for each participating school. Scores closer to one reflect more positive responses to survey questions, and scores closer to zero reflect negative responses. School B received a Physical Health score of .85 and a Psychological Health score of .80 .

\section{Overview of School C}

Located coastally near the community's center, School C serves many of the region's students living in apartments as well as those residing in a domestic violence shelter. Simultaneously, affluent families living along the coastline also choose to send their children to this school as opposed to another SUSD school or one of the many private schools in the area. School and district leaders describe the campus environment as the "school as a garden" whereby the space surrounding buildings has a variety of specialized planters and landscaping designed to offer outdoor learning alongside the traditional classroom environment. Embodied in their mission statement, School C commits to "[work] as a nurturing team of staff, parents, and community members [to] provide challenging bicultural and bilingual learning experiences."

Sixty-four administrators, teachers, and staff are listed within School C's staff directory. The list of staff positions include: a school nurse, health technician, safety

\footnotetext{
${ }^{18} 2011$-2012 California Healthy Kids Survey (CHKS) data were utilized to generate Physical Response and Psychological Response values. At the time of this study, 2011 2012 CHKS data are the most current.
} 
monitor, speech therapist, custodian, reading specialist, learning resource center aide, science enrichment, music enrichment, media center aide, health and wellness instructor, PE instructor, and food service personnel. Three to four credentialed teachers are generally placed within each grade level, and a combination class exists at every grade level beyond kindergarten. A principal, office manager, and secretary round out the administration staff.

Initiated in 2008, School $\mathrm{C}$ is the second SUSD school to offer a DLI program for a select number of interested students determined through an annual lottery. Introduced with School B's overview, participating students are educated and interact in both Spanish and English throughout the school day. Students in the DLI program at School C also often progress from grade-to-grade as a cohort, building their language skills in addition to their academic content knowledge. All students at School $\mathrm{C}$ engage in weekly enrichment activities termed "specials" funded through the Parent Teacher Association (PTA) and grant monies. While classroom teachers collaborate, students incrementally rotate through music, yoga, library, garden, and physical education with alternate teachers and staff.

An SUSD Assistant Superintendent shared that the past seven years have presented School C with three new principals. Currently concluding her third year, School C's principal was described by one SUSD district personnel during an interview as a leader who, "gets an idea, and finds a way to make it happen." This was a prevailing view of School C's principal shared throughout interviews. School C's principal encourages her staff to generate ideas, devise a strategy, and initiate change while working directly with the staff and students to bring such activities to fruition. Latina by 
decent, she utilizes her Spanish-speaking skills to teach bilingual health and wellness lessons to students, interact with parents, and advocate for the Latino community at her site. Her daughter is also a student at School C.

Approximately 560 students are enrolled at School C. ${ }^{19}$ The ethnic compilation of School C is: White (55\%), Hispanic/Latino (33\%), other (8\%), Asian (3\%), and African American $(>1 \%)$. School $\mathrm{C}$ has experienced a 17 percent increase in intra-district transfers since the onset of the district health and wellness initiative. During the 20132014 school year, 27 percent of School C students chose to attend School C as opposed to their neighborhood school. As with all fifth grade students in California, students whose parents consent at School C complete the California Healthy Kids Survey (CHKS) anonymously responding to questions that address their physical and mental well-being. Introduced in Chapter 3 , an analysis of 2012 CHKS data ${ }^{20}$ provided both a physical and psychological health score residing on a zero to one scale for each participating school. Scores closer to one reflect more positive responses to survey questions, and scores closer to zero reflect negative responses. School $\mathrm{C}$ received a Physical Health score of .82 and a Psychological Health score of .80 .

\section{Summary}

Schools A, B, and C have similarities and differences in vision, staffing, leadership, enrollment, and CHKS-derived Physical Health and Psychological Health scores. Further differentiation will be revealed as the construct of each school's health and wellness program is presented. Table 6 on the following page provides an overview

${ }^{19}$ Data were derived for the 2013-14 school year from http://datal.cde.ca.gov.

20 2011-2012 California Healthy Kids Survey (CHKS) data were utilized to generate Physical Response and Psychological Response values. At the time of this study, 2011 2012 CHKS data are the most current. 
and comparison of the school-level differences stakeholders presented throughout the 2014 school year. With this background information provided for each school, differences in student's physical response to health and wellness instruction will be addressed first by school, and then by student socioeconomic status across each of the three participating schools.

\begin{tabular}{|c|c|c|c|}
\hline \multicolumn{4}{|c|}{$\begin{array}{l}\text { Table } 6 \\
\text { School-Level Differences by Participatin }\end{array}$} \\
\hline \multicolumn{4}{|c|}{ 2013-2014 School Year } \\
\hline & School A & School B & School C \\
\hline \multirow[t]{2}{*}{ Vision } & "Global thinking" & "School of languages" & "School As a garden" \\
\hline & "Cultural proficiency" & $\begin{array}{l}\text { "Learning in harmony } \\
\text { through a } \\
\text { multicultural } \\
\text { community" }\end{array}$ & $\begin{array}{c}\text { "Bicultural \& } \\
\text { bilingual learning" }\end{array}$ \\
\hline School Highlights & $\begin{array}{c}\text { International } \\
\text { Baccalaureate/ Health } \\
\text { \& Wellness }\end{array}$ & $\begin{array}{c}\text { Dual Language } \\
\text { Economically diverse }\end{array}$ & $\begin{array}{l}\text { Dual Language } \\
\text { Campus Gardens }\end{array}$ \\
\hline Staffing & 61 staff members & 55 staff members & 64 staff members \\
\hline Leadership & $\begin{array}{l}1 \text { leader } 7 \text { years New } \\
\text { principal hired mid- } \\
\text { year } 2014\end{array}$ & $\begin{array}{l}4 \text { leaders } 7 \text { years } \\
\text { Year } 2 \text { for principal }\end{array}$ & $\begin{array}{l}3 \text { leaders } 7 \text { years } \\
\text { Year } 3 \text { for principal }\end{array}$ \\
\hline Enrollment & $\begin{array}{c}554 \text { students } 47 \% \\
\text { white; } 53 \% \text { of color }\end{array}$ & $\begin{array}{c}675 \text { students } 57 \% \\
\text { white; } 43 \% \text { of color }\end{array}$ & $\begin{array}{c}560 \text { students } 55 \% \\
\text { white; } 45 \% \text { of color }\end{array}$ \\
\hline $\begin{array}{c}\text { Intra-District } \\
\text { Transfers to school }\end{array}$ & 71 students $(13 \%)$ & 165 students $(25 \%)$ & 147 students $(27 \%)$ \\
\hline $\begin{array}{c}\text { Physical Health } \\
\text { Score }\end{array}$ & .82 & .85 & .82 \\
\hline $\begin{array}{l}\text { Psychological } \\
\text { Health Score }\end{array}$ & .80 & .80 & .80 \\
\hline
\end{tabular}

\section{Socioeconomic Impact of Students' Physical Response to Health and Wellness}

A review of the literature presented in Chapter 2 indicates students are likely to physically respond to health and wellness instruction in the following ways: Their 
nutritional habits can improve, physical activity levels can increase, obesity/Body Mass Index values can lessen, and engagement in risky health-related behaviors can occur lessfrequently. Using the literature as a guiding framework, this study first sought to determine how Surfside Union School District (SUSD) students at three Title 1 schools physically responded to their school's health and wellness program, and additionally determine if responses changed with the introduction of health and wellness. Findings derived both quantitatively and qualitatively indicate physical similarities and differences exist among all three schools, and findings derived from student focus groups also suggest student physical responses vary by socioeconomic status.

\section{School Level Physical Response}

To provide context for forthcoming socioeconomic findings, school-level quantitative and qualitative findings will first be introduced. Chapter 3 presented the California Healthy Kids Survey (CHKS), explaining that school-level findings are available but anonymity prevented findings from being presented by socioeconomic status. Instead, two student focus groups at each school separated by Free or Reduced Price Meal eligibility or ineligibility were formed to enable the researcher to learn whether the survey's quantitative findings are socioeconomically distinguishable. Both student focus groups at each school were conducted with 3-5 fifth graders during their 40-minute lunch period. In the succeeding section school-level quantitative and qualitative findings will first be offered before turning to student socioeconomic findings.

Quantitative findings. As noted earlier in the chapter, responses to sixteen CHKS questions targeting physical wellness were compiled into an average Physical Health score ranging from zero to one for schools A, B, and C. Separate Physical Health 
scores were calculated using the 2008-2009 CHKS survey before SUSD initiated their health and wellness efforts, and then the 2011-2012 survey once health and wellness education was underway. See Chapter 3 for more information on the compilation of Physical Health scores.

For a deeper understanding of students' physical responses, values for physical wellness and risky behavior avoidance subcategories were separately compiled using the Guidebook to the California Healthy Kids Survey: Part II: Survey Content-Core Module as a guide for the selection and compilation of appropriate CHKS questions for each value. Zero to one scores for the physical wellness and risky behavior avoidance subcategories were also compared from 2008-2009 and 2011-2012 offering insight on potential school-level changes in student physical wellness and risky behavior avoidance before and after schools offered health and wellness interventions. Scores closer to one reflect more positive responses to survey questions, and scores closer to zero reflect negative responses.

Table 7 on the following page presents the change in the physical wellness and avoidance of risky behaviors subcategories as well as the total Physical Health score for schools A, B, and C before and after the introduction of health and wellness instruction. Percentages of students receiving free or reduced price lunch during both survey administration periods are also presented in Table 7 providing context for the school's population during that time period. It is important to note once again that the CHKS scores are compiled for the school as a whole and not by student socioeconomic status. Longitudinally, School A experienced no change in its Physical Health score, School B 
experienced a .02 increase in its Physical Health score, and School C reported no change in its Physical Health score.

\begin{tabular}{|c|c|c|c|c|c|c|}
\hline \multicolumn{7}{|c|}{$\begin{array}{l}\text { Table } 7 \\
\text { Change in Physical Health Score by Partic }\end{array}$} \\
\hline School & \multicolumn{2}{|c|}{$\begin{array}{c}\text { 2008-2009 } \\
\text { Physical Health } \\
\text { Score } \\
\end{array}$} & \multicolumn{2}{|c|}{$\begin{array}{l}\text { 2011-2012 } \\
\text { Physical Health } \\
\text { Score }\end{array}$} & \multicolumn{2}{|c|}{$\begin{array}{c}\text { Change in } \\
\text { Physical Health } \\
\text { Score }\end{array}$} \\
\hline \multirow{2}{*}{$\begin{array}{c}\mathbf{A} \\
\text { Free/Reduced Lunch } \\
\text { Values: } \\
\text { 2008-2009: } 47 \% \\
\text { 2011-2012: } 41 \%\end{array}$} & $\begin{array}{l}\text { Physical } \\
\text { Wellness }\end{array}$ & $\begin{array}{c}\text { Risky } \\
\text { Behavior } \\
\text { Avoidance }\end{array}$ & $\begin{array}{l}\text { Physical } \\
\text { Wellness }\end{array}$ & $\begin{array}{c}\text { Risky } \\
\text { Behavior } \\
\text { Avoidance }\end{array}$ & $\begin{array}{l}\text { Physical } \\
\text { Wellness }\end{array}$ & $\begin{array}{c}\text { Risky } \\
\text { Behavior } \\
\text { Avoidance }\end{array}$ \\
\hline & .73 & .90 & .78 & .85 & .05 & -.05 \\
\hline $\begin{array}{c}\text { Total School A } \\
\text { Physical Health } \\
\text { Score }\end{array}$ & \multicolumn{2}{|c|}{$\begin{array}{c}.82 \\
n=31\end{array}$} & \multicolumn{2}{|c|}{$\begin{array}{c}\mathbf{. 8 2} \\
\mathrm{n}=51\end{array}$} & \multicolumn{2}{|c|}{ 0 } \\
\hline \multirow{2}{*}{$\begin{array}{c}\text { B } \\
\text { Free/Reduced Lunch } \\
\text { Values: } \\
\text { 2008-2009: } 23 \% \\
\text { 2011-2012: } 29 \%\end{array}$} & $\begin{array}{l}\text { Physical } \\
\text { Wellness }\end{array}$ & $\begin{array}{l}\text { Risky } \\
\text { Behavior } \\
\text { Avoidance }\end{array}$ & $\begin{array}{l}\text { Physical } \\
\text { Wellness }\end{array}$ & $\begin{array}{l}\text { Risky } \\
\text { Behavior } \\
\text { Avoidance }\end{array}$ & $\begin{array}{l}\text { Physical } \\
\text { Wellness }\end{array}$ & $\begin{array}{c}\text { Risky } \\
\text { Behavior } \\
\text { Avoidance }\end{array}$ \\
\hline & .77 & .88 & .80 & .88 & .03 & 0 \\
\hline $\begin{array}{l}\text { Total School B } \\
\text { Physical Health } \\
\text { Score }\end{array}$ & \multicolumn{2}{|c|}{$\begin{array}{c}.83 \\
n=57\end{array}$} & \multicolumn{2}{|c|}{$\begin{array}{c}.855 \\
n=62\end{array}$} & \multicolumn{2}{|c|}{+.02} \\
\hline \multirow{2}{*}{$\begin{array}{c}\mathbf{C} \\
\begin{array}{c}\text { Free/Reduced Lunch } \\
\text { Values: }\end{array} \\
\text { 2008-2009: } 28 \% \\
\text { 2011-2012: } 24 \%\end{array}$} & $\begin{array}{l}\text { Physical } \\
\text { Wellness }\end{array}$ & $\begin{array}{c}\text { Risky } \\
\text { Behavior } \\
\text { Avoidance }\end{array}$ & $\begin{array}{l}\text { Physical } \\
\text { Wellness }\end{array}$ & $\begin{array}{l}\text { Risky } \\
\text { Behavior } \\
\text { Avoidance }\end{array}$ & $\begin{array}{l}\text { Physical } \\
\text { Wellness }\end{array}$ & $\begin{array}{c}\text { Risky } \\
\text { Behavior } \\
\text { Avoidance }\end{array}$ \\
\hline & .75 & .88 & .78 & .84 & .03 & -.04 \\
\hline $\begin{array}{l}\text { Total School C } \\
\text { Physical Health } \\
\text { Score }\end{array}$ & \multicolumn{2}{|c|}{$\begin{array}{c}. .82 \\
n=31\end{array}$} & \multicolumn{2}{|c|}{$\begin{array}{c}.82 \\
n=42\end{array}$} & \multicolumn{2}{|c|}{ 0 } \\
\hline
\end{tabular}

Looking specifically at longitudinal change in values for the physical wellness and the avoidance of risky behaviors subcategories, students at all schools scored higher in their avoidance of risky behaviors than they did in physical wellness at both survey administration periods. Additionally, from 2008-2009 to 2011-2012, positive changes in 
physical wellness values were apparent whereas negative or no change was observed in the avoidance of risky behaviors. All schools have individually tailored health and wellness activities that will be presented in a subsequent section.

Although little change is evidenced in the total Physical Health scores for schools A, B, and C, Physical Health scores from 2008-2009 - before the onset of the health and wellness initiative - were already high leaving little room for effects to be observed. Because the 2008-2009 SUSD fifth grade sample reported high Physical Health scores before the onset of the health and wellness intervention, significant changes were not evident. In this case the statistical phenomenon, regression to the mean, is evident inaccurately inferring the intervention was ineffective when sampling already physically healthy students is likely a contributing factor in the outcomes.

Differences in the physical wellness and risky behavior avoidance subcategories offer interesting findings about the student experience with the health and wellness program at their school. Chapter 5 will include an in depth discussion of the relationship between these physical health data and the qualitative findings that are presented in the following section.

Qualitative findings. Using the literature reviewed in Chapter 2 as a guiding framework, findings from the student focus groups with fifth graders at Schools A, B, and C suggest nuanced difference in ways students physically respond to their school's health and wellness program. Regardless of socioeconomic status, students from each school shared common themes in the way to which they physically respond to the health and wellness interventions available at their school. This section qualitatively takes a closer look at these commonalities at the school level. 
School A. Focus groups with fifth grade students at School A affirm they have a variety of components in place to support their physical health and wellness. Participating students physically report responding to such activities in the following three ways: (1) students are dissatisfied with school lunch options; (2) students learn academic and interpersonal skills through the cooking component and take their nutritional knowledge home; and (3) students feel the addition of physical education would enhance their level of physical activity. Although all school-level responses cannot be guaranteed as a direct result of the school's health and wellness program, findings suggest the school's attention to health and wellness is influential.

Students in both focus groups at School A defined health and wellness from the physical perspective. Eating healthy, exercising, and avoiding injury by "trying to not fall down" encompassed the students' understanding of health and wellness. None of the students in School A focus groups made a connection to mental wellness. Like all SUSD student participants, they affirmed school lunches are a point of dissatisfaction and student comments mirrored those shared by students from Schools C and B concerning the lack of healthy options, variety, and quality of meals. Comments provided in both focus groups did not differ by socioeconomic status.

Unlike Schools C and B, School A has a nutrition lab and structured Sage Cooking program that all students experience bi-weekly through the rotational enrichment schedule. Students identified this health and wellness component as a preferred activity. They shared ways cooking lessons also target academic and interpersonal skills. Students in both focus groups share the following:

It's an easy choice for me. I like Sage Cooking... I always like cooking, and then sometimes my group lets me be, like, the head chef. We let each other be the 
head chef, except [student 1] doesn't want to be. So it's usually me and [student 2]. But mostly [student 2]. Yeah. And I just like my group and I like cooking with them. (School A low-income $5^{\text {th }}$ grade female)

Yeah, there's four groups and each group cooks with their own team. It's just fun 'cause you learn your recipes while you get to cook. And it's fun. (School A nonlow-income $5^{\text {th }}$ grade male)

And you, like, learn a bunch of different foods from other countries that you don't know about. (School A low-income $5^{\text {th }}$ grade male)

Though students in both focus groups speak to the enjoyment and benefits of the Sage Cooking component, low-income School A students said they've taken class left-overs or recipes home to try with family members. One female student stated, "Last Monday we made a salad in my group. I really loved it. And so our teacher let us bring a little of it home. And my brother tried it and he goes 'Oh, my gosh, it's so good.'" Other lowincome students referenced making salads, smoothies, and pizza recipes from class at home with family members. Students in the more affluent group did not share bringing meals home, but they did report enjoying the learning experience.

Structured physical education (PE) does not take place at School A outside the classroom, although yoga is designated by SUSD as a PE component. Regardless, participating students do not perceive yoga as PE, and students from both School A focus groups said that PE would be advantageous to increase their physical activity. Students stated the following:

I know we don't have PE, but if we did my favorite [health and wellness component] would probably be PE. (School A non-low-income $5^{\text {th }}$ grade male)

Yeah. 'Cause we don't do PE. We just run laps. And I think we need more exercise than that. [The classroom teacher] lets us run laps, but that's not really PE. (School A low-income $5^{\text {th }}$ grade male) 
Yeah. Maybe, like, games that would, like, be fun at the same time, and also be exercising. 'Cause right now PE is just running laps. (School A low-income $5^{\text {th }}$ grade female)

Though students did not explicitly describe how their physical response would differ with yoga, $\mathrm{PE}$, or running, their reference to organized games can infer they identified positive experiences with such activities leading to greater enjoyment and participation. Students did not speak to needing a separate PE instructor, but did allude to PE extending beyond running.

Several physically-related health and wellness components take place at School A, and students' description of each mirrors that of School A personnel and parent volunteers. Participating students report responding to such physical components in the following three ways: (1) They're dissatisfied with school lunch options; (2) students incorporate academic and interpersonal skills through a favorable experience with the cooking component and take their nutritional knowledge home; and (3) they identify the addition of physical education would enhance their physical activity.

School B. Students participating in the two focus groups at School B physically report responding to health and wellness activities in the following three ways: (1) like students in the focus groups for School A, they are dissatisfied with school lunch options; (2) they report feeling more calm and relaxed through their participation in yoga; and (3) they engage in health and wellness activities with family members outside the school day. Although such responses cannot be guaranteed a direct result of the school's health and wellness program, findings suggest the school's attention to health and wellness is influential. 
All focus group students at School B defined health and wellness solely from the physical perspective. One student defined health and wellness by "how you treat your body," suggesting avoiding injury and illness is also related to health and wellness behaviors. School B students did not make a connection to mental wellness. They did, however, unanimously agree in both focus groups that school lunches are a point of dissatisfaction. Collectively all students agreed that fresh, healthier options are needed. Statements from School B students include:

The school lunches. They should put more fruit. 'Cause they don't have that much fruit and I would eat it. (School B low-income $5^{\text {th }}$ grade female)

They give out pizza and stuff, but the only thing they really have that's healthy is the salad bar. (School B non-low-income $5^{\text {th }}$ grade female)

Cause they pre-order the food, so they don't make it right here. It's, like, frozen or something. (School B non-low-income $5^{\text {th }}$ grade male)

Consistent across the two student focus groups at School B, students identified yoga as a preferred health and wellness activity, and offered evidence to suggest their physical activity has changed since yoga was introduced. With the addition of yoga, students are receiving an alternative way to be physically active that differs from traditional physical education. Individual students referenced $\mathrm{PE}$ was still valuable to promote physical activity, but students indicate yoga has been especially influential in the way they engage in physical wellness. Students in both focus groups offered the following statements:

When I do yoga, I feel relaxed and calm. It's good to, like, stretch and stuff too. (School B low-income $5^{\text {th }}$ grade female)

Yoga's my favorite because you stretch and you relax after and before. I feel more calm after... And when [the yoga instructor] rings a bell, like, there's peace and quiet. It's really cool. (School B low-income $5^{\text {th }}$ grade male) 
Yoga is really peaceful. (School B non-low-income $5^{\text {th }}$ grade female)

Finally, participating students at School B indicate varying degrees of collective family engagement with health and wellness activities. Students in both focus groups spoke to joining parents in different physical activities outside of the school environment. None spoke to joining families in health and wellness activities at school. Ways in which families joined in wellness differed by focus group, which will be discussed later, but statements related to collective physical activity include:

My parents, we go out to play at basketball. Or sometimes we ride a bike, or walk. (School B low-income $5^{\text {th }}$ grade male)

We go camping, like, almost two or three times a year. And we do a bunch of trips. And we do hikes a lot. (School B non-low-income $5^{\text {th }}$ grade male)

Sometimes I go with my family, to, like, walk a whole lap. 'Cause there's a gigantic cliff, where you can see the whole city. (School B low-income $5^{\text {th }}$ grade female)

Collectively, students at School B physically report responding to health and wellness components in the following three ways: (1) They're dissatisfied with school lunch options and react in ways that may be impacted by their socioeconomic status; (2) they report feeling more calm and relaxed through their participation in yoga; and (3) they engage in health and wellness activities with family members outside the school day.

School C. Students participating in the two focus groups at School C report physically responding to health and wellness activities in the following two ways: (1) Like School A and B students, they are uniformly dissatisfied with school lunch options but react in ways that may be impacted by their socioeconomic status, and (2) they report enjoying the garden component and feel that more cooking instruction and activities would allow them to utilize the knowledge at home. Although socioeconomically 
different participating students from School C came to the same two conclusions about their health and wellness experience, evidence suggests the reasoning leading to these conclusions are different. Of all participating schools, School C focus groups presented the most divergent responses to interview questions and additionally reported the fewest between-group commonalities related to preferred health and wellness components, physical response to these components, and overall feelings toward school. As such, no other school-wide commonalities were presented within both focus groups at School C, and an interesting finding likely related to socioeconomic differences was reported and will be presented at the end of this section.

School $\mathrm{C}$ students in both focus groups described school lunches as an area where improvement is needed. Comments from both groups surrounded a lack of healthy meals, the poor quality of those meal options, and the frequent repetition of available meals. Representative comments from students at School $\mathrm{C}$ related to school lunch and nutritional choices include:

School lunches are not healthy here. The pizza is a little greasy. We like the fruit and the salad, but that's pretty much it. The chicken is a little bouncy though (giggling). (School C low-income $5^{\text {th }}$ grade female)

It's not, like, enforced that 'You have to get a Five Star Lunch'... It's more like 'You should get a Five Star Lunch' cause it's healthy. But some kids like [pointing to student participant] he just got a burrito. That's all he got and it's probably like just one star, and you can get that almost any day. (School C nonlow-income $5^{\text {th }}$ grade male)

I would want to change the lunches. Have more fruit and other healthy options. Sometimes, the apples are still ripe. I mean, they're still green inside and sometimes they're not ready. They get picked too early and don't taste good. (School C low-income $5^{\text {th }}$ grade male)

The school garden component was described by one student as an opportunity to “... work in the garden every other week. We eat some of the vegetables we grow, and 
we learn some stuff too." Students in both focus groups report learning about various plants, how plants are grown, what composting entails, and other activities that sporadically includes a tasting or cooking component. Instances of cooking, in particular, have been reported as valuable. Students from both focus groups offered the following sentiments about the physical impact of the garden program and presented ways the program could be more supportive:

I like the garden for two reasons. One because we eat fruits and vegetables and the other because we get to be outside. (School $\mathrm{C}$ non-low-income $5^{\text {th }}$ grade female)

In the garden, you get to plant plants, and sometimes you get to cut and learn how to prepare things if you want to do them in your house too. (School C lowincome $5^{\text {th }}$ grade male)

I feel like we don't have specials often enough. Things like garden, music, and PE we only have once every other week. We learn one thing one week and by the next week we forgot the thing we learned before... We should get all the specials more often. (School C non-low-income $5^{\text {th }}$ grade male student)

Maybe we could get some lessons- like real lessons- on cooking... I have to cook for myself everyday... (School $\mathrm{C}$ non-low-income $5^{\text {th }}$ grade male)

Low-income focus group participants at School $\mathrm{C}$ report valuing cooking opportunities because they're able to share their knowledge at home. Conversely, more affluent students at School C also value instances of cooking, but report valuing them because they're able to use the newly acquired knowledge when cooking for themselves. The reasons behind their appreciation for cooking may differ, but their desire for additional cooking instruction remained consistent across focus groups at this school.

Although School C's student responses cannot be guaranteed a direct result of the school's health and wellness program, findings suggest the school's attention to health and wellness is influential. As unanimously recounted by participating students at all 
participating schools, students at School $\mathrm{C}$ also report dissatisfaction in school lunches regardless of their socioeconomic status at this juncture. The lack of variety, quality, and healthy options are described as unappealing, and are believed to influence the way students make nutritional choices. Additionally, exposure to the school garden and cooking is viewed favorably providing students with outdoor experiences, cooking knowledge, and less-traditional learning opportunities. Students propose having garden and cooking instruction and other enrichment opportunities with more regularity would enhance their learning. Socioeconomic differences in student physical responses across participating schools will next be presented.

\section{Socioeconomically Influenced Physical Response}

Quantitative findings. Due to the anonymity of California Healthy Kids Survey (CHKS) data, it was not possible to link student socioeconomic status to survey responses.

Qualitative findings. Socioeconomically diverse students from Schools A, B, and $\mathrm{C}$ report two physical response variations when health and wellness programs are provided in school. First, low-income students at all schools provide evidence of parents and children collectively engaging in regular physical activity as a family. Higherincome students also identify their parents as physically active, but parent physical activity regularly occurs separate from the child. Second, although all students share dissatisfaction with school lunches, the way in which students respond to this nutritional dissatisfaction varies and causes concern for SUSD personnel.

When asked if parents do anything to enhance their own health and wellness, lowincome students collectively shared instances when they joined their mothers or fathers in 
physical activity. Comments from students at each school offering evidence of collective physical activity include:

My mom- well, last night we wanted to eat even more healthy. So we ended up making salad for dinner. (School A low-income male)

My parents- we go out to play at basketball. Or sometimes we ride a bike, or walk. (School B low-income male)

When my dad gets back from work, he's really tired but he doesn't really care. So he still takes my sister and I out on our bikes or play foursquare. (School C low-income female)

Conversely, more affluent students offer the different ways their parents independently engage in physical activity.

My mom can't run because she's expecting a baby. But my dad - my stepdad he's lifting weights so much, like, bunches. And he runs, like, across the whole neighborhood. (School A non-low-income male)

My mom has done the Iron Man a few times... Right now she's doing a 21 -day get-fit thing, where you can only- it's like a diet, pretty much. (School B nonlow-income male)

My dad surfs, bikes, and goes on runs. He even goes on runs at work on his lunch breaks. My mom does a lot of gardening like I said. (School C non-low-income female)

A clear distinction between family-based physical activity emerged by focus group, but students of means did offer a few instances of family physical activity just as low-income students shared times when parents independently exercise. Such cross-over was most apparent at School A and least apparent at School B. Affluent students at School A shared that their parents sporadically participated in School A's family wellness program with them. This program will be introduced in more detail in a later section. The only instance affluent School B students referenced family physical activity occurred while recounting activities taking place during family vacations. Collective findings 
suggest socioeconomic status impacts the ways in which parents and children engage in physical activity outside the school day.

Low-income and more affluent students alike unanimously expressed dissatisfaction with school lunches. Complaints about the quality of food, variety, availability of certain items, temperature, and wasteful behaviors were expressed by students regardless of socioeconomic status. The SUSD Director of Food Services acknowledged the students' sentiment and admitted to forthcoming changes to school lunches in fall of 2014. More importantly, she acknowledged that the number of school meals presently sold across SUSD was low, but Schools A, B, and C offered the largest number of school lunches due to the number of students eligible for Free or Reduced Price Meals. Despite this fact, she went on to say, $30 \%$ or more students eligible for Free or Reduced Priced Meals are electing to not take school lunch on a daily bases. Explicitly, she stated:

That's completely alarming because you typically see those [Meal Count] numbers in the $93-94 \%$ utilizing those free or reduced meals. Here, you're only seeing $68 \%$ of reduced and $70 \%$ of free. The biggest thing is the stigma that the meals are bad, and no one wants to eat them. Even the kids who are low income, they're either eating whatever their parents are sending with a limited budget, they're not eating, or they're sharing with their friends. Whatever they're doing $30 \%$ of them might not be eating.

Lunchtime focus groups with low-income students offered evidence of students' regular eating habits while at school. At School A, one of three low-income participants joined with a school lunch and two students joined with lunch from home. At School B, all five low-income participants joined the conversation with a school-provided lunch. At School C, two students brought lunch from home, two joined with school lunches, and one had no lunch claiming he had finished his lunch during snack time. Few affluent students at 
Schools $\mathrm{A}$ and $\mathrm{C}$ arrived to the meeting with school-purchased lunches, no higher income students from School B purchased a school lunch, and no affluent students joined any conversation without lunch.

\section{Summary}

Physical health and wellness components vary by component, availability, access, and longevity at all participating schools. These variations correlate to the nuanced differences that emerged in focus group conversations. Collectively, socioeconomic differences by student focus group indicate two prominent differences exist in the way students physically respond to health and wellness instruction. First, low-income students provide evidence of parents and children collectively engaging in regular physical activity as a family. Higher-income students also identify their parents as

physically active, but parent physical activity regularly occurs separate from the child. Second, although all students share dissatisfaction with school lunches, the way in which students respond to this nutritional dissatisfaction varies and causes concern for SUSD personnel. Findings regarding students' psychological response to health and wellness will be offered in the following section.

\section{Socioeconomic Impact on Student Psychological Response to Health and Wellness}

A review of the literature presented in Chapter 2 indicates students are likely to psychologically respond to health and wellness instruction in the following ways: They can enhance their mental wellness reducing instances of depression, anxiety, or other stressors; experience a change in attitude toward their self (self-concept, self-efficacy, or self-esteem); and experience a change in behavior and interaction with others. Using the literature as a guiding framework, this study sought to determine how Surfside Union 
School District (SUSD) students at three Title 1 schools psychologically responded to their school's health and wellness program, and additionally determine if responses changed with the introduction of health and wellness. Findings derived both quantitatively and qualitatively indicate psychological similarities and differences exist among all three schools, and findings derived from student focus groups also suggest student psychological response varies by socioeconomic status in one significant way.

\section{School Level Psychological Response}

To provide a context for forthcoming socioeconomic differences, school-level quantitative and qualitative findings will first be introduced. Chapter 3 presented the California Healthy Kids Survey (CHKS), explaining school-level findings are available, but anonymity prevented findings by socioeconomic group to be distinguished. Instead, two student focus groups at each school separated by Free or Reduced Price Meal eligibility or ineligibility ultimately allowed for qualitative findings to be socioeconomically distinguishable. In the succeeding section school-level quantitative and qualitative findings will be first offered before turning to socioeconomic findings.

Quantitative findings. As presented earlier in this chapter, responses to seventeen CHKS questions targeting psychological wellness were compiled into an average Psychological Health score ranging from zero to one for Schools A, B, and C. Scores closer to one reflect more positive responses to survey questions, and scores closer to zero reflect negative responses. Separate Psychological Health scores were calculated using the 2008-2009 CHKS survey before SUSD initiated their health and wellness efforts and the 2011-2012 survey once health and wellness education was underway. See Chapter 3 for more information on the compilation of Psychological Health scores. 
For a deeper understanding of students' psychological responses, values for the following three subcategories were compiled using a review of current literature: subcategory 1 (students' connection to school), subcategory 2 (bullying avoidance), and subcategory 3 (perception of self). The rationale behind the compilation of questions for each category is available in Chapter 3. Zero to one scores for each category were also compared from 2008-2009 and 2011-2012 to offer insight on potential school-level changes in student mental wellness before and after schools offered health and wellness interventions. Scores closer to one reflect more positive responses to survey questions, and scores closer to zero reflect negative responses.

Table 8 presents the change in subcategories 1,2, and 3 and the Psychological Health score for Schools A, B, and C before and after the introduction of health and wellness instruction. Percentages of students receiving Free or Reduced Price Meals during both survey administration periods are also presented in Table 8 providing context for the school's population during that time period, but it is important to note once again that the CHKS scores are for the schools as a whole and not by student socioeconomic status. Longitudinally, School A experienced a .02 improvement in the Psychological Health score, School B experienced a .01 decrease in the Psychological Health score, and School C reported no change in the Psychological Health score.

Looking specifically at longitudinal change in values for each subcategory, students at all schools showed a decrease in feeling connected to people at school (subcategory one), substantially fewer experiences with bullying (subcategory two), and no change or a slight reduction in their perception of self (subcategory three). From 2008-2009 to 2011-2012, the largest gains and losses were evident at School C. All 
schools have individually tailored health and wellness activities that will be presented in a subsequent section.

\begin{tabular}{|c|c|c|c|c|c|c|c|c|c|}
\hline \multicolumn{10}{|c|}{$\begin{array}{l}\text { Change in Psychological Health Score by Participating Surfside Union School District } \\
\text { School }\end{array}$} \\
\hline \multicolumn{10}{|c|}{ 2008-2009 \& 2011-2012 School Year } \\
\hline School & \multicolumn{3}{|c|}{$\begin{array}{c}2008-2009 \\
\text { Psychological Health } \\
\text { Score } \\
\end{array}$} & \multicolumn{3}{|c|}{$\begin{array}{c}2011-2012 \\
\text { Psychological Health } \\
\text { Score }\end{array}$} & \multicolumn{3}{|c|}{$\begin{array}{c}\text { Change in } \\
\text { Psychological } \\
\text { Health Score }\end{array}$} \\
\hline $\mathbf{A}$ & 1 & 2 & 3 & 1 & 2 & 3 & 1 & 2 & 3 \\
\hline $\begin{array}{l}\text { Free/Reduced Lunch } \\
\text { Values: } \\
\text { 2008-2009: } 47 \% \\
\text { 2011-2012: } 41 \% \\
\end{array}$ & .96 & .42 & .98 & .95 & .53 & .98 & -.01 & .11 & 0 \\
\hline $\begin{array}{c}\text { Total School A } \\
\text { Psych. Health } \\
\text { Score } \\
\end{array}$ & \multicolumn{3}{|c|}{$\begin{array}{c}.78 \\
n=31\end{array}$} & \multicolumn{3}{|c|}{$\begin{array}{c}.80 \\
n=51\end{array}$} & \multicolumn{3}{|c|}{.02} \\
\hline \multirow{2}{*}{$\begin{array}{c}\text { B } \\
\begin{array}{c}\text { Free/Reduced Lunch } \\
\text { Values: }\end{array} \\
\text { 2008-2009: } 23 \% \\
2011-2012: 29 \% \\
\end{array}$} & 1 & 2 & 3 & 1 & 2 & 3 & 1 & 2 & 3 \\
\hline & .97 & .45 & .99 & .94 & .54 & .98 & -.03 & .09 & -.01 \\
\hline $\begin{array}{c}\text { Total School B } \\
\text { Psych. Health } \\
\text { Score } \\
\end{array}$ & \multicolumn{3}{|c|}{$\begin{array}{c}.81 \\
n=57\end{array}$} & \multicolumn{3}{|c|}{$\begin{array}{c}.80 \\
n=62\end{array}$} & \multicolumn{3}{|c|}{-.01} \\
\hline $\mathrm{C}$ & 1 & 2 & 3 & 1 & 2 & 3 & 1 & 2 & 3 \\
\hline $\begin{array}{l}\text { Free/Reduced Lunch } \\
\text { Values: } \\
\text { 2008-2009: } 28 \% \\
\text { 2011-2012: } 24 \%\end{array}$ & .96 & .43 & 1 & .92 & .59 & .93 & -.04 & .16 & -.07 \\
\hline $\begin{array}{c}\text { Total School C } \\
\text { Psych. Health } \\
\text { Score } \\
\end{array}$ & \multicolumn{3}{|c|}{$\begin{array}{c}.80 \\
n=31\end{array}$} & \multicolumn{3}{|c|}{$\begin{array}{c}.80 \\
n=42\end{array}$} & \multicolumn{3}{|c|}{$\mathbf{0}$} \\
\hline
\end{tabular}

Although little change is evidenced in the total Psychological Health scores for schools A, B, and C, Psychological Health scores from 2008-2009 - before the onset of the health and wellness initiative - were already high leaving little room for effects to be observed. Because the 2008-2009 SUSD fifth grade sample reported high Psychological Health scores before the onset of the health and wellness intervention, significant post- 
intervention changes were not evident. In this case the statistical phenomenon, regression to the mean, is evident inaccurately inferring the intervention was ineffective when sampling already physically healthy students is likely a contributing factor in the outcomes.

Although little change is evidenced in the total Psychological Health scores for Schools A, B, and C, differences in feeling connected to people at school, fewer experiences with bullying, and perception of self subcategories offer interesting findings about the student experience once health and wellness instruction was introduced at their school. Chapter 5 will include an in depth discussion of the relationship between these psychological health data and the qualitative findings that are presented in the following section.

Qualitative findings. Using the literature reviewed in Chapter 2 as a guiding framework, interviews with the two student focus groups of fifth graders at Schools A, B, and $\mathrm{C}$ suggest nuanced difference in ways students psychologically respond to their school's health and wellness program. Regardless of socioeconomic status, participating students from each school shared common themes in the way to which they psychologically respond to the health and wellness interventions available at their school. This section qualitatively takes a closer look at these commonalities at the school level.

School A. Adult interviews and student focus groups at School A support the claim that physical wellness support is more prominent than psychologically-supportive health and wellness components. Each school's health and wellness program components will be presented in the next section, but components addressing mental wellness are either more recent additions at School $\mathrm{A}$ or are not available to all students. 
Consistent across student focus groups at School A, students did not recognize mental wellness as a component of health and wellness; they solely defined health and wellness in terms of physical well-being. Although unable to articulate a connection to wellness, students participating in the Kindergarten Community (KC) club $^{21}$ spoke fondly of their participation, the mentorship they provide to younger students, and they admitted to feeling good about the overall experience. Finally, the fewest recounts of bullying were articulated by School A students, and more affluent students agreed bullying was nonexistent at their school.

When asked to interpret the term health and wellness, students in both focus groups drew upon examples of physical wellness to articulate their understanding. Statements such as "We're not just sitting around all day watching TV," "Eating healthy foods," and "playing soccer" were articulated by students in both groups as healthy behaviors. Attempting to make a connection to mental wellness, students were asked how they kept their brain healthy. Students shared "practicing your math" and "doing brain exercises" as responses they felt were connected to mental wellness.

Despite this lack of clarity around mental wellness, students in both groups did reference newer programs believed to support mental wellness as their preferred health and wellness component. Students in both groups identified KC Club as a favorite lunchtime component and spoke to how it makes them feel. A representative non-lowincome male student stated, "I feel really good when I'm at KC Club. It makes me feel like I can help people, and, like, I have the feeling that I'm, like, real useful. ." Of the

${ }^{21}$ Described in Appendix I, the KC club offers select students the opportunity to mentor kindergarten students during recess and engage them in organized play. Students are selected through an application process, are given t-shirts, and participate based on a schedule. 
components perceived by adults to support mental wellness, KC Club was the only program to elicit a student response. The remaining components stakeholders identified to target mental wellness left students questioning why they were listed as health and wellness components.

When comparing perceptions of bullying, student focus group participants from School A recounted far fewer instances of bullying or interpersonal conflict than focus groups at Schools B and C. Two instances of bullying were shared in the low-income student focus group, and more affluent students shared no instances of bullying. Problems with upper-grade $6^{\text {th }}$ graders were mentioned by low-income students, but students acknowledge they would first turn to a classmate and then a teacher in order to resolve an issue. One higher income student reported, "If there was bullying here I'd tell the teacher, but I don't think [bullying] has ever happened here." Differing experiences with bullying and interpersonal conflict are evident amongst the groups, but fewer instances of bullying were referenced at School A compared to the other schools.

Consistent across student focus groups at School A, students did not recognize mental wellness as a component of health and wellness; they solely defined health and wellness in terms of physical well-being. Although unable to articulate a connection to wellness, students participating in the Kindergarten Community $(\mathrm{KC})$ club spoke fondly of their participation and the mentorship they provide to younger students and admit to feeling good about the experience. Finally, the fewest recounts of bullying were articulated by School A students, and more affluent students agreed bullying was nonexistent at their school. 
School B. Interviews and observations indicate minimal health and wellness components exist at School B to support students' mental health. A detailed recount of the school's health and wellness program will be provided later in the chapter. As a possible result of this lack of programmatic psychological support, students at School B report numerous instances of bullying and dissatisfaction with the available support at specific points in the day. Experiences with bullying and psychologically related challenges differed by focus group, and will be addressed when socioeconomic differences are reported.

Collectively, School B students shared two prominent themes across focus groups: (1) The after school Y club $^{22}$ is not adequately supportive of participating students, and (2) a classroom teacher is the primary point of contact for school day interpersonal conflict. Students offered differing rationale as to why Y club was unsupportive; such responses concerned an appropriate amount academic support for homework and a lack of supervision during free play. Collectively, all students regardless of the focus group identified their classroom teacher as the person they go to when problems arise. One representative student stated, "I talk to my teacher when I get bullied, and if it's like, really bad, I tell the principal."

Programmatically, components designed to support mental wellness are newly implemented at School B, or they are not available to all students. Showing Our Acceptance and Respect (SOAR) and Playground Partners, for example, were introduced in the fall of 2014. No students participating in either focus group could speak to the

\footnotetext{
${ }^{22}$ Described in Appendix I, the $\mathrm{Y}$ club is an after school component available free of charge to all School B students through grant funding. Staff indirectly affiliated with School B offers tutoring, structured play, and socialization.
} 
programs' connection to mental wellness, nor had they participated in either component. Comments involving SOAR include:

SOAR is really for kids that have, like, special needs. (School B non-low-income $5^{\text {th }}$ grade male)

Yeah. We've both, like, done mostly everything except SOAR. (School B lowincome $5^{\text {th }}$ grade female)

Playground Partners, a component engaging YMCA members to lead organized play with students at recess, was identified by School B personnel to assist with interpersonal conflict and mental wellness. Alternately, students reported Playground Partners supported physical wellness explaining that organized play gave them the opportunity to play dodge ball, soccer, or other sports. Though student and personnel described the program similarly, students did not report the component's addition has reduced instances of bullying. Perhaps as these mental health components become more embedded in the school's culture, student participation will increase, instances of interpersonal conflict will lessen, and students will receive added mental health support.

School C. Student focus group participants at School C articulated two collective findings that distinguish them and their health and wellness programmatic experience from their peers' experience at other schools. First, when discussing the impact of health and wellness components perceived by stakeholders interviewed for this study to target psychological health, students were able to articulate the program's connection to mental wellness and address how the program may be beneficial. Second, components supporting mental wellness are more established at School C's campus and students participating in them spoke fondly of their programmatic involvement. Conversely, those students who had not been selected to participate in these programs shared feelings of 
jealousy and exclusion. Feelings were not dependent upon socioeconomic status but rather their involvement in these psychological health components.

When overviewing the list of health and wellness components available at School C, students affirmed the presence of each psychological health component, described what the component entails, and articulated how the component supported them psychologically. Students referenced the anti-bullying club, Safe School Ambassadors (SSA), the organization targeting interpersonal relationships, Showing Our Acceptance and Respect (SOAR), the school-wide positive behavior program Safe, Responsible, Respectful, and Flexible (SRRF), and the direct instruction mental health program Achieving your Potential Through Education/ PX2 Kids (PX2) as components supporting mental health and wellness. When asking students if they would classify components as health and wellness activities, School C students responded:

SRRF is health and wellness... If you see someone doing something nice, something like sharing their lunch if they don't have any, you give them a SRRF ticket. You're being Safe, Responsible, Respectful and Flexible. And when they give you a SRRF ticket, they circle one of those [reasons for the ticket]. (School $C$ non-low-income $5^{\text {th }}$ grade male)

For example, one day no one was playing with a kid because he was, like, really different. He would do a lot of things that were different from the other kids. And so one of the other kids came up to him and started hanging out [with him]. It's not fair that they won't, like, treat him the same way. And I gave him a SRRF ticket because he was being respectful of the kid. (School C low-income $5^{\text {th }}$ grade female)

I would consider PX2 wellness but not health. I would put in a wellness category because it makes you feel good and, yeah, it also makes you laugh a ton which is good too. (School C non-low-income $5^{\text {th }}$ grade male)

The SUSD Mental Health Teacher on Special Assignment indicated during the interview that components designed to support student psychological health have been in place at School C for "eight or nine years." This indicates the school has emphasized 
mental wellness for some time. Evidence suggests participating students may speak fondly of their programmatic involvement as a result of this longevity. One-student stated:

In [Safe Student Ambassadors] we have, like, meetings. We have a little group and we have meetings. We do important work, and we talk about how to prevent bullying or how to fix problems if we have ever seen bullying in school. Or sometimes we talk about times when ambassadors have, like, stopped bullying. (School C low-income $5^{\text {th }}$ grade female)

Student participation with School C's established psychological health components were reported as problematic by students in both focus groups. Students indicate teachers choose which children they invite to participate. A low-income female student stated, "You don't really choose if you want. Well, you can. But sometimes they just pick you. And you can agree if you want to be in the program. If you don't, you don't have to. But they pick you." Students not selected for these programs share feelings of exclusion:

I wish that [Showing Our Acceptance and Respect] SOAR and [Safe School Ambassadors] SSA were different. Because the people who do them are all secretive about them. They're always telling secrets. It's like, you don't get to choose if you're in it, so the people who are in it are constantly talking about it with the teachers. (School $\mathrm{C}$ non-low-income $5^{\text {th }}$ grade male)

There's a kid that his mom, she works here, and she has a program for, like, she picks kids that, like just picks the kids, and if they want to, they could. Yeah, just picks, and they're, like, stop bullying. (School C low-income $5^{\text {th }}$ grade female)

When asking students if they would be interest in joining either of these programs if they were invited to participate, affirmative head nods and comments such as "I'd want to be in SSA" were indicated by both low-income and non-low-income student groups. Although participating students speak favorably of components supporting mental wellness, feelings of exclusion are evident with students who have not received an invitation. In sum, school level findings at School C suggest long-term exposure to 
mental health components have aided children in their understanding of mental health and their ability to speak to their own psychological wellness, but restructuring the recruitment of student participants into these components would be valuable. Socioeconomic differences in psychological response across participating schools will next be presented.

\section{Socioeconomically Influenced Psychological Response}

Quantitative findings. Due to the anonymity of California Healthy Kids Survey (CHKS) data, it was not possible to link student socioeconomic status to survey responses.

Qualitative findings. Collectively, socioeconomically diverse students from Schools A, B, and C report one psychological response variation when health and wellness programs are provided in school: Low-income students identify personal experiences with on-campus bullying or interpersonal conflict while more affluent students speak to such situations as a third-party observer, or they believe bullying is not a problem at their school. Aside from this difference, low-income and more affluent students at participating schools experience similar responses to the psychological health and wellness support they receive at each school.

When asked to describe and reflect upon experiences with current health and wellness components, low-income students at Schools A, B, and C offered varying degrees of knowledge of, and participation with mental health components. Low-income students at School C regard the benefits of these psychological wellness components as valuable components to their school's health and wellness program, and most students (especially low-income students) identify them as their favorite activity. One low- 
income student stated, "I really think that students shouldn't say hurtful things or spread

rumors. Safe School Ambassadors tells you what to do when you see bullying, and helps you learn more about it than maybe you know." Low-income students at School C admit that bullying is still a problem for them, but feel the support provided through health and wellness components is valuable. Low-income students at Schools A and B share the sentiment that bullying is a problem at school as well. Evidence of bullying or interpersonal conflict is evidenced in the following recounts from low-income students:

Like, one time, in handball, I caught [the ball] and they got out. And then the next, like, couple minutes they just said that they didn't want to be my friends. And it's only because of a game. And I guess they're really mad. . (School A low-income student)

So what happened was I was- I was just playing basketball with my friends, and then [a group of boys] came to the game. We didn't have any problems or anything. I was trying to knock a ball, and this kid gets mad at me 'cause I knocked his friend's ball. I really don't know why he gets mad because that's the point of the game. It's called knockout. That's the point of the game. And then he starts calling me a bunch of bad-really bad - names and everything. And then he says that I'm the bully! When he's a sixth-grader calling me a bunch of names... Well, to be honest, I didn't really care about him telling me that. Plus, I know if I said something bad, we would both be in trouble. So I just let him do whatever he wanted, and let him rage. (School B low-income student)

Many kids just walk around and watch other kids play... In this school kids use more the words than pushing and hurting... They'll get your ball and kick it away, or say bad words to you. It makes you sad. (School C low-income student)

Low-income students at schools A, B, and C collectively offered first-hand experiences with interpersonal conflict or bullying that happened at school. Conversely, higher-income students represented in the second focus group at each school either could not recall instances of interpersonal conflict or bullying, or they offered third party perspectives of such behaviors. No students from the non-low-income focus groups offered stories of instances when they themselves were bullied. They offered situations 
they'd observed, or identified individual students who were viewed as school bullies, but no students of means shared negative personal experiences with bullying. When asked to comment on school safety and potential conflicts, responses from higher-income students included the following:

I don't think it has ever happened... This school is like- like a no-bullying zone... I don't think anyone would want to bully. And there's, like, iPads and everything. (School A non-low-income student)

Yeah. Like, last year, [a girl] had something bad happen, 'cause these girls were teasing her a lot. They trapped her in the bathroom and stuff... She went to the principal because of that. Well... she went to the teacher first, but the person was the teacher's favorite person, so she went to the principal instead. (School B nonlow-income student)

There's a lot of anti-bulling things so we don't usually have problems like that... There are some sixth graders who cause problems, but it doesn't happen so much. (School C non-low-income student)

\section{Summary}

Psychological health and wellness components vary by component, availability, access, and longevity at the three participating schools. As discussed in detail in the next section, these variations correlate to the one nuanced difference that emerged in focus group conversations: Socioeconomic variation by student focus group indicates lowerincome students have experienced more instances of bullying, more challenges with interpersonal conflict at school, and possibly more willingness to articulate such problems publicly. Higher-income students, conversely, are unaware of bullying on their campus, they report it happening to other classmates, or they are less willing to publicly articulate personal instances of bullying.

With the exception of the non-low-income student focus group at School A, school level findings collectively suggest that bullying and interpersonal conflict remain 
problematic at participating schools, and such conflict is especially prominent with lowincome-students. At all schools, quantitative school level data do indicate some positive change in bullying avoidance has occurred since the onset of health and wellness instruction suggesting schools are experiencing fewer instances of bullying or interpersonal conflict. Concurrently, quantitative data indicate students are feeling less connected to school and perceive themselves less favorably now than they did before the health and wellness initiative was introduced. These findings should encourage school and district leaders to incorporate effective health and wellness components targeting psychological wellness.

The following section will report findings for research question three that discusses the construct of each school's health and wellness program. As mentioned earlier in the chapter, this study was designed to identify existing health and wellness components at the three participating Title I schools, but data are not sufficiently comprehensive to offer comparisons of the participating schools, nor can an evaluation of each program's effectiveness be made conclusively. However, as will be discussed in Chapter 5, the findings do offer some insight into the degree to which the health and wellness program at each of the schools relates to the ten components of emerging Whole School, Whole Community, Whole Child model (see Figure 1) and what future research is necessary in this context.

\section{Surfside Union School District School Health and Wellness Construct}

A review of the health and wellness literature indicates two types of school-based health and wellness interventions exist within public elementary schools: Local School Wellness Policies and Coordinated School Health Programs. As public school health and 
wellness gains traction politically, the $\mathrm{ASCD}^{23}$ and Centers for Disease Control and Prevention's Whole School, Whole Community, Whole Child (WSCC) model will likely expand and ultimately replace the Coordinated School Health program. SUSD schools have taken significant strides to incorporate measures aligned to the WSCC targeting a holistic approach to health and wellness education whether or not they were intentionally doing so.

This section will begin by introducing the health and wellness perceptions stakeholders offered about each participating school, and discussing how individuals perceive each school attends to the health and wellness needs of its student population. Programs and activities related to health and wellness will next be introduced in order to report how district and school leaders are supporting the health and well-being of their students. To the extent to which they are available, SUSD stakeholders, parent volunteers, and student reactions to programmatic components will also be reported in this section. Data resulting from this present study are not sufficiently comprehensive to offer comparisons of the participating schools, nor can an evaluation of each program's effectiveness be made conclusively. Instead, concluding findings about each school's health and wellness construct will be summarized at the end of this chapter, and Chapter 5 will discuss the impact of each schools health and wellness program in relation to the quantitative and qualitative findings that were uncovered regarding student physical and psychological responses.

23 Formerly named the Association for Supervision and Curriculum Development, visit http://www.ascd.org to learn more about ASCD. 


\section{SUSD Perception of School Health and Wellness}

To clarify each school's outlook on health and wellness, stakeholder perspectives toward the each school's commitment to - and vision for - health and wellness reform will be introduced. Just as an overview of each school was provided at the start of this chapter, a summary of each school's health and wellness components that were in place throughout the 2013-2014 school year will be reported. SUSD stakeholder and student perspectives of health and wellness components will be presented before turning to the presence of specific programmatic components.

Health and wellness perception of School A. Protocols used throughout all SUSD interviews posed two identical questions about School A, "What makes [School A] a unique school in SUSD?" and "How do you perceive [School A] attends to the health and wellness of its students?" All participating SUSD stakeholders and parent volunteers received this question, and data related to School A's reputation and emphasis on student health and wellness were compiled. Findings indicate that School A attends to health and wellness primarily through the promotion of physical wellness by enhancing the physical activity level of students and parents alike. This attention is driven by School A's staff and a strong contingent of parent volunteers.

Leaders and staff at School A have sought out funds and partnerships to offer progressive school-based wellness resources that predominantly emphasize physical health. Such programs will be expanded in the following section and are available in Appendix I, but it is apparent that these resources are unique to public education and highly regarded on a national level. Although School A does offer programs that address 
mental health, findings indicate those programs are either new to School A, are made available to select students who have applied for participation, or are nominated by a staff member. All programs addressing physical health are regularly available to all School A students. The following statements reflect SUSD stakeholder and parent volunteer perspectives about School A's attention to physical health and wellness:

Cause if someone comes through feeling bad about themselves because of their weight, or because they didn't sleep well, or because they didn't eat enough, or whatever, everything else that I would put in place goes out the door. Because they're not here to - they can't attend to what's going on academically. (School A staff member)

They are learning things they may not have learned elsewhere, and they're taking those things home, which is interesting. "Mom we had kale today at school!" "What's kale?" Taking things home that may impact how the family does things. Maybe also building some of those life skills about here's how I stay healthy, here's what I can do as an individual in terms of exercise, because I may not be in a soccer camp all summer long. I really believe the greater impact will be on our lower-SES kids. (SUSD district personnel)

We have student clubs. One of the goals was to start giving kids a sense of purpose here at school, to come to school every day and tap into the inner self... So then my thing was, you know, how do we tap into certain kids that do have those leadership skills, either inherently or want to seek them out? To have an opportunity early on instead of having to wait for middle school or high school for all the opportunities that happen. So that's when we came up with the Kinder Companion. (School A staff member)

Children are obese and yoga is not going to help reverse obesity. It's cardiovascular fitness and aerobic exercise. I mean you can tell me, I don't do yoga but I don't see it as effective at preventing obesity... I'm not trying to make waves or anything. I just think we need to be cognizant that the kids need to be more physically active. (School A staff member)

School A parent volunteers have taken an active role in the institution of activities that support student and parent physical wellness. . Such volunteer-led activities involve a morning family wellness program, preventative health screenings, and a partnership with a nearby university. Select parents have organized and operate a morning family 
wellness program to encourage parents and children to engage in physical activity together. Extrinsic rewards are tabulated and offered from parents volunteers through monthly assemblies to recognize students for their involvement in this physical outlet. Free wellness screenings from a neighboring health clinic are provided annually to School A parents as a method of preventative wellness. Finally, a parent connection with a neighboring university has brought college students to School A during lunch recess to engage in more rigorous physical activity. The following statements reflect stakeholder and parent volunteer perspectives about School A's community engagement related to physical wellness:

When her son started kindergarten, [a School A parent] took it upon herself and started going out to businesses and literally knocking on their doors, saying "I'm a parent of a kindergartener at the school, and I want to build a school garden. She transformed that garden - or that piece of overgrown, weedy dirt - into a garden. She built the beds, she researched curriculum, and rallied up parents to come and take groups of kids out into the garden. (School A staff member)

Through the Family Wellness Program, we offer zumba on Mondays, we offer pilates on Tuesdays, yoga on Thursdays and running every day. It's been kind of loosely monitored by the volunteers out there, and we encourage the parents to stay and exercise with their kids. The point of it is not to just drop off their kids before they go to spin class. The point of it is to for the kids to see us being healthy. (School A parent volunteer)

And we're also doing adult screenings too. I've done the body composition, and they really seem to like that. We bring [a] Community Health Center down and they do the blood glucose screening. We just had one a couple weeks ago. It's amazing to see these families come through with high blood pressure, super high cholesterol, and super high glucose. We've sent them for immediate attention and they've come back to the next screening 30 pounds lighter, normal values, so it's been amazing to watch. (School A parent volunteer)

So [parent name] is a parent of a kid at [School A] who runs the acre garden that's connected to [School A]. [Parent name] runs, with her partner, a nonprofit with the district. They do SO much, but one of the things they do is bring healthy snacks to school for kids who can't afford them. [The non-profit leaders] were the ones that got the acre farm developed and reached out to community partners to help finance their efforts... Their official title, is [SUSD's] Green Team. 
They've been contracted by [SUSD] to help "greenify" the whole district. (School A staff member)

An array of health and wellness activities have taken shape at School A under the former principal's seven-year leadership. Such programs have been upheld since the new principal was hired. Although programs have been enacted to support the mental wellness of students at School A, findings indicate that School A primarily attends to the physical components health and wellness. This attention to physical wellness has been expanded by volunteers to encompass parent wellness as well as student wellness.

Health and wellness perception of School B. Protocols used throughout all SUSD interviews posed two identical questions about School B, "What makes [School B] a unique school in SUSD?" and "How do you perceive [School B] attends to the health and wellness of its students?" All participating SUSD stakeholders and parent volunteers received this question, and data related to School B's reputation and emphasis on student health and wellness were compiled. Findings indicate School B has adopted a health and wellness model that is in direct alignment to the health and wellness program provided to all SUSD schools and does not offer additional components at this point in time.

Although an explicit list of School B's health and wellness components will be provided in the following section, the components that were identified throughout the data collection process were either implemented in a top-down manner from SUSD, or they were programs piloted at other sites that were expanded to all SUSD schools. The following statements represent the SUSD perspective of School B's attention to student health and wellness:

You know, that's not something that comes to my mind when I think of [School B]... health and wellness doesn't come to my mind as one of their signature practices. (SUSD district personnel) 
The health and wellness program really does seem to be the yoga program [at School B]. As far as I'm really aware, we don't have a major garden program started or going right now. . As a systemic program, it definitely seems like more components could come in to [School B] that would benefit the kids. (School B staff member)

So a lot of work at School B is being done through the nutrition department, as far as our salad bar and healthy foods in that kind of way. There was a promotion they were doing to highlight different healthy foods once a week. That came through the district. The gardening piece, I would say, it's not something that we've implemented. (School C staff member)

...As far as trying to address the socio-emotional piece for our students. We have a learning resource center model for special education. But in that model we serve students who have emotional needs. And so there's curriculum that they use in the learning resource center.... it's just a curriculum with lessons on how to address conflicts... I would like to do more in that area because we do have a lot of needs. But it's just working with what we have, which is our school psychologist, our special education team, and then reaching out to community resources. (School C staff member)

Although a variety of highly regarded school-based activities such as the DLI program, were identified by stakeholders as beneficial programs for School B's population, all health and wellness components taking place at School B are those provided to all SUSD schools. Given their alignment to SUSD's health and wellness vision and timeline, School B was recognized as having an attention to health and wellness that reflects that of the school district's vision and current level of implementation.

Health and wellness perception of School C. Protocols used throughout all SUSD interviews posed two identical questions about School C, "What makes [School C] a unique school in SUSD?" and "How do you perceive [School C] attends to the health and wellness of its students?" All participating SUSD stakeholders and parent volunteers received this question, and data related to School C's reputation and emphasis on student health and wellness were compiled. Although findings indicate School $\mathrm{C}$ is unique due 
to its extensive garden component and commitment to outdoor education, a drive to support student mental wellness was reported by School C staff and closely affiliated district personnel to be at the heart of School C's health and wellness agenda.

School C's gardens are apparent on campus and are present to both beautify the campus and enhance academic instruction. Flowering beds and plants native to California are scattered throughout, and alternate walkways and rest areas surrounded by citrus trees and lush foliage provide children with natural space to commute and spend recess. Instructional working gardens are also interwoven through campus. Smaller garden beds are classroom managed, others are sanctioned for students supported through special education, and an expansive outdoor classroom and surrounding garden is utilized by all students weekly through the school's rotational schedule. School C's distinction of "School As a garden" can be captured through the following statements offered by School C staff and closely affiliated district personnel:

So the biggest component that we have under health and wellness would probably be the garden... We have various types of gardens throughout campus. There is both a garden teacher and garden manager, and the garden teacher teaches the garden rotations. So every two weeks all 530 students go through the garden rotations...The garden manager takes care of day-to-day garden things: up-keep, work orders, and being the liaison for the community. (School C staff member)

They've always had amazing school gardens and always had children working out in them. [School C's principal] tightened and expanded that concept. Tightened around what are the kinds of things we're doing in the garden rather as opposed to not just going to go out there to plant seeds. They're doing focused work in the gardens. (SUSD district personnel)

[School C] has a lot going on. It has the garden component, and they get to not only grow the food but then they get to harvest it and then cook, either with their [classroom] teacher or the garden teachers. They're learning how to cook food and have meaningful outdoor experiences. (School C staff member) 
The gardens at School $\mathrm{C}$ also serve to connect families and the surrounding community. Family workdays, Parent Teacher Association (PTA) functions, and a weekend farmers market were reported to emphasize the "School As a garden" concept. One parent volunteer stated, "They've had garden workdays, really great ones, too! Where the families come, and you'll see, like, they've done a whole variety of things to improve the garden. They've painted things, built fences, even a parent installed the kitchen station!" The principal has utilized the garden to promote wellness to parents by hosting events such as "coffee with the principal in the garden" as a PTA function. Although produce from School C is not sold, a community farmers market is held at School C on Sunday mornings for neighboring families to obtain local produce.

Although less publicly recognized, School C's commitment to supporting mental wellness was reported as a priority health and wellness endeavor. A variety of activities provided in the next section emphasize both an interpersonal and intrapersonal approach to socio-emotional learning, and SUSD personnel directly involved at School C referenced such activities to signify School C's commitment to mental wellness support. District personnel less directly involved at School C, however, referenced the "school as a garden" concept as School C's way of attending to health and wellness. Such participants did not address mental wellness in the interviews. SUSD personnel closely involved at School C shared the following sentiments about the school's commitment to student mental wellness:

I think the socio-emotional part is a constant evolution. We're constantly trying to figure out how to influence kids to make great choices, you know, make great choices for themselves and also with others. And I think that that's, like, slowly in development... We have daily breathing exercises over the loudspeaker. [Students] are encouraged to have positive behavior, which is called SRRF: Safe, Responsible, Respectful, and Flexible. (School C staff member) 
We've moved away from [extrinsic motivation] over the last two years, and shifted more toward a recognition-based program. In fact, this year we've switched it to SRRF tickets, and anybody can give each other SRRF tickets. So we've gradually moved away from that extrinsic approach to a more intrinsic approach. And I think that's made a difference. (School C staff member)

You don't teach children character. You know, you nurture character. So you work with what's there and you create this environment where you're communicating that that's valued, you're modeling it, and you're recognizing it. That's what is starting to happen at [School C]. (SUSD district personnel)

But here, in particular for our Title 1 population, you do have a lot of live situations in which you're going to be encountered with difficult situations. Your habits are going to come into question, and maybe your whole belief system as well. So what kinds of skills can we give you so that it carries you through and you make the right choices for you and you have success and you reach your whole potential? (School C staff member)

The Pacific Institute has their spin on what personal skills should be and what self-talk should look like... There's a lot of cross over between what they're doing and [the district wide] health and wellness program. That's why the fit seems good... [Achieving your Potential Through Education/ PX2 Kids] integrates well with our district wide world-ready skills and personal skills-inter and intra. I like the focus they put on self-talk and some of the setting expectations within yourself at [School C]. (SUSD district personnel)

Although School C's emphasis on mental wellness was not reported as a health and wellness focus beyond stakeholders intimately involved at School C, participants directly involved with School C reported this emphasis on mental health to be valuable and beneficial to students. School C's exploration of socio-emotional learning and piloting mental health programs new to SUSD is a component of health and wellness that is unique to this school site. Coupled with the school garden, School C was recognized for its emphasis on outdoor education and psychological support.

\section{School Health and Wellness Components}

With an understanding of stakeholder perceptions about each school's attention to health and wellness, a programmatic breakdown of each school's health and wellness 
construct will be presented in the sections below. An ongoing list of health and wellness components for each school was compiled during the data collection process and crosschecked throughout interviews in order to validate the presence, participation, and regularity that such components took place. Health and wellness components reported by SUSD stakeholders to target physical and mental wellness will be delineated in the sections below, and an explicit description of all programs is accessible in Appendix I. A cross-case comparison of schools and their affect on socioeconomically different students' physical and psychological well-being will be offered in Chapter 5.

School A health and wellness components. Throughout the data collection phase of this study, staff and students from School A helped compile and affirm the presence of twelve programmatic components that comprises School A's health and wellness program. Table 9 presents a list of the twelve health and wellness programs and identifies them to emphasize physical or mental wellness based on school personnel confirmation. This table also identifies if the program is available to all students or if a subsection of students is selected to participate. A detailed description of each program is available in Appendix I. In total, seven components at School A are believed to support physical wellness: Physical Education, Sage Garden, Sage Cooking, the annual jog-a-thon, Lunch physical activity with university students, Family Wellness Program, and the Five Star Lunch Program. Four components are believed to support mental wellness: International Baccalaureate (IB) Attitudes, Kindergarten Community (KC) Club, Sharing Our Acceptance and Respect (SOAR), and the Student Commissioners Club. Finally, yoga is believed to support both the physical and mental well-being of School A students. 
Table 9

Health and Wellness Components: School A 2013-2014 school year

\begin{tabular}{|l|l|l|}
\hline Component Name & $\begin{array}{l}\text { Described as Physical or } \\
\text { Mental Wellness }\end{array}$ & $\begin{array}{l}\text { Who Participates? } \\
\text { How Frequently? }\end{array}$ \\
\hline Physical Education & Physical Wellness & All students; weekly \\
\hline Sage Garden Science & Physical Wellness & All students; bi-weekly \\
\hline Sage Cooking & Physical Wellness & All students; bi-weekly \\
\hline Annual Jog-a-thon & Physical Wellness & $\begin{array}{l}\text { All students; once } \\
\text { annually }\end{array}$ \\
\hline $\begin{array}{l}\text { Lunch physical activity with } \\
\text { university students }\end{array}$ & Physical Wellness & $\begin{array}{l}\text { All students; voluntarily } \\
\text { at recess daily }\end{array}$ \\
\hline Family Wellness Program & Physical Wellness & $\begin{array}{l}\text { All students/parents; } \\
\text { voluntarily at parents' } \\
\text { discretion }\end{array}$ \\
\hline Five Star Lunch Program & Physical Wellness & $\begin{array}{l}\text { All students; voluntarily } \\
\text { at lunch daily }\end{array}$ \\
\hline Yoga & Physical \& Mental Wellness & $\begin{array}{l}\text { All students; twice } \\
\text { weekly }\end{array}$ \\
\hline $\begin{array}{l}\text { International Baccalaureate } \\
\text { (IB) Attitudes }\end{array}$ & Mental Wellness & All students; daily \\
\hline $\begin{array}{l}\text { Kindergarten Community } \\
\text { "KC" Club }\end{array}$ & Mental Wellness & $\begin{array}{l}\text { Students selected } \\
\text { through applications; } \\
\text { participate sporadically }\end{array}$ \\
\hline $\begin{array}{l}\text { Sharing Our Acceptance \& } \\
\text { Respect (SOAR) }\end{array}$ & Mental Wellness & $\begin{array}{l}\text { Students selected by } \\
\text { stakeholders; } \\
\text { participate sporadically }\end{array}$ \\
\hline Student Commissioners Club & Mental Wellness & $\begin{array}{l}\text { Students selected } \\
\text { through applications; } \\
\text { participate sporadically }\end{array}$ \\
\hline & & and \\
\hline
\end{tabular}

In addition to School A's staff, district personnel and teachers from other schools spoke very highly of School A's commitment to health and wellness. SUSD outsiders perceive the staff and teachers work as a team alongside their principal to elevate the school's attendance, academic performance, and both their regional and national 
reputation. Although teachers and staff themselves may not directly run the health and wellness programs, they support and encourage those volunteers and staff members who do run them, and largely embrace new ideas that are perceived as valuable for their students' success. Findings are exemplified in the following statements:

To be academically up to par you have to be healthy, feel good about yourself, and just be healthy too. And kids have to be safe. . And once you have those things then the academics just fall into place. (School A staff member)

At [School A], you have a staff that will follow you off a cliff if you tell them where you're going. So great staff, great leadership, very innovative, willing to take risks. Great sense of purpose and passion, we just needed a direction... when they went to [International Baccalaureate] it gave [the staff] a context for all the work they're doing, and their staff has really run with that. (SUSD district personnel)

All our schools are great, but you can see this very unique energy that comes out of [School A]. (SUSD district personnel)

Like, maybe some campuses need that, and that's totally fine. But here, I feel like yes, there's always going to be behavioral issues that go on, but I feel like overall stuff has been pretty manageable. And if it's not, then I can go to the teachers, and I have their support. I feel like overall they are more responsive, like, if the kids are acting up, it's not acceptable. (School A staff member)

I see a real- there's a really tight-knit professional community there. And they really value each other. And they seem to have a very common mission in terms of they're wanting their kids to be successful academically, but are open to other possibilities. (SUSD district personnel)

Participating students and parents share a similar pride in, and commitment to their school's health and wellness program. Students spoke to feeling lucky to attend School A. "The activities that other schools don't have, like cooking" commented a student, "we get to do all the time. They're one of my favorite things about [School A]." Another student said, "I like this school. I get a good education and it's really fun." Participating students recognized a variety of health and wellness components as their favorite activity and each struggled to identify components they favored less, or didn't 
enjoy.

As previously discussed, School A students did struggle to make the connection between their understanding of health and wellness, and how components targeting mental wellness fit into their schools health and wellness program. School A students defined health and wellness solely from the perspective of physical wellness: physical activity, nutrition, and behaving in a safe way. When asked if they thought mental wellness programs such as SOAR, Kindergarten Community club, and IB Attitudes support their health and wellness, students struggled to classify each as a health and wellness component. They alluded to a health and wellness connection if the program involved nutrition or a degree of physical activity, but skills acquired through character education and socio-emotional learning were not directly perceived by students to support health and wellness. The following student comments corroborate this finding:

Sometimes IB attitudes could be health and wellness, by it's more like acting like we can be an IB school. If we commit to following the rules, for example, then maybe we won't get hurt. So we're being healthier. (School C non-low-income student)

Well... KC Club could maybe be health and wellness. Because you have to play with them and sometimes organize soccer or do things with them, so it can sometimes be like healthy. (School C low-income student)

Yea, $\mathrm{KC}$ club is like health and wellness. You have to sometimes run a lot and you leave really tired... Even when they're slow! (School C non-low-income student)

SOAR is kind a health and wellness thing. I don't really know too much about it. I do know you get a buddy and you help them out. It's sometimes health and wellness because you can do different activities with your buddy. (School C lowincome student)

Stakeholder interviews did affirm SOAR and IB attitudes were new additions to the school community. As programs gain prominence and more children are involved, 
students' perception of health and wellness may expand beyond the physical component to include mental well-being.

Participating parent volunteers expressed deep pride in the school's commitment to their child's overall well-being, and choose to volunteer their time to contribute to the effort. One parent volunteer stated, "I'll ultimately spend twelve years at [School A] as my three children go through this elementary school. This is my way of supporting them and helping make this school even better." Data collection proved challenging around receiving a representative voice from parents, however. Attempts were made to interview parents through the school's English Language Advisory Council (ELAC) in hopes to gain a more representative parent voice about health and wellness. Connections were made, but formal interviews did not take place due to unanswered emails and telephone calls.

Observations of Parent Teacher Association (PTA) meetings, the Family Wellness Program, and various other school-day activities offer the hypothesis that white, moreaffluent parents are leading the volunteer charge toward health and wellness at School A. It is hypothesized that additional support to involve School A's parents of color in school-wide activities would be advantageous. At PTA meetings, for example, translation services were not provided. Of the thirty attendees at an evening PTA meeting six could be identified as persons of color, but were communicating with others in English. Childcare services were provided for the evening's event, but no translation services were available. Few parents of color were observed participating in other school-wide activities such as the Family Wellness Program, garden enrichment, or serving as classroom volunteers, and only one parent of color was seen holding a 
volunteer leadership role. Although School A has a strong volunteer contingent making an impact on the school's health and wellness program, these parent 'champions', a term offered by School A staff members to indicate a dedicated level of campus involvement, appear to be predominantly white and more affluent members of the school community.

Comments reflecting the participating parent voice include:

I feel like the [health and wellness] program would get more buy-in if it was led by the teachers rather than through us [volunteers]... run by a peer rather than just a parent. We do have to be cognizant that teachers have to prepare for classes and have other things to be doing. They need to be responsible for the education component and getting the classroom ready. I do understand why there isn't as much buy in, so we parents take the lead where we can. (School A parent volunteer)

Although in its first year, I see that program [SOAR] is going to take off here. I mean, we've got kids who want to be part of it already. And the parents are very invested in it. So that's been exciting to see. (School A parent volunteer)

I'm pretty involved on campus... [School A] it is the perfect storm of connecting academics, the environment and nutrition with the perfect population of children. There are quite a few parent champions who strive to ensure all our students have this unique and valuable experience. (School A parent volunteer)

Findings indicate a commitment for student health and wellness exists at School A, and the collaboration between the principal, staff, and parent 'champions' has contributed to this sentiment. Much of that commitment resides with physical wellness, and steps to enhance mental wellness support are forthcoming. 'Champion' parents often lead the charge implementing components to support physical wellness, and school personnel welcome their enthusiasm and largely support such efforts. Although the interviews did not speak to this issue, observations allude to a lack of holistic buy-in for health and wellness within the full school community. 'Champion' parents appear to be predominantly white and affluent, and the participation in and leadership of school health and wellness activities from parents of color is minimal. Given $53 \%$ of students at 
School A are students of color, a concerning lack of representation exists and will be further addressed in Chapter 5 .

School B health and wellness components. Throughout the data collection phase of this study, staff and students from School B helped compile and affirm the presence of seven programmatic components that comprise School B's health and wellness program. Table 10 presents a list of the seven health and wellness components and identifies them to emphasize physical or mental wellness based on school personnel confirmation. This table also identifies if the component is available to all students or if a subsection of students is selected. A detailed description of each health and wellness component is available in Appendix I. In total, four components at School B are believed to support physical wellness: physical education, the annual jog-a-thon, the Five Star Lunch Program, and the after-school "Y Club". Two components are believed to support mental wellness: Playground Partners and Sharing Our Acceptance and Respect (SOAR). Finally, yoga is believed to support both the physical and mental well-being of School B students. 


\begin{tabular}{|c|c|c|}
\hline $\begin{array}{l}\text { Table } 10 \\
\text { Health and Wellness Comp }\end{array}$ & ats: School B & \\
\hline \multicolumn{3}{|c|}{ 2013-2014 school year } \\
\hline Component Name & $\begin{array}{l}\text { Described as Physical or } \\
\text { Mental Wellness }\end{array}$ & $\begin{array}{l}\text { Who Participates? } \\
\text { How Frequently? }\end{array}$ \\
\hline Physical Education & Physical Wellness & All students; weekly \\
\hline Annual Jog-a-thon & Physical Wellness & $\begin{array}{l}\text { All students; once } \\
\text { annually }\end{array}$ \\
\hline Five Star Lunch Program & Physical Wellness & $\begin{array}{l}\text { All students; voluntarily } \\
\text { at lunch daily }\end{array}$ \\
\hline "Y Club" & Physical Wellness & $\begin{array}{l}\text { Select students; daily at } \\
\text { parents' discretion }\end{array}$ \\
\hline Yoga & Physical \& Mental Wellness & $\begin{array}{l}\text { All students; twice } \\
\text { weekly }\end{array}$ \\
\hline Playground Partners & Mental Wellness & $\begin{array}{l}\text { All students; voluntarily } \\
\text { at recess daily }\end{array}$ \\
\hline $\begin{array}{l}\text { Sharing Our Acceptance \& } \\
\text { Respect (SOAR) }\end{array}$ & Mental Wellness & $\begin{array}{l}\text { Students selected by } \\
\text { stakeholders; participate } \\
\text { sporadically }\end{array}$ \\
\hline
\end{tabular}

As introduced in the previous section, the seven components affirmed by School B stakeholders are health and wellness endeavors that are present at all SUSD schools. Stakeholders at School B speak positively about the presence of these components, but agree that expanding the school's health and wellness program would be beneficial. One teacher commented:

[School B] has a really positive school culture, but I'm curious if we're really meeting the health and wellness needs of our students. We have yoga and character building and the lessons that are [also] going on at other schools. They cover a lot, but I think we're missing another tier [of mental wellness] that needs more support. (School B staff member)

Individual efforts have been made to emulate other schools' health and wellness endeavors and institute them at School B. Components such as Sharing Our Acceptance and Respect (SOAR) and Playground Partners are newer to School B's campus as 
resources recently have been provided for their implementation. Proposed components that do not have clearly articulated implementation plans have not been as quickly accepted. One staff member noted, for example:

I tried presenting Safe School Ambassadors to bring it to [School B]. Although the principal values the potential benefits of adding the program, she recognized its addition would require another staff member dedicate the time to take it on. It just wasn't something we could take on this year.

At this point in time, School B's health and wellness program is shaped by the district's decision making as to the components deemed valuable to support and implement at all schools.

Students at School B spoke favorably of physical wellness components that are present at School B. "I like doing PE because you get to, like play knockout, lightning, two-touch, and four-square" shared one student. "Yoga is my favorite," says another student, "...because you stretch and you relax after or before. Sometimes when [the yoga instructor] rings the bell, it's really peaceful and quiet." Students did not offer additional suggestions for components to improve their physical health and wellness experience.

Findings from School B's health and wellness program indicate a need exists for socio-emotional learning and mental wellness support. The school psychologist commented, "A lot of kids are feeling anxious these days I'm noticing. Perhaps it's the change in common core, the stress we're feeling, but there is a lot of wariness in our kids. I have kids coming to me with greater levels of anxiety than in years past." The evidence from student focus groups below supports the psychologist's statement.

When asked if students feel supported when they have problems at school, students began to recount challenging social interactions and instances of bullying happening on the playground. Abbreviated testimonials include: "... then he starts 
calling me a bunch of bad - really bad - names and everything..." "When we were playing football, he hit me right in the ear. Instead of helping me he just kept on running and I got really mad" " ...there was this girl. She pinched me because she said I got in her way, but we were both running the same way." In such situations, students indicate they first go to their teacher to resolve matters during the school day, but supervision lessens during the after school Y Club component, and adequate support becomes less available. "There are more problems at Y club. In class nothing bad happens to me," stated one student. Providing additional socio-emotional learning opportunities during the school day would be beneficial for students to reference during recess and during $\mathrm{Y}$ club.

Students, parents, and staff largely are pleased with the health and wellness program at School B. Although few are aware of the additional components taking shape at other SUSD campuses, School B's community enjoys having access to the health and wellness components provided at their school. Concurrently, problems related to school climate were voiced by staff and students. Although those components supporting mental wellness are newer to School B, additional socio-emotional learning support would be advantageous.

School $\mathbf{C}$ health and wellness components. Throughout the data collection phase of this study, staff and students from School $\mathrm{C}$ helped to compile and affirm the presence of eleven programmatic components that comprises School C's health and wellness program. Table 11 presents a list of the eleven health and wellness components and identifies them to emphasize physical or mental wellness based on school personnel confirmation. This table also identifies if the component is available to all students or if a 
subsection of students is invited to participate. A detailed description of each component is available in Appendix I. In total, four health and wellness components at School C are believed to support physical wellness: physical education, garden science/cooking lessons, Five Star Lunch Program, and the Aspire after school program. Six components are perceived to support mental wellness: Playground Partners, Safe School Student Ambassadors (SSA), Sharing Our Acceptance and Respect (SOAR), Safe Responsible, Respectful, Flexible (SRRF) lessons, daily affirmations, and Achieving your Potential Through Education/ PX2, Finally, yoga is believed to support both the physical and mental well-being of School C students. 


\begin{tabular}{|c|c|c|}
\hline $\begin{array}{l}\text { Table } 11 \\
\text { Health and Wellness Com }\end{array}$ & onents: School C & \\
\hline 2013-2014 school year & & \\
\hline Component Name & $\begin{array}{l}\text { Identified as Physical } \\
\text { or Mental Wellness }\end{array}$ & $\begin{array}{l}\text { Participants \& } \\
\text { Frequency of Participation }\end{array}$ \\
\hline Physical Education & Physical Wellness & All students; weekly \\
\hline $\begin{array}{l}\text { Garden Science/Cooking } \\
\text { Lessons }\end{array}$ & Physical Wellness & $\begin{array}{l}\text { All students; weekly/cooking at } \\
\text { teachers' discretion }\end{array}$ \\
\hline Five Star Lunch Program & Physical Wellness & $\begin{array}{l}\text { All students; voluntarily at lunch } \\
\text { daily }\end{array}$ \\
\hline Aspire & Physical Wellness & Select students; select days ${ }^{24}$ \\
\hline Yoga & $\begin{array}{l}\text { Physical \& Mental } \\
\text { Wellness }\end{array}$ & All students; twice weekly \\
\hline Playground Partners & Mental Wellness & $\begin{array}{l}\text { All students; voluntarily at recess } \\
\text { daily }\end{array}$ \\
\hline $\begin{array}{l}\text { Safe School Student } \\
\text { Ambassadors (SSA) }\end{array}$ & Mental Wellness & $\begin{array}{l}\text { Students selected by stakeholders; } \\
\text { participate sporadically }\end{array}$ \\
\hline $\begin{array}{l}\text { Sharing Our Acceptance } \\
\text { \& Respect (SOAR) }\end{array}$ & Mental Wellness & $\begin{array}{l}\text { Students selected by stakeholders; } \\
\text { participate sporadically }\end{array}$ \\
\hline "SRRF lessons" & Mental Wellness & $\begin{array}{l}\text { All students; voluntarily } \\
\text { throughout school day }\end{array}$ \\
\hline Daily Affirmations & Mental Wellness & All students; daily \\
\hline $\begin{array}{l}\text { Achieving your Potential } \\
\text { Through Education/ PX2 } \\
\text { Kids }\end{array}$ & Mental Wellness & $\begin{array}{l}\text { Piloted weekly in all classrooms } \\
\text { with all } 1^{\text {st }}-6^{\text {th }} \text { grade students }\end{array}$ \\
\hline
\end{tabular}

Stakeholder sentiments toward School C's health and wellness programmatic components were generally positive in nature. Staff and parents offered valuable comments about School C's desire to support student wellness, and are pleased their students have the opportunity to learn both in and outside of the traditional classroom environment. Student sentiments reflected those of the school leadership regarding the presence of, and satisfaction with, all physical wellness components with the exception of the cooking component. They reported cooking to not regularly take place at School C,

${ }^{24}$ Grant funding is available for low-income students to participate in the Aspire program free of charge. 
and only surface as an infrequent addition to their garden rotation. Students spoke favorably toward the cooking opportunities they experienced, but would not classify cooking as an additional health and wellness component. Articulating the benefit of the cooking component, one student said:

Sometimes my parents are gone. Maybe we could get some lessons on cooking. My parents are at work, my sister is twelve and dealing with my little brother, so she asks me to cook and all I know how to make is burritos... By the time we're in middle school, we might need to make some food on our own more often. (School C non-low-income student)

Student focus group participants were in agreement with this statement owning that their cooking abilities were minimal, their parents were often not home after school, and that learning how to prepare meals independently would improve their health and wellness.

Positive feedback was offered regarding the connection between School C's emphasis on both gardening/outdoor education and mental wellness. One teacher stated, "You'll see some of our non-verbal or socially challenged students drawn to the garden. They specifically like to visit the chickens. You'll find them out petting and talking to the chickens where they regularly struggle to communicate with people." The newly added activities and pilot socio-emotional components currently being explored at School $\mathrm{C}$ were well received by the students and staff and additionally perceived as beneficial.

With the exception of two mental health and wellness components, students mirrored School C's leadership and spoke highly of the health and wellness program. However, as noted in the previous section, conflicting sentiments emerged regarding the feelings of exclusion that resulted from the selection for Safe School Ambassadors (SSA) and Sharing Our Acceptance and Respect (SOAR) components. According to participating students, School C personnel select students to join SOAR and SSA for the 
school year. Students participating in either program described them to be their favorite health and wellness component in the following ways:

With SSA, we have a group and have meetings to talk about how to fix problems and prevent bulling. I like it because I really think that people shouldn't bully or say hurtful things to other people. Why would you do that? It's really not nice. SSA really helps you a lot. (School C low-income student)

SSA tells you what to do if you see someone get bullied or what should you do if you're getting bullied. It helps you a lot to know more about bullying than you probably already know... At this school they use more of the words than the pushing and hurting. SSA helps you know what to do when those things happen. (School C low-income student)

Alternately, students who were not selected to participate in SSA or SOAR expressed feelings of exclusion from both the activities and their participating peers. The following statement evidences their sentiment:

What happens in SSA stays in SSA, so we don't know much about it. But I think it's about anti-bullying... You get offered to be in SSA. I personally think that's kind of unfair that they only pick people and you don't ever get to apply. (School C non-low-income student)

Reflected in their emphasis on mental wellness, School $\mathrm{C}$ has a variety of components taking place to target socio-emotional learning. In the pilot stage this year for example, Achieving Your Potential Through Education/PX2 Kids is a thirty-minute weekly lesson available in Spanish or English that targets life skill development through the utilization of multiple intelligences (Pacific Institute, 2014). Elaborated upon by the school principal:

You go in and you talk to the kids about scotomas, or blind spots. What happens when you do have a blind spot? How does it affect you in school or how could it affect you at home? It's all about queuing your potential...the conscious, the subconscious... How does that impact you? Just empowering kids with these tools is valuable. 
Modules of Achieving Your Potential Through Education/PX2 Kids have additionally been incorporated through full staff trainings where School C personnel were encouraged to reflect on their own "habits, attitudes, beliefs, and expectations" both internally and in their interaction with students. The reasoning behind this decision, the principal noted, "was because we felt that if we addressed the basic curricular factors with us as educators, then we could see a difference in how we educated, [and] how we behaved as professionals at school."

In sum, staff and community are pleased with School C's attention to health and wellness through outdoor education and mental wellness. Students are generally happy with the health and wellness support, but offered suggestions to further enhance the program. Though exploratory at this juncture, components supporting socio-emotional learning and mental wellness have been well-received, and are deemed beneficial to School C's students. Moreover, the connection between mental wellness and the extensive gardening component is perceived to be valuable to staff and advantageous to students. As School C's emphasis on mental wellness develops, additional work to define goals and programmatic outcomes surrounding mental wellness will be necessary.

\section{SUSD School Health and Wellness Programmatic Summary}

Participants from the district level collectively had unique and favorable things to say about each school's attention to the health and well-being of its student population. SUSD stakeholders recognize differences in leadership, staff, and resources exist, but acknowledge all schools are working within their means to support health and wellness. School B does so by offering all components provided collectively to SUSD schools, School A maximizes staff and volunteer enthusiasm to promote physical wellness, and 
School $\mathrm{C}$ is taking strides to programmatically support mental wellness. Findings will be further discussed in Chapter 5.

Internally, leaders, staff, volunteers, and students take pride in their school's attention to health and wellness, and feel a holistic educational experience is advantageous to their students' development. In select cases, students offered suggestions to enhance their physical health and wellness experience, or offered situations where mental wellness components could be beneficial. Parents, too, offered pride and appreciation towards their schools for going beyond the traditional academic construct of public education. In some cases, select parents have taken a leadership role in promoting health and wellness at their site. Volunteers, especially at School A, do not appear representative of the school's population at this time, but the parent volunteer presence offers the opportunity for health and wellness components to happen where they may otherwise not.

\section{Conclusion}

This chapter began by providing a detailed overview of each participating SUSD Title I school and presenting findings about each school's vision, staff, leadership, and enrollment, in addition to their Physical Health and Psychological Health scores. To answer research question one, California Health Kids Survey (CHKS) questions targeting physical health were quantitatively analyzed to understand how students at schools A, B, and $\mathrm{C}$ physically responded when health and wellness programmatic components were available. Although little or no change in Physical Health scores were evident at any school, students at all schools scored higher in their avoidance of risky behaviors than they did in physical wellness, but positive changes over time in physical wellness 
occurred at all schools whereas negative changes over time in the avoidance of risky behaviors occurred at all schools between 2008-2009 and 2011-2012. This finding will be further discussed in Chapter 5 .

Qualitatively, student focus groups at each school offered both similarities and differences in the way current students physically respond to health and wellness, but two significant findings likely to be socioeconomically influenced emerged: Low-income students at all three schools provided evidence of parents and children collectively engaging in regular physical activity as a family. Higher-income students also identified parents as physically active, but parent physical activity regularly occurred separate from the child. Second, although all students shared dissatisfaction with school lunches, the way in which students respond to this nutritional dissatisfaction varies and causes concern for SUSD personnel. Although participating students reported different programs to be both effective and enjoyable for different reasons, School A and C students most frequently referenced the garden science program and accompanying cooking component as most desirable, and students provided evidence as to how they respond to that activity. School B does not currently have an active school garden to corroborate this finding.

To answer research question two, CHKS questions targeting psychological health were quantitatively analyzed to understand how students at schools A, B, and C psychologically responded when health and wellness programmatic components were available. Although little or no change in Psychological Health scores were evident at any school, longitudinal change in values for each subgroup indicate students at all schools showed a decrease in feeling connected to people at school, no change or a slight 
reduction in their perception of self, but substantially fewer experiences with bullying. Qualitatively, student focus groups at each school offered both similarities and differences in the way students psychologically respond to health and wellness, but one significant finding likely to be socioeconomically influenced emerged from student focus groups at all three schools: Low-income students identify personal experiences with oncampus bullying or interpersonal conflict while more affluent students speak to such situations as a third-party observer, or they believe bullying is not a problem at their school.

To answer research question three and understand how schools with large numbers of low-income students incorporate health and wellness instruction, evidence from SUSD interviews, focus groups, and observations provided the community's perception of each school's attention to health and wellness, and how each program is constructed. Participants from the district level collectively had unique and favorable things to say about each school's attention to the health and well-being of their student population. SUSD stakeholders recognize differences in leadership, staff, and resources exist, but acknowledge all schools are working within their means to support health and wellness. School A does so by maximizing staff and volunteer enthusiasm to promote physical wellness, School B offers all components provided collectively to SUSD schools, and School C is taking strides to programmatically support mental wellness. In the next chapter, a discussion of findings answering research questions one and two will be shared. Chapter 5 will additionally discuss findings for research question 3 by utilizing the Center for Disease Control and Prevention and the ASCD's Whole School, Whole Community, Whole Child (WSCC) model to understand the how 
participating schools address the WSCC's ten component framework. The chapter will consider areas where schools are in alignment with the framework, and suggest areas where schools can further expand their health and wellness efforts. To conclude, the researcher will discuss the study's limitations but additionally draw upon findings from this study to discuss implications for future research in health and wellness. Concluding remarks will discuss the significance of the work SUSD schools have done in the area of health and wellness, and utilize findings from this study to improve and expand health and wellness instruction to better educate the whole child. 


\section{CHAPTER 5}

\section{IMPLICATIONS AND RECOMMENDATIONS}

This study set out to understand the impact of health and wellness education on the physical and psychological well-being of kindergarten through sixth grade students at three Title I schools in the Surfside Union School District ${ }^{25}$ (SUSD), and additionally determine if students are affected by health and wellness interventions differently based on their socioeconomic status. A systematic review of the literature and findings from this study indicate a correlation exists between a physical or psychological change in elementary-age children and the presence of health and wellness instruction.

Additionally, research affirms three substantial differences are apparent based on student socioeconomic status. Using the literature as a guide, this mixed-methodological study was initiated to answer the following three research questions:

1. How do low-income students' physical responses to health and wellness instruction differ from their non-low-income peers at these schools?

2. How do low-income students' psychological responses to health and wellness differ from their non-low-income peers at these schools?

3. In what ways do schools with large numbers of low-income students incorporate health and wellness instruction?

This chapter begins by summarizing findings in the order the research questions are presented above. As noted in Chapter 4, data are not sufficiently comprehensive to offer comparisons of the participating schools, nor can an evaluation of each program's effectiveness be made conclusively. The findings do offer insight into the degree to

\footnotetext{
${ }^{25}$ Surfside Union School District and the forthcoming school names are pseudonyms to protect the privacy of each school and all participating staff and students.
} 
which the health and wellness program at each of the schools relates to the ten components of emerging Whole School, Whole Community, Whole Child model, which will be provided following the summarization of findings. The chapter concludes with implications for future research, limitations, and concluding remarks about the study.

\section{Summary of Findings}

Two significant findings from this study indicate socioeconomic differences are correlated to variations in SUSD students' physical response when health and wellness instruction is incorporated into the school day. One important finding suggests socioeconomic differences are correlated to SUSD students' psychological response to health and wellness instruction. The chapter will commence with a summary of schoolbased and socioeconomically impacted physical and psychological findings. It is important to note that the California Healthy Kids Survey (CHKS) provided only schoolwide quantitative data. It did not break down the data by student socioeconomic status. To obtain information in this context, focus group discussions were held with lowincome and non-low-income students at each of the three Title I schools. Following the summary of findings for research questions one and two, findings about school context, health and wellness components, and the resulting health and wellness program at Schools A, B, and C are summarized.

\section{Physical Response to Health and Wellness}

School-wide findings. Quantitative and qualitative data were collected, analyzed, and compiled to learn whether student physical wellness has improved in SUSD since the implementation of health and wellness programs at each of the three SUSD schools. Substantial gains in total Physical Health scores, collectively, were not found when 
comparing CHKS data from before and after the onset of the SUSD health and wellness initiative. As described in Chapter 3, scores closer to one reflect more positive responses to survey questions, and scores closer to zero reflect negative responses. Total Physical Health scores from 2008-2009 to 2011-2012 showed no improvement at School A, a 0.2 improvement at School B, and no change at School C. See Chapter 3 for more information about the construct of each Physical Health score and subcategory, and see Chapter 4 for more information about the resulting CHKS Physical Heath scores and the regression to the mean phenomenon that impacted the significance of these quantitative findings.

Improvements in the physical wellness scores, a subcategory of the total Physical Health score created using the Guidebook to the California Healthy Kids Survey: Part II: Survey Content-Core Module as a guide, suggest student physical wellness at all three schools has improved slightly since SUSD's health and wellness initiative began in 20102011. Gains in physical wellness scores, a subcategory of Physical Heath, increased by 0.3 at Schools B and C, and by 0.5 at School A between 2008-2009 and 2011-2012. Qualitatively, all student focus group participants reported benefitting from available health and wellness components, and those with access to school gardens and cooking opportunities at Schools A and C spoke of this experience most favorably. School B students, not having a school garden or cooking component, reported yoga and physical education (PE) to be most beneficial.

While physical wellness scores went up in SUSD, risky behavior avoidance scores went down, resulting in little to no change in the total Physical Health score for all schools. Qualitative data indicate that all three schools are paying some degree of 
attention to supporting student physical wellness, but SUSD stakeholders who were interviewed for this study did not offer evidence of schools taking steps to reduce risky behaviors such as substance use, weapon concealment, or safety precautions including wearing seatbelts in cars or helmets on bicycles. Although the literature suggests risky health behavior avoidance falls under the health and wellness umbrella, SUSD stakeholders did not reference these behaviors as components of their health and wellness program, nor did they speak to this type of support being offered at this juncture when discussing their school's health and wellness program. As a porential result, student quantitative CHKS data from Schools A and C suggest that SUSD students are less safe and are engaging in more harmful behaviors in 2011-2012 than they did in 2008-2009 prior to health and wellness instruction. There was no change at School B in its risky behavior avoidance subcategory score.

Qualitative school-level data supported each school's prioritization of health and wellness components targeting physical wellness, and an absence of data addressing risky behavior avoidance corroborated the decline, or no change in quantitative values. Although each school is unique in its programmatic construct, Schools $\mathrm{A}, \mathrm{B}$, and $\mathrm{C}$ have each incorporated four different components perceived by SUSD to support students' physical wellness. None of those programs were reported to address risky health behaviors. Tables 9,10 , and 11 in Chapter 4 provide more information about the available physical health components respectively at Schools A, B, and C.

Socioeconomic findings. Student focus groups separated by Free or Reduced Price Meal status allowed for findings at each of the three Title I schools to be socioeconomically identified. Students from participating SUSD schools indicated two 
different ways low-income and non-low-income student groups physically respond to health and wellness programs. First, low-income students at all schools provided evidence of parents and children collectively engaging in regular physical activity as a family. Higher-income students also identified parents as physically active, but parent physical activity regularly occurs separately from the child. Second, although all participating students reported dissatisfaction with school lunches, the way in which students responded to this nutritional dissatisfaction varied and causes concern for SUSD personnel. Numerous comments from SUSD students and stakeholders are provided in Chapter 4 to validate these findings.

Students in each of the two focus groups at each school were asked about the types of activities their parents engage in to support their own health and wellness. All students offered evidence of parents having some degree of physical activity, but the way in which they engaged in physical activity differed socioeconomically. Low-income students reported joining in regular physical activity as a family through bike rides, walks to the park or beach, and hikes. Higher-income students also identified parents as physically active, but their parents' physical activity regularly occurs separate from the child. Evidence from more affluent students at all schools includes parents going to the gym, lifting weights, dieting, or engaging in fitness classes that occur without the child's participation. Parent volunteers at School A were aware of this fact and have taken strides to join parents and children in exercise at the school site, as will be discussed later in the chapter.

Perhaps due to extensive nutritional knowledge, all participating SUSD students unanimously reported dissatisfaction with school lunches. Complaints about the quality 
of food, variety, availability of certain lunch items, temperature, and wasteful behaviors were described by students - regardless of their socioeconomic status - as unsatisfactory. The SUSD Director of Food Services acknowledged that the number of school meals sold across SUSD was low in 2013-2014, but Schools A, B, and C were reported to receive the largest number of school lunches due to the number of students eligible for Free or Reduced Price Meals. Despite this fact, she reported, $30 \%$ or more students eligible for Free or Reduced Priced Meals in 2013-2014 elected to not take a school lunch on a daily basis. Thus, though they could receive a school lunch at little or no out of pocket expense, $30 \%$ of SUSD's low-income students did not obtain lunch from the school cafeteria during the 2013-2014 school year. The Director of Food Services hypothesized that the percentage of low-income students not accessing free or reduced price lunches could mean one of three scenarios: Parents are providing lunch from home on an already limited budget, students are sharing lunch with lower-income peers, or low-income students are not eating lunch. Lunchtime focus groups and observations indicated that any of these three scenarios could be happening on a given day.

The impact of physical wellness components generated both school-wide and socioeconomically influenced findings that are discussed in more detail with accompanying quotations in Chapter 4. Though the construct of each participating schools' health and wellness program is different, commonalities across schools and socioeconomic subgroups offered evidence of the benefits physical wellness support can provide to K-6 students. Moreover, differences by socioeconomic status can be of particular value to practitioners when considering the construct of their school 
community and a forthcoming health and wellness program. A more in-depth discussion will ensue later in the chapter.

\section{Psychological Response to Health and Wellness}

School-wide findings. Psychological health and wellness components vary by component, availability, access, and longevity at the three participating schools. Minimal change in the total Psychological Health score was apparent at any school from 20082009 to 2011-2012 with a 0.2 improvement at School A, a 0.1 decrease at School B, and no change at School C. Introduced in Chapter 3, scores closer to one reflect more positive responses to survey questions, and scores closer to zero reflect negative responses. Changes in subcategories were more substantial. The bullying avoidance subcategory indicated students had fewer incidences of with bullying at all participating schools after health and wellness instruction began. Score improvements for this subcategory ranged from .09 (School B) to .16 (School C). The additional two subcategories, students' connection to school and perception of self, indicated that changes in students' feeling connected to school as well as their perception of themselves decreased slightly or had no change in scores between 2008-2009 and 2011-2012. See

Chapter 3 for more information about the construct of each Psychological Health score and subcategory, and see Chapter 4 for more information about the resulting CHKS Psychological Heath scores and the regression to the mean phenomenon that impacted the significance of these quantitative findings.

At all schools, quantitative school level data from the CHKS survey indicated positive change in bullying avoidance, suggesting schools are experiencing fewer instances of bullying or interpersonal conflict in 2011-2012 than they did in 2008-2009. 
Still, bullying avoidance scores ranged from $.42-.59$ on the zero to one scale indicating bullying continues to be a problem in SUSD. Qualitatively, with the exception of the non-low-income student focus group at School A, school level findings collectively suggest that bullying and interpersonal conflict remain problematic at participating schools in 2014 , and such conflict is especially prominent with low-income-students. Student comments from both low-income and non-low-income students are set forth in Chapter 4. Collectively, though some improvement has been quantified with longitudinal CHKS data, quantitative and qualitative evidence suggests bullying and interpersonal conflict remain problematic within participating schools.

Socioeconomic findings. Student focus groups separated by Free or Reduced Price Meal eligibility or ineligibility allowed for findings to be socioeconomically differentiated. Collectively, socioeconomically diverse students from Schools A, B, and $\mathrm{C}$ report one psychological response variation may correlate to a health and wellness program's presence in school: Low-income students identified personal experiences with on-campus bullying or interpersonal conflict while more affluent students spoke to such situations as a third-party observer, or they believed bullying is not a problem at their school.

During student focus groups, all participating students were asked who they turn to at school when they have a problem. Experiences with bullying or instances of interpersonal conflict resulted from this question, and students shared stories or situations that affirm social conflict remains problematic at each of the three schools. How students shared these stories varied by socioeconomic status, however. At all schools, lowincome students provided first-hand experience with instances of bullying or 
interpersonal conflict. Playground conflicts, physical violence, and verbal abuse were all reported by low-income students. More affluent students told stories about other students being physically or emotionally bullied, but they did not offer instances when they were the victim.

Socioeconomic variation by student focus group indicates lower-income students have experienced more instances of bullying, are more challenged with interpersonal conflict at school, or are possibly more willing to articulate such problems publicly. Higher-income students, conversely, are unaware of bullying on their campus, they report it happening to other classmates, or they are less willing to publicly articulate personal instances of bullying.

The impact of psychological wellness components generated both school-wide and socioeconomically influenced findings that are discussed in more detail and with accompanying quotations in Chapter 4. Though the construct of each participating schools' health and wellness program is different, commonalities across schools and socioeconomic subgroups offer evidence of the benefits mental wellness support can provide to K-6 students. Moreover, differences by socioeconomic status can be of particular value to practitioners when considering the construct of their school community and a forthcoming health and wellness program. A more in-depth discussion will be provided later in the chapter.

\section{Health and Wellness Instructional Findings}

Findings reported in Chapter 4 indicate participating schools with large numbers of low-income students have taken three different approaches to incorporate health and wellness instruction: School A does so by maximizing staff and volunteer enthusiasm to 
promote physical wellness, School B offers all components provided collectively to SUSD schools, and School C is taking strides to programmatically support mental wellness. Evidence from Schools A and C suggests school stakeholders have tailored their programs to meet the needs of their school community whereas School B allocates resources elsewhere and utilizes the district to provide health and wellness support to students according to the district's overarching health and wellness vision.

Respectively, Schools A, B, and C offer eleven, seven, and ten health and wellness components that target physical and psychological wellness. Certain components are provided to all students at all schools, and other components are unique to a specific school and may be accessible only to certain students based upon the school's selection criteria. Variations in access and programmatic components led to the identification of three different programs at Schools A, B, and C, and student experiences with health and wellness instruction differed.

Of the five mental wellness components identified at School A, only two are accessible to all students. Comparably, four of six mental wellness components at School $\mathrm{C}$ are accessible to all students. School B, the SUSD model, offers a nearly equivalent balance of physical and psychological components, and two mental wellness components are accessible for all students. All school-level health and wellness variations are detailed in Chapter 4 offering evidence of the different ways to which health and wellness instruction can be provided.

\section{Interpretation of Findings}

This section provides an interpretation of the study's findings aligned to the literature provided in Chapter 2. The Whole School, Whole Community Whole Child 
model is introduced in Chapter 2, but the figure is reintroduced on the following page to assist the reader in understanding the discussion in this section. Using the WSCC model as a guide, this section will offer insight as to how each school attends to student health and wellness according to the WSCC, and where questions or room for improvement resides. Using data derived from both quantitative and qualitative methods, the observed implications of each program's construct within the school context will be set forth in hopes to aid other schools and districts acquire knowledge to physically, psychologically, and academically support the whole child.

Figure 1

Whole School, Whole Community, Whole Child Model 2014

WHOLE SCHOOL,

.... E CHLO

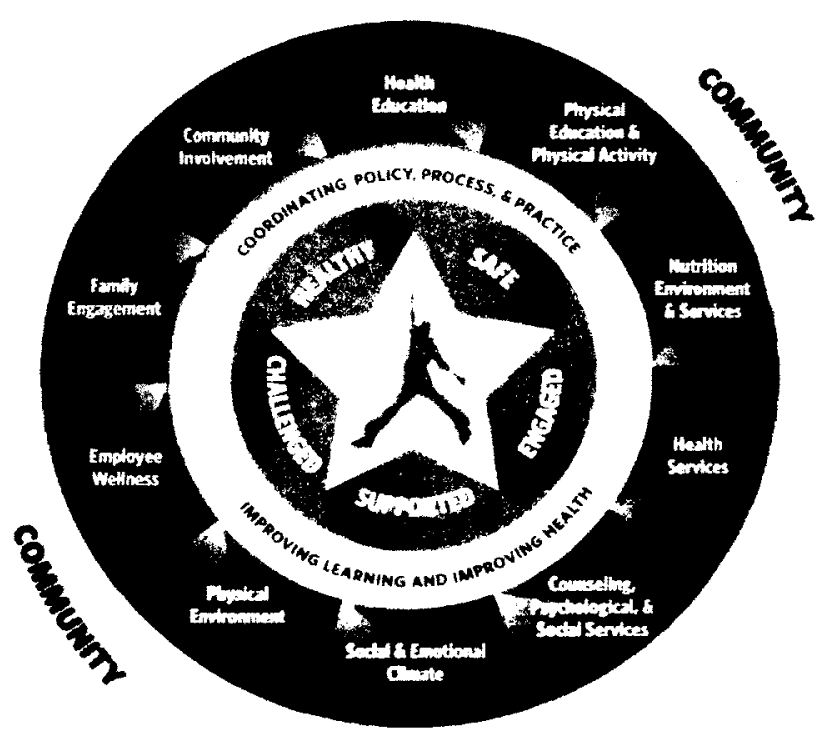




\section{School A}

Evidence from the 2013-2014 school year suggests School A's health and wellness program takes a noteworthy approach to the following four WSCC components: Nutritional Environment \& Services, Community Involvement, Physical Education \& Activity, and Family Engagement. Much can be learned from School A's thorough attention to Nutritional Environment \& Services and Community Involvement, but additional knowledge can be gained from limitations in the Physical Education \& Activity and Family Engagement WSCC components at this school.

School A has gone beyond the confines of the SUSD Five Star Lunch Program and created enrichment opportunities contributing to the Nutritional Environment \& Services WSCC component. Being only one of two SUSD schools to offer a school breakfast option whether students qualify for Free or Reduced Lunch or not, School A values the importance of students' nutritional well-being. Though the task of offering breakfast to students is not required at this juncture, School A stakeholders choose to do so to further support the whole child.

Additionally, the Sage Garden and Sage Cooking components offer School A students opportunities to obtain nutritional knowledge and become excited about making healthy choices with food. Grant funds and parent volunteers have generated opportunities for all students to have equal access to these health and wellness components, and student focus groups indicate students are taking their knowledge home, sharing it with families, and additionally making independent healthy nutritional choices during the school day. Though a need for improvement in the district wide school lunch program was made apparent by students, parent volunteers, and district stakeholders 
alike, the access all School A students have to a robust nutritional environment has excited students about gardening, nutrition, and healthy eating habits. As SUSD school lunches incorporate healthier options for students, evidence suggests such improvements will be especially well-received given School A's nutritional enrichment.

Community Involvement at School $\mathrm{A}$ is extensive within multiple facets of School A's construct. The health and wellness program, in particular, is led by many parent volunteers and community members perceived to be excited about offering such opportunities to a diverse student population. One SUSD district official interviewed for this study described School A's former veteran principal as, "Literally the queen of, 'if there's a resource out there, I am going to get it'." There was a consensus among district personnel that her acceptance of new ideas, a drive for reform, and her leadership style are likely to have generated the level of community support that continues to exist today. School A's community involvement with health and wellness extends to garden and cooking instructional components through the Sage Garden Foundation, free healthy snacks for students from the Healthy Day Partners nonprofit, health screenings through the Vista Community Center, and recess volunteers through California State University San Marcos.

Physical activity components evident at School A include yoga, the Family Wellness Program, lunchtime physical activity with university students, and other schoolwide annual events. Students receive multiple opportunities to engage in physical activity throughout the school day, and School A's physical wellness score derived from CHKS data indicates students have remained as physically well in 201 l-2012 as they were in 2008-2009. Counter to this fact, the number of students eligible to receive Free 
or Reduced Price Meals fell substantially from $47 \%$ in $2008-2009$ to $41 \%$ in $2011-2012$ making the argument that School A's population has become more affluent in recent years. Given research suggests that children of a lower socioeconomic status (SES) are reported to have greater risk of obesity than wealthier children (Keane et al., 2012; Kumanyika \& Grier, 2006; Ogden, Carroll, \& Flegal, 2008; Richmond \& Subramanian, 2008), one could argue that the unwavering physical wellness scores may be affected by a change in population as well as by the introduction of certain health and wellness components.

Questions remain as to how changes in student population have affected students' physical wellness, and if a need for traditional physical education (PE) should be expanded given student focus group participants' desire for a more structured PE component at this school. K-12 PE standards are present in California to ensure students are acquiring specific skills and knowledge related health, movement, and the importance of physical activity. With the exception of the school's yoga program, little evidence was provided as to each health and wellness component's association with PE standards, and further inquiry about this association is warranted.

SUSD personnel and School A stakeholders affirmed that students at School A are exceeding the required $200 \mathrm{PE}$ minutes every ten school days, and the various ways students can access physical activity is extremely valuable. Further consideration as to how the socioeconomic change in student population has affected School A's student wellness scores is warranted as is the need to ensure health and wellness components are aligned to PE standards. Addressing both matters would be valuable to further improve student physical wellness and arguably student achievement. 
School A is perceived by SUSD stakeholders to have taken an impressive initiative to provide nutritional experience, community resources, and physical activity to students and additionally urge parents to be involved in various health and wellness components available on the school's campus. Thus, they are making valiant strides to address the Family Engagement WSCC component. The Family Wellness Program, preventative health screenings, parent yoga, zumba, pilates and garden volunteer opportunities were described as ways School A parents could be more involved with the school's health and wellness program and additionally improve their own health and well-being. Though offering various activities to engage families in health and wellness occurs, evidence suggests that an excitement or appreciation for School A's health and wellness effort is not embraced by all families. Representative parent participation in health and wellness components is minimal, challenges recruiting a diverse and representative parent sample to interview for this study were encountered, and programmatic observations all suggest contextually related challenges may be contributing to a current divide.

Morning observations of the Family Wellness program revealed parent volunteers initiated the Family Wellness program just as the school breakfast program became available. Students who hadn't yet had breakfast made their way to the cafeteria line just as students who had likely already had breakfast began earning extrinsic rewards by running laps on the field and accumulating participation points. Observations revealed children perceived to be persons of color received a school-provided breakfast while students and parents perceived as white participated in the Family Wellness program. A few parents of color did engage in the program by walking or running laps, but the 
majority of participants appeared to be white students and parents while parents and children having a school-provided breakfast appeared to be families of color. Volunteers leading the Family Wellness program all appeared to be white.

Experiences like the one described above were observed on more than one occasion at School A. Parents perceived as white led and promoted school-wide activities in which a minimal number of parents of color engaged. Combined with comments from parent volunteers, a sense of urgency seemed to exist within the parent volunteer contingent (who appear to largely be white) to motivate parents of color to engage in health and wellness activities. Although reasons unable to be directly supported by data from this study led to this perception, observations along with formal and informal conversations suggest there are barriers hindering all parents from becoming involved in School A's health and wellness program. Given that $53 \%$ of School A students are non-white and a substantial contingent of parents are not engaged in school-wide health and wellness activities, speculation remains around parent and student empowerment, access, and biases.

\section{School B}

Evidence from the 2013-2014 school year suggests School B's health and wellness program takes a noteworthy approach to the following WSCC components: Physical Education \& Activity, Health Services, Social \& Emotional Climate, and Counseling, Psychological \& Social Services. Much can be learned from School B's Physical Education program and the heath services it provides to all students regardless of socioeconomic status. More importantly, much can be learned through School B's experience with aligning its health and wellness program to the district's present model. 
Participating students' vocalization of challenges with interpersonal conflict and bullying suggest a need to address the Social \& Emotional Climate and Counseling, Psychological, \& Social Services WSCC components in ways that extend beyond the current district model.

Within the WSCC Physical Education \& Activity component, all School B students participate in two 30-minute yoga classes and one PE class each week. Additional PE was also observed to occur with classroom teachers suggesting students at School B meet or exceed the state's PE mandate. Both physical wellness and the total Physical Health scores at School B are the highest of all participating schools, and risky behavior avoidance remained unchanged between 2008-2009 and 2011-2012.

Qualitatively, students from both focus groups identified PE and yoga as their preferred health and wellness components, and reported enjoying the organized games in PE and the opportunities to be peaceful and relax in yoga. Providing different ways to engage in physical activity was perceived as advantageous to School B students.

School B's principal reported how her school offers health services to all students. In addition to mandated vision and hearing screenings, School B staffs a school nurse, occupational therapist, and a psychologist to support student health in a variety of ways. Additionally the principal identified the program Early and Periodic Screening, Diagnosis, and Treatment (EPSDT), provided by the California Department of Health Care Services, to be accessible to her lower income students. She explained the service:

If a student has MediCal, then they are able to qualify [for EPSDT]. We do a referral to Rady Children's Hospital, and they have the ability to provide counseling for youth or families. The counseling sessions are minimal cost, if not free, for them. 
All students are reported to have access to physical and mental health services regardless of socioeconomic status. Individual support from School B stakeholders and collective support from the Learning Resource Center were referenced by students in focus groups. Though School B could continue to expand its degree of support in this WSCC component, low-income students' ability to access EPSDT, individual support from stakeholders, and collective support from the Learning Resource Center substantiates School B's support of all students' health.

School B stakeholders provided insight as to how a top-down health and wellness program is received at the elementary level. Though SUSD shares a district-wide vision to promote student health and wellness, evidence suggests that School B stakeholders are more engaged in other school matters and less driven to expand their health and wellness program due to a need to emphasize other school matters at this juncture. District-wide components are in place, but observations suggest they are not as valued at School B as they are at other participating schools. For example, yoga instructors have no designated space and relocate between the library, multipurpose room, or a concrete patio. Additionally, health and wellness instructors are not listed on the staff directory, and heath and wellness components unique to School B have yet to be piloted. Though there is no question School B's staff aims to provide students with a quality education, evidence suggests a robust health and wellness program is not yet embraced as a priority educational component at this school. School B provides a model of how a health and wellness program is received when school stakeholders do not fully support a need for such additions. 
This school further presents a need for SUSD to incorporate mental wellness components into its district-wide program. Declines in the Psychological Health score and two of three subcategory scores (students' connection to school and perception of self) corroborated by recounts of bullying through student focus groups affirm School B students are in need of mental wellness support recommended through the Social \& Emotional Climate, and Counseling, Psychological \& Social Services WSCC components. A few mental health components are in place such as Sharing our Acceptance and Respect (SOAR) and Playground Partners, but they are new additions and only available to select students by design. School-wide mental health support provided as a component of the district's health and wellness model would be especially valuable at School B.

\section{School C}

Evidence from the 2013-2014 school year suggests School C's health and wellness program takes a noteworthy approach to the following WSCC components: Nutritional Environment \& Services, Counseling, Psychological \& Social Services, and Social \& Emotional Climate. Qualitative and quantitative findings indicate School C touches upon all WSCC categories to a degree, and its prioritization of student psychological wellness serves as an incubator for SUSD to explore the impact of different mental health components in a school community that embraces this type of support.

Just as SUSD stakeholders described School C as a "school as a garden," an appreciation for nutrition, cooking, and garden science was evident through observations and interviews validating this district-wide perception. Garden science instructors 
excitedly reported how students participate in the current garden and cooking components, and shared forthcoming changes that are anticipated to enhance the student experience. Students in both School $\mathrm{C}$ focus groups positively recounted their learning by participating in both gardening and cooking, and indicated a desire to more frequently engage in this type of learning.

Like School A, School C has gone beyond the confines of the SUSD Five Star Lunch Program and is the second of only two SUSD schools to offer a school breakfast option whether students qualify for Free or Reduced Lunch or not. This valuable addition and the robust nutritional environment at School C provides opportunities for students to make healthier nutritional choices with food. Non-low-income student focus group participants requested more cooking opportunities specifically so they could prepare healthier meals when parents were away from the home, and low-income students recounted meals they'd made and sampled from produce grown in the school garden. In sum, as School $\mathrm{C}$ expands the garden and cooking health and wellness components and SUSD school lunches incorporate healthier options for students, evidence suggests such improvements will be especially well-received given School C's nutritional enrichment.

The longevity of Sharing Our Acceptance and Respect (SOAR), Safe School Ambassadors (SSA), and Playground Partners, along with the more recent yoga program, Achieving your Potential Through Education/PX2, and the school wide Safe, Responsible, Respectful, and Flexible (SRRF) component collectively contribute to an exemplary preliminary model to promote a strong social and emotional climate. Though the quantitative Psychological Health score remains unchanged, and two of three 
subcategories (students' connection to school and perception of self) experienced declines from 2008-2009 to 2011-2012, School B experienced a .16 growth in the bullying avoidance subcategory indicating school climate strongly improved since 20082009. This growth was, by far, larger than improvements that transpired at other schools. Similarly, student focus group participants identified mental health as a component of health and wellness, and students described how mental health components positively fit into their school's health and wellness program.

Quotations provided in Chapter 4 evidence how students valued opportunities to address bullying and have taken strides to promote pro-social behavior through components such as SRRF, SOAR, and SSA. According to student focus groups, the two most influential components, SOAR and SSA, are available only to students invited by School C stakeholders to participate. Evidenced in quotations provided in Chapter 4, students not selected to participate reported feelings of exclusion and jealousy. This lack of universal access was seen across all participating schools, but School C students explicitly vocalized their dissatisfaction and suggested ways to reform the present method of student recruitment. Students reported applying to the program would be an improvement.

The value School C stakeholders are perceived to place in incorporating health and wellness support suggests School C will continue to serve as an incubator for SUSD's mental health vision. Strides to enhance the presence of all WSCC components is still warranted at School C, and the emphasis placed on the Counseling, Psychological, \& Social Services, and the Social \& Emotional Climate WSCC components will provide a unique model for other schools and districts as they search for ways to support student 
mental wellness. Though continued emphasis on components supporting physical wellness should receive equal support, this school's commitment to support mental wellness and the leadership's forward thinking drive to seek out ways to reform make School C a desirable school community to warrant further study.

\section{Summary}

As the WSCC model continues to gain prominence and be recognized as the nationally agreed-upon way schools should address student health and wellness, it will be important for Schools A, B, C and SUSD at large to continue expanding each school's health and wellness program to encompass the ten WSCC components listed in the model. Moreover, school and district leaders should take strides to embrace the importance of these components as opposed to complying with WSCC components in order to maximize the program's impact on student well-being. Noteworthy examples of current WSCC components were discussed for each school above, but certain WSCC components were more prominent than others at the participating three schools. A plausible next step would be to explore whether models with comprehensive WSCC programs are more beneficial for students compared to models like Schools A, B, and C that only have selective components in place. If a holistic approach to the WSCC is found to be advantageous, SUSD should utilize the WSCC to strategically improve health and wellness instruction.

Though quantitative and qualitative evidence from Schools A, B, and C present findings that expand the literature base about health and wellness instruction, unique implications from each of these three schools suggest many contextual factors need to be understood and addressed by school and district stakeholders to ensure programmatic 
components positively influence student physical and psychological wellness. Dynamics related to school leadership, school culture, student enrollment, teacher buy-in, and community involvement are all deserving of attention and valuable to consider before progressing towards incorporating health and wellness instruction in a new school.

An important take-away Schools A, B, and C offer relates to the accessibility of each health and wellness component to the student population at large. At this juncture, evidence from all schools suggests components specifically targeting psychological wellbeing are only accessible to select students largely based upon teacher or stakeholder recommendation. Students at School C, the school with a longstanding dedication to mental wellness, reported feeling excluded and generally unhappy with how students are selected. Limiting access to students who admittedly want to participate and are unfairly not selected could impair the mental well-being of excluded students. Quantitative evidence suggest School C hasn't experienced a tremendous improvement in its Psychological Health score despite the program's longstanding presence on campus. Part of this explanation may be related to some desirable programmatic components only being available to select students. Therefore, schools intending to introduce a health and wellness program to their school community should proceed by ensuring students have equal access - or equal opportunity to access - all programmatic components.

\section{Limitations}

As with most research studies conducted within the public school context, limitations emerged that inhibit the generalizability of findings. Limitations surfaced both before this study commenced and throughout the data collection process. Still, valuable knowledge can be gained from this mixed-methodological study and used in the 
development of future health and wellness research. This section will report the limitations that emerged from January to June 2014. Limitations include the regional uniformity of participating schools, the study's focus on low-income elementary school students, the prioritization of qualitative data, and the outcomes resulting from conveniently sampling student focus groups.

Chapter 3 provides an overview of the sampling procedures and the final selection of the three participating schools. Purposeful and convenience sampling resulted in a crosscase analysis of three Title 1 schools within the Surfside Union School District (SUSD). SUSD uniquely encourages families to choice into SUSD schools that best meet their students' needs, and intra-district transfers are prominent at all SUSD schools. At participating schools, $13 \%$ of School A students, $25 \%$ of School B students, and $27 \%$ of School C students have chosen to attend their school as opposed to enrolling at their neighborhood school. The buy-in of parents choosing into a school's culture may affect the findings of this study, particularly with regard to School B and C as compared with Schools A. Additionally, although these K-6 schools primarily support the community's lowest-income students, all three schools still reside within a region that does not emulate the nation's low-income student population at large. The large number of intra-district transfers also hinders these school's ability to resemble traditional Title I schools. Compared to school districts with substantially larger low-income populations, the resources, opportunities, and systemic challenges are very different.

Most student participants at Schools B and C, for example, have attended school in a bilingual environment since kindergarten through the Dual Language Immersion (DLI) program. Student participants at School A attend an International Baccalaureate school 
where all students are exposed to intellectual, personal, and emotional skills through a variety of contexts. Students at all three schools have been exposed to school-specific health and wellness components discussed in detail in Chapter 4, and all students have school issued iPads to connect them and their families to the internet. Just these examples alone evidence how low-income SUSD students have a very different school experience than students form a more traditional low-income community.

As discussed in Chapter 1, children of a lower socioeconomic status (SES) are reported to have greater risk of obesity than wealthier children regardless of gender or age (Keane et al., 2012; Kumanyika \& Grier, 2006; Ogden, Carroll, \& Flegal, 2008; Richmond \& Subramanian, 2008). Children residing in low-income communities are additionally vulnerable to crime and violence (Berman, Kurtines, Silverman, \& Serafini, 1996). This exposure results in emotional consequences such as post-traumatic stress disorder symptoms (Berman et al., 1996), psychological distress (Hill, Levermore, Twaite, \& Jones, 1996; Jenkins \& Bell, 1994) or anxiety (Kuther \& Fisher, 1998). Because the SUSD community is largely affluent, those students who are classified as low-income through Free and Reduced Price Meal eligibility have a very different public school experience than students residing in a low-income community. Thus, findings generated through focus groups with low-income students at Schools A, B, and C cannot be generalized to the low-income student voice in a collective way.

Because this study concentrates on how socioeconomically different elementary school students respond to school-based health and wellness education, current literature about health and wellness in relation to the student population at all levels of public schooling was not included. The literature reviewed in Chapter 2 prioritized studies 
whose participants were enrolled in primary K-6 public schools and, to the extent that was possible, low-income. This study was conducted in Title I kindergarten through sixth grade schools, and the literature reviewed in Chapter 2 mirrored this work. Findings from this study cannot be applied to the secondary school environment due to developmental and systemic differences.

Although this study included both quantitative and qualitative methods by design, limitations emerged compromising the quality of findings resulting from the quantitative data. Such quantitative limitations are explained in Chapter 3. Two that are significant are small sample sizes and the anonymity of certain data that inhibited the ability to discern which respondents were low-income. Ultimately, 276 students across two school years and three schools comprised the California Healthy Kid Survey (CHKS) dataset. Though valuable information was provided, the sample size is small and cannot provide definitive explanations for all students' physical and psychological health.

Anonymity additionally became a CHKS limitation when data became unavailable at the school district. District personnel were unable to uncover the original data files, which were initially explained to be stored, and CHKS data became available only from WestEd, who provided the data stripped of all identifiers. Though the unit of analysis could still be the student, students could only be grouped at the school level and not by other variables. This unforeseen circumstance altered the research design and meant more data were collected and analyzed qualitatively than was initially intended.

To compensate for socioeconomic anonymity of the CHKS data, SUSD stakeholders assisted the researcher to construct focus groups separated by Free or Reduced Priced Meal eligibility or ineligibility. Focus groups were held on separate occasions to uncover 
potential differences in student experiences and responses. Valuable findings were generated from the socioeconomically different focus groups, but limitations are present in the small sample size of each student focus group and the way in which groups were constructed. Also, as was just discussed, SUSD low-income students cannot mirror the voice of low-income students at large, and findings differentiated by focus group should be taken with this limitation in mind.

Preexisting relationships with classroom teachers at Schools A, B, and C from a separate research study provided the researcher access to certain fifth grade classrooms. Therefore, select teachers volunteered to support the researcher to conduct the focus groups as opposed to teachers being randomly selected from each school. Though consented students were randomly selected within each class to participate, randomization was limited only by class and not by the grade level. Had teachers been randomly selected, or had students been randomly selected from the schools fifth grade level, a stronger representational voice may have emerged.

Perhaps more importantly, classrooms from Schools B and C were bilingual classrooms participating in the school's DLI program. Speculation about differences between DLI and non-DLI students is warranted given DLI participation. Although DLI participation was determined through a lottery, students must begin the DLI program in kindergarten or demonstrate proficiency in Spanish to participate. Hence, non-DLI classes may enroll more transient students or possibly fewer native Spanish-speaking students. Questions remain about how selecting students from DLI classrooms at Schools B and C influenced findings. 


\section{Implications for Future Research}

Findings from this study offer the first identifiable evaluation of three different health and wellness programs that serve large numbers of low-income students and additionally understand how each health and wellness program is designed to support the physical and psychological well-being of kindergarten through sixth grade students. It additionally offers evidence to suggest that students are affected by health and wellness interventions differently based on their socioeconomic status. Although the limitations described above hinder the findings' generalizability to other schools, districts, and regions, the information contained herein can serve as a model to help practitioners incorporate health and wellness components in K-6 schools and additionally support future research in this field. This section will offer suggestions for future areas of research.

As noted throughout all chapters, this study was designed to identify existing health and wellness components that the three participating Title I schools have incorporated into their health and wellness program and to understand how socioeconomically different students at each school have responded both physically and psychologically. Data were not sufficiently comprehensive to offer comparisons of the participating schools, nor could an evaluation of each program's effectiveness have been made conclusively. Future research should entail analyzing the effectiveness of the health and wellness components recognized by students and stakeholders as most valuable, comparing these components within the systemic context of the WSCC, and incorporating school-level contextual differences each component is embedded within. Evidence from this study suggests district vision, school leadership, and stakeholder buy- 
in are imperative for health and wellness programs to be successful at this juncture, and contextual factors must be considered when evaluating the effectiveness of a health and wellness component.

This study's cross-case analysis provides insight about the importance of continuity of leadership and its impact on a school community. High principal turnover may have influenced the implementation of Schools B's health and wellness program and hindered buy-in at the school level. Conversely, School A's principal spent seven years working to turn her school around and ultimately generated a school community that embraced and expanded the health and wellness opportunities students have experienced. Findings suggest that school leadership and continuity impact how health and wellness support is incorporated and how components of the WSCC are embraced to effectively support the whole child.

Moreover, limitations involving the unique low-income student experience of SUSD participants warrant additional research. Participating low-income students' experiences within SUSD are recognized to be dissimilar to low-income students living in challenged communities. Evaluating the effectiveness of health and wellness education in low-income communities could potentially validate findings from this study or identify additional health and wellness components that could be more valuable to schools located within low-income communities. Taking strides to identify longstanding physical and psychological health and wellness components within traditional lowincome schools and studying the effects of their presence may help validate findings herein and additionally deepen the field of literature. 
Future health and wellness research conducted within SUSD would be valuable to expand upon findings from this study. In November of 2014, California Healthy Kids Survey (CHKS) data from the 2013-2014 school year become available. Joining this third database to the 2008-2009 and 2011-2012 databases would strengthen findings determined quantitatively, and more accurately represent the present-day health and wellness programmatic experiences that were qualitatively revealed in this study through SUSD student and stakeholder interviews and focus groups. Because components have come and gone since the 2010-2011 onset of the SUSD health and wellness movement, incorporating the 2013-2014 student voice - although still anonymous at the student level - would offer findings more directly correlated to the three health and wellness programs that were presented in Chapter 4. Furthermore, working directly with SUSD district personnel to link CHKS data to student-level demographics (as opposed to obtaining anonymous data from WestEd) could provide a richer dataset.

The strategic compilation of the total Physical and Psychological Health scores and their respective subcategories proved valuable to longitudinally analyze student physical and mental health at schools in SUSD. Since CHKS data are collected at all schools across the state every other school year, additional exploration of the Physical and Psychological Health scores as a worthwhile tool to measure student physical and psychological health could be valuable. School and district stakeholders would have a tangible way to longitudinally interpret and compare CHKS data from school to school, and practitioners and policy makers would have a method to evaluate the effectiveness of agreed-upon health and wellness interventions. The applicability and compilation of CHKS questions to student physical and psychological wellness should be studied further 
and validated to ensure the construct of both the Physical and Psychological Health scores is appropriate for scalability.

Finally, expanding this method of research to the secondary level would be warranted. Few studies were uncovered to understand how middle and high schools support incorporate a health and wellness program. One could infer that this lack of literature could be present because few secondary schools implement health and wellness programs - which is another matter altogether - but future research depicting how secondary schools could support student health and wellness would serve as models for school communities in search for evidence to emulate.

\section{Concluding Remarks}

This study was undertaken to offer initial evidence as to how student physical and mental health and wellness correlates to the presence of an instructional day-embedded health and wellness program. Also, distinguishing between socioeconomically different student experiences provided the opportunity to understand if students respond to health and wellness instruction in different ways based on their Free or Reduced Price Meal eligibility or ineligibility. Though valid limitations emerged to hinder the generalizability of findings to the public educational community at large, preliminary evidence surfaced to indicate differences exist, and more research is warranted to clarify those findings and expand the field of literature.

Two important socioeconomically different physical wellness findings and one socioeconomically different mental wellness finding emerged during the 2013-2014 school year. First, subgroups differed by socioeconomic status in the manner parents and children engage in collective physical activity. Second, socioeconomically different 
subgroups responded to their mutual dissatisfaction with SUSD school lunches in ways that cause concern among SUSD district personnel. Psychologically, socioeconomically different students' experiences with interpersonal conflict and on-campus bullying differed indicating low-income students more directly experience challenging interactions with peers. These three findings alone are important to consider and explore further.

The unique construct of each participating school's health and wellness program invoked different health and wellness experiences for students at Schools A, B, and C. Dynamics related to school leadership, school culture, teacher buy-in, and community involvement are all attributable to the different health and wellness student experiences that were uncovered by this study. They additionally impact the school-level findings that were provided in Chapter 4 and further discussed alongside the WSCC model in this chapter. As school and district leaders turn to the SUSD health and wellness models presented throughout this document, understanding how numerous contextual factors contributed to the findings should provide insightful.

As schools begin to take strides to move away from the No Child Left Behind era of scripted academic instruction and standardized assessments to address new important ways to support the well-being of the whole child, health and wellness programs will become a more common occurrence within the public educational community. It is important that high quality research is undertaken to ensure students are exposed to effective physical and psychological wellness components, and that appropriate access is provided to all students to improve the school culture in addition to the individual student's well-being. 
As quoted in Chapter 1, "Studies have provided evidence that poor nutrition and limited physical activity among today's children and youth negatively impact their physical, social, and emotional health as well as their school attendance, learning, and academic achievement" (Argon, Berends, Ellis \& Gonzalez, 2010). Findings from this study corroborate this statement and offer preliminary evidence as to how socioeconomically different students respond physically and mentally when a school supports their well-being and academic achievement. Though more research is necessary, findings from this study affirm the need for schools to address student health and wellness, and take a larger role to support the whole child. . 


\section{References}

Allensworth, D., \& Kobe, L. (1987). The comprehensive school health program: exploring an expanding concept. Journal of School Health, 57(10), 409-412.

Argon, P., Berends, V., Ellis, K., \& Gonzalex, M. (2010). School wellness policies: perceptions, barriers, and needs among school leaders and wellness advocates. Journal of School Health, 80(11), 527-535.

ASCD. (2014). Whole school whole community whole child: A collaborative approach to learning and health. Alexandria, VA: ASCD.

Au, N. (2012). The health care cost implications of overweight and obesity during childhood. Health Services Research, 47(2), 655-676.

Aud, S., Fox, M., Kewal-Ramani, A. (2010). Status and trends in the education of racial and ethnic groups: NCES 2010-015. National Center for Education Statistics: Washington, DC.

Austin, G., Bates, S., \& Duerr, M. (2013). Guidebook to the California healthy kids survey: Part II: Survey content core module. WestEd. Retrieved April 17, 2014 from https://chks.wested.org/resources/chks_guidebook_2_coremodules.pdf.

Barry, M., Clarke, A., Jenkins, R., Patel, V. (2013). A systemic review of the effectiveness of mental health promotion interventions for young people in low and middle income countries. BMC Public Health, 13(835).

Basch, C. (2010). Healthier students are better learners: A missing link in school reforms to close the achievement gap. The Campaign for Education Equity. Teachers College, Columbia University. 
Bates, H., \& Eccles, H. (2008). Wellness curricula to improve the health of children and youth. Alberta: Alberta Education.

Bavarian, N., Lewis, K., DuBois, D., Acock, A., Vuchinich, S., Silverthorn, N... \& Flay, B. (2013). Development to improve academic outcomes: A matched-pair, cluster-randomized controlled trial in low-income schools. Journal of School Health, 83(11), 771-779.

Beehler, S., Birman, D., \& Campbell, R. (2012). The effectiveness of a cultural adjustment and trauma services (CATS): Generating practice-based evidence on a comprehensive, school-based mental health intervention for immigrant youth. American Journal of Community Psychology, 50, 155 168.

Beets, M., Flay, B., Vuchinich, S., Snyder, F., Acock, A., Burns, K., Washbum, I., \& Durlak, J. (2009). Use of a social and character development program to prevent substance use, violent behaviors, and sexual activity among elementary-school students in Hawaii. American Journal of Public Health, 99(8), 1438-1445.

Belansky, E., Cutforth, N., Delong, E., Litt, J., Gilbert, L., Scarbro, S.,... Marshall, J. (2010). Early effects of the federally mandated local wellness policy on school nutrition environments appear modest in Colorado's rural, low-income elementary schools. America Dietetic Association, 110, $1712-1717$. 
Berman, S., Kurtines, W., Silverman, W., \& Serafini, L. (1996). The impact of exposure to crime and violence on urban youth. American Journal of Orthopsychiatry, 66, 329-336.

Botvin, G., Griffin, K., \& Nichols, T. (2006). Preventing youth violence and delinquency through universal school based prevention approach. Preventative Science, 7, 403-408.

Boxer, P., Guerra, N., Huesmann, L., \& Morales, J. (2005). Proximal peer-level effects of a small-group selected prevention on aggression in elementary school children: An investigation of the peer contagion hypothesis. Journal of Abnormal Child Psychology, 33(3), 325-338.

Braveman, P., Cubbin, C., Egerter, S., Williams, D., \& Pamik, E. (2010). socioeconomic disparities in health in the United States: What the patterns tell us. American Journal of Public Health, 100(S1), S186-S 196.

Breier, M. (2014, February, 28). Going green yields big honor for Encinitas district. San Diego Union Tribune. Retrieved from http://www.utsandiego.com/news/2014/feb/28/green-honor-state-encinitasschool-district/.

Brown, R. \& Wade, G. (1987). Superordinate goals and intergroup behavior: the effect on role ambiguity and status on intergroup attitudes and task performance. The European Journal of Social Psychology, 17, 131-142.

California 2013 Legislative Services. (2013). S.B. No. 330: Education-schools and school districts- mental health instruction. 2013 Cal. Legis. Serv. Ch. 481 (S.B. 330)(West). 
California Department of Education. (2005). A guide for testing vision in California Public schools. Retrieved June 20, 2014 from http://www.cde.ca.gov/ls/he/hn/documents/visionreport.pdf.

California Department of Education. (2014). School garden program overview.

Retrieved April 14, 2014 from http://www.cde.ca.gov/ls/nu/he/gardenoverview.asp. California Department of Education (2009). Health education contend standards for California public schools: Kindergarten through grade twelve. Retrieved July 3, 2014 from http://www.cde.ca.gov/ci/he/cf/.

California Department of Education. (2013a). Dataquest. Retrieved October 31, 2013 From http://datal.cde.ca.gov/dataquest/.

California Department of Education. (2013b). Free or reduced price lunch eligibility scales. Retrieved October 30, 2013 from http://www.cde.ca.gov/ls/nu/rs/scales1112.asp.

Carlson, J., Mignano, A., Norman, G., McKenzie, T., Kerr, J., Arredondo, E...\& Sallis, J. (2013). Socioeconomic disparities in elementary school practices and children's physical activity during school. American Journal of Health Promotion, 28(3), 47-53.

Carr, D., Schaible, A., Thomas, K (2013). Health in mind: Improving education through wellness. Healthy Schools Campaign \& Trust for America's Health. Retrieved November 9, 2013 from http://healthyamericans.org/report/103/. 
Centers for Disease Control and Prevention. (2011). Trends in the prevalence of selected Risk behaviors and obesity for all students national YRBS: 1991-2011. Retrieved April 12, 2012 from http://www.cdc.gov/healthyyouth/yrbs/pdf/us_summary_all_trend_yrbs.pdf

Centers for Disease Control and Prevention (2013a). . Childhood obesity facts. Retrieved March 24, 2013 from http://www.cdc.gov/healthyyouth/obesity/facts.htm.

Centers for Disease Control and Prevention (2013b). Coordinated school health FAQs. Retrieved December 12, 2013 from http://www.cdc.gov/healthyyouth/cshp/faq.htm.

Centers for Disease Control and Prevention. (2013c). Health and academics. Retrieved November 24, 2013 from http://www.cdc.gov/healthyyouth/health_and_academics/index.htm.

Centers for Disease Control and Prevention (2014). Local school wellness policy. Retrieved January 17, 2014 from http://www.cdc.gov/healthyyouth/npao/wellness.htm

Center on Education Policy. (2007). Choices, changes, and challenges: Curriculum and instruction in the NCLB era. Washington, D.C: Center on Education Policy.

Chalmers-MacDonald, J. (2005). The effects of a culture based social skills program on the pro-social behavior of elementary school boys and girls. (Unpublished Doctoral Dissertation). The Adler school of professional psychology, Chicago, IL. 
Collins, S., Woolfson, L., \& Durkin, K. (2014). Effects on coping skills and anxiety of a Universal school-based mental health intervention delivered in Scottish primary schools. School Psychology International, 35(1), 85-100.

Common Core Standards Initiative (2013). Retrieved September 17, 2013 from http://www.corestandards.org.

Conrod, P., Stewart, S., Comeau, N., \& Maclean, A. (2010). Efficacy of cognitivebehavioral interventions targeting personality risk factors for youth alcohol misuse. Journal of Clinical Child and Adolescent Psychology, 35(4), 550-553.

Cornwell, L., Hawley, S., \& Roman, T. (2007). Implementation of a coordinated school health program in a rural, low-income community. Journal of School Health, 77(9), 601-606.

Coyle, K., Kirby, D., Marin, B., Gomez, C., Gregorich, S. (2004). Draw the line/respect The line: A randomized trial of a middle school intervention to reduce sexual risk Behaviors. American Journal of Public Health, 94(5), 843851.

Cradock, A., Barrett, J., Carter, J., McHugh, A., Sproul, J., Russo, E...\& Gortmaker, D. (2014). Impact of the Boston active school day policy to promote physical activity among children. American Journal of Health Promotion, 28(3), 54-64.

Craggs, C., Corder, K., van Sluijs, E., \& Griffin, S. (2011). Determinants of change in physical activity in children and adolescents: A systematic review. American Journal of Preventative Medicine, 40(6), 645-658. 
Creswell, J., \& Plano Clark, V. (2011). Designing and conducting mixed methods research, second edition. Thousand Oaks, CA: Sage Publications, Inc.

Cuijpers, P., van Straten, A., Smits, N., Smit, F. (2006). Screening and early psychological intervention for depression in schools: Systematic review and meta- analysis. European Child Adolescent Psychiatry, 15, 300-307.

Dalgas-Pelish. (2006). Effects of a self-esteem intervention program on school-age children. Pediatric Nursing, 32(4), 341-348.

Datar, A., \& Sturm, R. (2004). Physical education in elementary school and body mass Index: Evidence from the early childhood longitudinal study. American Journal of Public Health, 94, 1501-1506.

Delima, J. \& Vimpani, G. (2011). The neurobiological effects of childhood maltreatment: An often overlooked narrative related to the long-term effects of early childhood Trauma? Family Matters, 89, 42-52.

Dellert, J., \& Johnson, P. (2013). Interventions with children and parents to improve physical activity and body mass index: A meta analysis. American Journal of Health Promotion, 28(4), 259-267.

Demetriou, Y. \& Honer, O. (2012). Physical activity interventions in the school setting:A systematic review. Psychology of Sport and Exercise, 13, 186-196.

Dencker, M., Thorsson, O., Karlsson, M., Linden, C., Wollmer, P., \& Andersen, L. (2006). Daily physical activity relate to aerobic fitness and body fat in an urban sample of Children. Scandinavian Journal of Medicine \& Science in Sports, $18(6), 728-735$. 
Dowda, M., Sallis, J., McKenzie, T., Rosengard, P., \& Kohl, H. (2005). Evaluating the sustainability of SPARK physical education: A case study of translating research into practice. Research Quarterly for Exercise and Sport, 76, 11-19.

Durlak, J., Taylor, R., Kawashima, K., Pachan, M., DuPre, E., Celio, C...\&

Weissberg, R. (2007). Effects of positive youth development programs on school, family, and Community systems. American Journal of Community Psychology, 39, 269-286.

Durlak, J. \& Wells, A. (1997). Primary prevention mental health programs for children and adolescents: A meta-analytic review. American Journal of Community Psychology, 25(2), 115-152.

Durlak, J., Weissberg, R., Dtmnicki, A., Taylor, R., \& Schellinger, K. (2011). The impact of enhancing students' social and emotional learning: A meta-analysis of school-based universal interventions. Child Development, 82(1), 405-432.

Dvorsky, M. (2013). The critical role of school psychology in the school mental health movement. Psychology in the Schools, 50(3), 245-258.

Eather, N., Morgan, P., \& Lubans, D. (2013). Improving the fitness and physical activity levels of primary school children: Results of the Fit-4-Fun group randomized control trial. Preventative Medicine, 56, 12-19.

Eaton, D., Kann, L., Kinchen, S., Shanklin, S., Flint, K., Harris, W... Wechsler, H. (2012). Youth risk behavior surveillance- United States, 2011. Morbidity and Mortality Weekly Report, 61(4). Retrieved March 21, 2014 from http://www.cdc.gov/mmwr/pdf/ss/ss6104.pdf. 
Eisenmann, J., Alaimo, K., Pfeiffer, K., Paek, H., Carlson, J., Hayes, H...\& Holmes, D. (2011). Project FIT: Rationale, design and baseline characteristics of a schooland community-based intervention to address physical activity and healthy eating among low-income elementary school children. BMC Public Health, 11(607), 110.

Eisennmann, J., Bartee, R., Smith, D., Welk, G., \& Fu, Q. (2008). Combined influences of physical activity and television viewing on the risk of overweight in U.S. youth. International Journal of Obesity, 32(4), 613-618.

Elinder, L., Heinemans, N., Hagberg, J., Quetel, A., \& Hagstromer, M. (2012). A participatory and capacity-building approach to healthy eating and physical activity- SCIP-school: a 2-year controlled trial. International Journal of Behavioral Nutrition and Physical Activity, 9(145), 1-13.

Fairclough, S., Hackett, A., Davies, I., Gobbi, R., Mackintosh, K., Warburton, G...\& Boddy, L. (2013). Promoting healthy weight in primary school children through physical activity and nutrition education: a pragmatic evaluation of the CHANGE! Randomized intervention study. BioMed Central Public Health, 13(626), 1-14.

Farahmand, F., Grant, K., Polo, A., \& Duffy, S. (2011). School-based mental health and behavioral programs for low-income, urban youth: A systematic and metaanalytic review. Clinical Psychology of Science and Practice, 18(4), 372-390.

Farhat, T., lannotti, R., \& Simons-Morton, B. (2010). Overweight, obesity, youth, and health-risk behaviors. American Journal of Preventive Medicine, 38(3), 258267. 
Faulkner, G., Buliung, R., Flora, P., \& Fusco, C. (2009). Active school transport, physical activity levels and body weight of children and youth: A systematic review. Preventative Medicine, 48, 3-8.

Flynn, M., McNeil, D., Maloff, B., Mutasingwa, D., Wu, M., Ford, C., \& Tough, S. (2006). Reducing obesity and related chronic disease risk in children and youth: a synthesis of evidence with 'best practice' recommendations. International Association for the Study of Obesity. 7(suppl. 1), 7-66.

Food Research Action Council. (2013). Child nutrition and WIC reauthorization act of 2004. Retrieved November 3, 2013 from http://frac.org/leg-actcenter/legislative-successes/child-nutrition-and-wic-reauthorization-act-of-2004/.

Frey, K., Hirschstein, M., Snell, J., Edstrom, L., MacKenzie, E., \& Broderick, C. (2005a). Reducing playground bullying and supporting beliefs: An experimental trial of Steps to Respect Program. Developmental Psychology, $41(3), 479-491$.

Frey, K., Nolen, S., Edstrom, L., \& Hirschstein, M. (2005b). Effects of a schoolbased Socio-emotional competence program: Linking children's goals, attributions, and behavior. Applied Developmental Psychology, 26, 171-200.

Fung, C., Kuhle, S., Lu, C., Purcell, M., Schwartz, M., Storey, K., \& Veugelers, P. (2012). From "best practice" to "next practice": the effectiveness of schoolbased health promotion in improving healthy eating and physical activity and preventing childhood obesity. International Journal of Behavioral Nutrition and Physical Activity, 9(27), 1-9. 
Gibb, L., Staiger, P., Johnson, B., Block, K., Macfarlane, S., Gold, L... \& Ukoumunne, O. (2013). Expanding children's food experiences: The impact of a school-based kitchen garden program. Journal of Nutrition Education \& Behavior, $45(2), 137-146$.

Gonzalez-Suarez, C., Worley, A., Grimmer-Somers, K., \& Dones, V. (2009). Schoolbased interventions on childhood obesity: A meta-analysis. 37(5), 418-427.

Gordon-Larsen, P., Nelson, M., Page, P., \& Popkin, B. (2006). Inequality in the built environment underlies key health disparities in physical activity and obesity. Pediatrics, 117, 417-424.

Graham, H., Zidenberg-Cherr, S. (2005). California teachers perceive school gardens as an effective nutritional tool to promote healthful eating habits. Journal of the American Dietetic Association, 105, 1797-1800.

Haboush, A., Phebus, T., Ashby, D. T., Zaikina-Montgomery, H., \& Kindig, K. (2010). Sill unhealthy 2009: Building community research to identify risk factors and health outcomes in childhood obesity. Journal of Community Health, 36, 111120.

Hahn, R., Fuqua-Whitley, D., Wethington, H., Lowy, J., Crosby, A., Fullilove, M...\& Chattopadhyay, S. (2007). Effectiveness of universal school-based programs to prevent violent and aggressive behavior: A systematic review. American Journal of Preventative Medicine, 33(2s), S114-S129.

Hayes, L., Giallo, R., \& Richardson, K. (2010). Outcomes of an early intervention program for children with disruptive behavior. Australian Psychiatry, 18(6), $560-566$. 
Hill, H., Levermore, M., Twaite, J., \& Jones, L. (1996). Exposure to community violence And social support as predictors of anxiety and social and emotional behavior Among African American children. Journal of Child and Family Studies, 5, 399-414.

Hill, L., Lochman, J., Coie, J., Greenberg, \& Conduct Problems Prevention Research Group. (2005). Effectiveness of early screening for externalizing problems: issues of screening accuracy and utility. Journal of Consulting and Clinical Psychology, 72, 809-820.

Hoagwood, K., Olin, S., Kerker, B., Kratochwill, T., Crowe, M., Saka, N. (2007). Empirically based school interventions targeted at academic and mental health functioning. Journal of Emotional and Behavioral Disorders, 15, 66-92.

Hollar, D., Messiah, S., Lopez-Mitnik, G., Hollar, L., Alman, M., \& Agatston, A. (2010a). Effect of a two-year obesity prevention intervention on percentile changes in body mass index and academic performance in low-income elementary school children. American Journal of Public Health, 100(4), 646653.

Hollar, D., Lombardo, M., Lopez-Mitnik, G., Hollar, T., Almon, M., Agatston, A., \& Messiah, S. (2010b). Obesity prevention program improves weight, blood pressure, and academic performance, especially among low-income minority children. Journal of Health Care for the Poor and Underserved, 21, 93-108.

Hoxie-Setterstrom, G., \& Hoglund, B. (2011). School wellness policies:

Opportunities for change. Journal of School Nursing, 27(5), 330-339. 
Hyndman, B., Benson, A., Ullah, S., \& Telford, A. (2014). Evaluating the effects of the lunchtime enjoyment activity and play (LEAP) school playground intervention on children's quality of life, enjoyment and participation in physical activity. BMC Public Health, 14(164), 1-29.

Institute of Medicine. (1997). Schools and Health: Our Nation's Investment. Washington, DC: National Academy Press.

International Baccalaureate. (2014) About the International Baccalaureate. Retrieved June 5, 2014 from www.ibo.org.

Jackson, C., Geddes, R., Haw, S., \& Frank, J. (2011). Interventions to prevent substance Use and risky sexual behavior in young people: A systematic review. Addiction, 107, 733-747.

Jenkins, E., \& Bell, C. (1994). Violence among inner city high school students and post-traumatic stress disorder. In S. Friedman (Ed.), Anxiety Disorders in African Americans (pp. 76-88). New York: Springer.

Katzmarzyk, P., Baur, S., Lambert, E., Oppert, J., \& Riddoch, C. (2008). Expert panel report from Internation Converence on Physical Activity and Obesity in Children, 24-27 June 2007, Toronto, Ontario: Summary statement and recommendations. Applied Physiology, Nutrition, \& Metabolism, 33(2), 371388.

Keane, E., Layte, R., Harrington, J., Kearney, P., \& Perry, I. (2012). Measured parental weight status and familial socio-economic status correlates with obesity at age 9.PLos ONE, 7(8): e43053. Doi:10.1371/journal.pone.0043503. 
King, K., \& Zucker, S. (2005). Policy report: Curriculum narrowing. Pearson Education Inc.: San Antonio, TX.

Kumanyika, S., \& Grier, S. (2006). Targeting interventions for ethnic minority and low-income populations. The Future of Children, 16(1), 187-207.

Kuther, D., \& Fisher, C. (1998). Victimization by community violence in young adolescents from a suburban city. Journal of Early Adolescence, 18, 53-76.

Larkin, R. \& Thyer, B. (1999). Evaluating cognitive-behavioral group counseling to improve elementary school students' self-esteem, self-control, and classroom behavior. Behavioral Interventions, 14, 147-161.

Lee, R., Tiley, C., \& White, J. (2009). The Place2be: Measuring the effectiveness of a primary school-based therapeutic intervention in England and Scotland. Counseling and Psychotherapy Research, 9(3), 151-159.

Legislative Counsel's Digest. (October 2, 2013). S.B. No. 330 Education-schools and school district mental health instruction. California 2013 Legislative Services.

Leviton, L. (2008). Children's' healthy weight and the school environment. Annals of The American Academy of Political and Social Science, 615, 38-55.

Lewis, K., Schure, M., Bavarian, N., DuBois, D., Day, J., Ji, P...\& Flay, B. (2013). Problem behavior and urban, low-income youth: A randomized control trial of Positive Action in Chicago. American Journal of Preventative Medicine, 44(6), $622-630$. 
Lineberger, S., \& Zajicek, J. (2000). School gardens: Can a hands-on teaching tool affect students' attitudes and behaviors regarding fruits and vegetables? HortTechnology, 10(3), 593-597.

Lohman, T., Ring, K., Pfeiffer, K., Camhi, S., Arredondo, E., Pratt, C. (2008). Relationships among fitness, body composition, and physical activity. Medicine \& Science in Sports \& Exercise, 40(6), 1163-1170.

Long, M., Sobol, A., Cradock, A., Subramanian, S., Blendon, R., \& Gortmaker, S. (2013). School-day and overall physical activity among youth. American Journal of Preventative Medicine, 45(2), 150-157.

Lyn, R., O’Meara, S., Hepburn, V., \& Potter, A. (2012). Statewide evaluation of local wellness policies in Georgia: An examination of policy compliance, policy strength, and associated factors. Journal of Nutrition Education and Behavior, $44(6), 513-518$.

McAlessee, J., \& Rankin, L. (2007). Garden-based nutrition education affects fruit and vegetable consumption in sixth grade adolescents. Journal of the American Dietetic Association, 107(4), 662-665.

McKenzie, T., Li, D., Derby, C., Webber, L., Luepker, R., \& Cribb, P. (2003). Maintenance of effects of the CATCH physical education program: Results from the CATCH ON study. Health Education and Behavior, 30, $447-462$.

McKenzie, T., \& Kahan, D. (2008). Physical activity, public health, and elementary schools. The Elementary School Journal, 108(3), 171-180. 
Merikangas, K., He, J., Brody, D., Fisher, P., Bourdon, K., \& Koretz, D. (2010). Prevalence and treatment of mental disorders among US children in the 2001-2004 NHANES. Pediatrics, 125, 75-81.

Meyer, U., Schindler, C., Zahner, L., Ernst, D., Hebestreit, H., van Mechelen, W...\& Kriemler, S. (2014). Long-term effect of a school-based physical activity program (KISS) on fitness and adiposity in children: A cluster-randomized controlled trial. PLOS One, 9(2), 1-11.

Meyers, L., Gamst, G., \& Guarino, A. (2005). Applied multivariate research. Thousand Oaks, CA: Sage Publications.

Moore, L., Diez, R., Evenson, K., McGinn, A., \& Brines, S. (2008). Availability of recreational resources in minority and low socioeconomic status areas. American Journal of Preventive Medicine, 34(1), 16-22.

Morris, J., \& Zidenberg-Cherr, S. (2002). Garden-enhanced nutrition curriculum improves fourth-grade school children's knowledge of nutrition and preferences for vegetables. Journal of the American Dietetic Association, 102(1), 91-93.

Morris, J., Neustadter, A., \& Zidenberg-Cherr, S. (2001). First-grade gardeners more likely to taste vegetables. California Agriculture, 55(1), 43-46.

Morris, J., Zidenberg-Cherr, S. (2009). Garden-enhanced nutrition curriculum improves fourth-grade school children's knowledge of nutrition and preferences for some vegetables. Journal of the American Dietetic Association, 102(1), 91-93. 
Munoz, M., \& Vanderhaar, J, (2006). Literacy-embedded character education in a large urban district: Effects of the child development project on elementary school students and teachers. Journal of Research in Character Education, 4(1), 47-64.

National Board on Educational Testing and Public Policy. (2003). National survey of Teachers show state testing programs have resulted in major changes in Instructional practices. Chestnut Hill, MA: Boston College.

National Center for Education Statistics (2014). Retrieved January 12, 2014 from http://nces.ed.gov/globallocator/.

National Institute of Mental Health. (2014). Child and adolescent mental health. Retrieved March 21, 2014 from http://www.nimh.nih.gov/health/topics/child-andadolescent-mental-health/index.shtml.

Ogden, C., Carroll, M., \& Flegal, K. (2008). High body mass index for age among US children and adolescents, 2003-2006. Journal of the American Medical Association, 299(20), 2401-2405.

Ogden, C., Carroll, M., Curtin, L., McDowell, M., Tabek, C., \& Flegal, K. (2006). Prevalence of overweight and obesity in the United States, 1999-2004. Journal of the American Medical Association, 295(1), 549-1555.

Ohl, M., Mitchell, K., Cassidy, T., \& Fox, P. (2008). The pyramid club primary school-based intervention: Evaluating the impact on children's socio-emotional health. Child and Adolescent Mental Health, 13(3), 115-121.

Ortega, F., Tresaco, B., Ruiz, J., Moreno, L., Martin-Matillas, M., \& Mesa, J. (2007). Cardiorespiratory fitness and sedentary activities are associated with adiposity in adolescents. Obesity (Silver Spring), 15(6), 1589-1599. 
Ozer, E. (2007). The effects of school gardens and schools: Conceptualization and considerations for maximizing healthy development. Health Education and Behavior, 34(6), 846-863.

Pacific Institute. (2014). Achieving your potential through education. Retrieved June 11, 2014 from http://www.thepacificinstitute.asia/resources/programdetails/achieving-your-potential-through-education.

Patton, M.Q. (2002). Qualitative research $\&$ evaluation methods, $3^{\text {rd }}$ ed. Thousand Oaks, CA: Sage Publications.

Patton, G., Bond, L., Carlin, J., Thomas, L., Butler, H., Glover, S...\& Bowes, G. (2006). Promoting social inclusion in schools: A group-randomized trial of effects on student health risk behavior and well-being. American Journal of Public Health, $96(9), 1582-1587$

Polkinghorne, D. (1995). Narrative configuration in qualitative analysis. Qualitative Studies in Education, 8(1), 5-23.

Probart, C., McDonnell, E., Weirch, J., Schilling, L., Fekete, V. (2008). Statewide assessment of local wellness policies in Pennsylvania public school districts. Journal of the American Dietetic Association, 108(9), 1497-1502.

Puma, J., Romaniello, C., Crane, L., Scarbro, S., Belansky, E., Marshall, J. (2013). Long-term student outcomes of the Integrated Nutritional and Physical Activity program. Journal of Nutrition and Education Behavior, 45(6), 635-642.

Rappaport, E., Daskalakis, C., \& Sendecki, J. (2013). Using routinely collected growth data to assesses a school-based obesity prevention strategy. International Journal of Obesity, 37, 79-85. 
Ravitch, D. (2010). The death and life of the great American school system: How testing and choice are undermining education: How the standards movement turned testing into the testing movement. New York: Basic Books.

Reed, J., Einstein, G., Hahn, E., Hooker, S., Gross, V., \& Kravitz, J. (2010).

Examining the impact of integrating physical activity on fluid intelligence and academic performance in an elementary school setting: A preliminary investigation. Journal of Physical Activity and Health, 7, 343-351.

Richmond, T., \& Subramanian, S. (2008). School level contextual factors are associated with the weight status of adolescent males and females. Obesity (Silver Spring), 16(6), 1324-1330.

Rito, A., Carvalho, M., Ramos, C., \& Breda, J. (2013). Program obesity zero (POZ) a community-based intervention to address overweight primary-school children from five Portuguese municipalities. Public Health Nutrition, 16(6), 1043-1051.

Robinson-O’Brien, R., Story, M., \& Heim, S. (2009). Impact of garden-based youth nutrition intervention programs: A review. Journal of the American Dietetic Association, 109(2), 273-280.

Russell-Mayhew, S., McVey, G., Bardick, A., Ireland, A. (2012). Mental health, wellness, and childhood overweight/obesity. Journal of Obesity, 12: 281801. Doi:10.1155/2012/281801.

Sharma, M. (2005). School-based interventions for child adolescent obesity. International Association for the Study of Obesity, obesity reviews, 7, 261-269. 
Shoup, J., Gattshall, M., Dandamudi, P., \& Estabrooks, P. (2008). Physical activity, quality of life, and weight status. Quality of Life Research, 17(3), 407-412.

Siegrist, M., Hanssen, H., Lammel, C., Haller, B,. \& Halle, M. (2011). A cluster randomized school-based lifestyle intervention programme for the prevention of childhood obesity and related early cardiovascular disease. BioMed Central, Ltd, $11(1), 258-267$.

Simms, K., Bock, S., \& Hackett, L. (2013). Do the duration and frequency of physical education predict academic achievement, self-concept, social skills, food consumption, and body mass index? Health Education Journal, 0(0), 1-13.

Snyder, F., Vuchnich, S., Acock, A., Washburn, I., \& Flay, B. (2012). Improving elementary school quality through the use of a social-emotional and character development program: A matched-pair, cluster-randomized controlled trial in Hawai'i. Journal of School Health, 82, 11-20.

Spense, S., \& Shortt, A. (2007). Research review: Can we justify widespread dissemination of universal, school-based interventions for the prevention of depression among children and adolescents. Journal of Child Psychology and Psychiatry, 48(6), 526-542.

Stallard, P. (2013). School-based interventions for depression and anxiety in children and Adolescents. Evidence Based Mental Health, 16(3), 60-61.

Stewart, I., Purner, E., \& Guzman, P. (2013). Economic disparities in the provision of school gardens in Santa Clara County, Children, Youth and Environments, 23(2), $127-137$. 
Story, M., Kaphinhgst, K., \& French, S. (2006). The role of schools in obesity prevention. In S. McLanahan (Ed.), Childhood Obesity 16(1), (109-142). Princeton: The future of children.

Telles, S., Singh, N., Kumar, A., Kumar, A., \& Balkrishna, A. (2013). Effects of yoga or physical exercise on physical, cognitive and emotional measures in children: A randomized control trial. Child \& Adolescent Psychiatry \& Mental Health, 7(1), $1-28$.

Tercyak, K., \& Tyc, V.(2007). Opportunities and challenges in the prevention and control of cancer and other chronic diseases: Children's diet and nutrition and weight and physical activity. Journal of Pediatric Psychology, 31(8), 750-763.

Trost, S., \& van der Mars, H. (2009). Why we should not cut P.E. Educational Leadership, 67(4), 60-65.

Twiss, J., Dickenson, J., Duma, S., Kleinman, T., Paulsen, H., \& Rilveria, L. (2003). Community gardens: Lessons learned from California healthy cities and communities. American Journal of Public Health, 93(9), 1435-1438.

United States Department of Education. (2014). State and local implementation of the No Child Left Behind Act, Volume III- Accountability under NCLB: Interim report. Retrieved June 17, 2014 from http://www2.ed.gov/rschstat/eval/disadv/nclb- accountability/index.html?exp=2.

Valois, A. (2011). The healthy school communities model: Aligning health and education in the school setting. Danvers, MA: ASCD. 
Van Grieken, A., Renders, C., Veldhuis, L., Looman, C., Hirasing, R., \& Raat, H. (2014). Promotion of a healthy lifestyle among 5-year-old overweight children: Health behavior outcomes of the 'Be active, eat right' study. BioMed Central Public Health, 14(59). 1-24.

Veugelers, P., \& Fitzgerald, A. (2005). Effectiveness of school programs in preventing childhood obesity: A multilevel comparison. American Journal of Public Health, 95(3), 432-435.

Waliczek, T., Bradley, J., Zajicek, J. (2001). The effect of school gardens on children's interpersonal relationships and attitudes toward school. HortTechnology, $11(3), 466-468$.

Wardle, J., \& Cooke, L. (2005). The impact of obesity on psychological well-being. Best Practice \& Research Clinical Endocrinology \& Metabolism, 19(3), 421-440.

Webster-Stratton, C., Reid, M., \& Stoolmiller, M. (2008). Preventing conduct problems and improving school readiness: evaluation of the incredible years and child training programs in high-risk schools. Journal of Child Psychology and Psychiatry, 49(5), 471-488.

Weist, M. \& Paternite, C. (2006). Building an interconnected policy-training-practiceresearch agenda to advance school mental health. Education \& Treatment of Children, 29, 173-196.

Wilson, S., \& Lipsey, M. (2007). School-based interventions for aggressive and disruptive behavior. American Journal of Preventative Medicine, 33(2S), S130S143. 
World Health Organization (2008). Principals and methods for the risk assessment of chemicals in food: Dose-response assessment. Retrieved May 27, 2014 from http://www.who.int/foodsafety/chem/dose_response.pdf.

World Health Organization. (2012). Child overweight and obesity. Retrieved June 15, 2013 from http://www.who.int/dietphysicalactivity/childhood/en/.

World Health Organization. (2014). Child overweight and obesity. Retrieved January 11, 2014 from http://www.who.int/dietphysicalactivity/childhood/en/. 
Appendix A

Surfside Union School District Superintendent Interview Protocol 
Surfside Union School District Superintendent Interview Protocol

1. Can you start by giving some background about what brought you to SUSD?

a. How long have you worked in SUSD?

2. What makes School $\mathrm{C}$ a unique school in SUSD?

a. How do you perceive School C attending to the health and wellness of its students?

3. What makes School B a unique school in SUSD?

a. How do you perceive School B attending to the health and wellness of its students?

4. What makes School A unique school in SUSD?

a. How do you perceive School A attends to the health and wellness of its students?

5. Given these differences and the differences of the 6 other SUSD schools, can you offer some background on the SUSD health and wellness program?

a. When and why did it get started?

b. How was it started?

c. How do you anticipate the program will develop/change in the coming months/years?

6. Given the background of each school and the district's health and wellness vision, what are the substantial differences I'm likely to uncover while talking to people and observing at each of the three schools?

7. Are students receiving different health and wellness experiences and affected differently at each of these schools?

8. Are low-income students being supported differently at each school?

a. Would you anticipate differences in the health and wellness tools and life skills they're acquiring at each school?

9. Is there anything else that would be important for me to know about these three schools to better understand their health and wellness programs? 
Appendix B

Surfside Union School District Personnel Interview Protocol 
Surfside Union School District Personnel Interview Protocol

1. Can you start by giving some background about what brought you to SUSD?

a. Previous work in other districts, responsibilities, duration, etcetera.

b. How long have you worked in SUSD?

2. As a SUSD employee, can you describe what your job responsibilities entail?

a. Time on school campuses and degree of student interaction.

3. What makes School $\mathrm{C}$ a unique school in SUSD?

a. How do you perceive School C attends to the health and wellness of its students?

4. What makes School B a unique school in SUSD?

a. How do you perceive School B attending to the health and wellness of its students?

5. What makes School A unique school in SUSD?

a. How do you perceive School A attends to the health and wellness of its students?

6. Give these differences and the differences of the six other SUSD schools, can you offer some background on the SUSD health and wellness program?

a. When did it get started?

b. From your perspective, what does the program consist of?

7. How do you envision your role as fits into the district and school level health and wellness program?

8. Could you offer examples of your day-to-day responsibilities that support the health and wellness of SUSD students?

a. Does this differ between schools? How?

9. Are SUSD students receiving different health and wellness experiences and affected differently at each of these schools?

a. Probe for differences by age, gender, race, socioeconomic status

10. Would you anticipate differences in the health and wellness tools and life skills they are acquiring at each school?

a. If so, in what ways?

11. Is there anything else that would be important for me to know about either your role at SUSD or about these three schools to better understand their health and wellness programs? 
Appendix C

Surfside Union School District School Stakeholder Interview Protocol 
Surfside Union School District School Stakeholder Interview Protocol

1. Can you start by giving some background about what brought you to School - ?

a. Previous work in other districts, responsibilities, duration, etcetera.

b. How long have you worked at School __?

2. Please tell me about your school: e.g., size, staff size, student enrollment, mission, etcetera.

3. What health and wellness components comprise your school's health and wellness program?

a. Probe for student participation, schedule, pedagogy, staff leadership, etcetera.

4. What makes your school a unique school in SUSD?

a. How do you perceive you and your staff attend to the health and wellness of your students?

5. What makes School _ a unique school in SUSD?

a. How do you perceive School _ attends to the health and wellness of its students?

6. What makes School _ a unique school in SUSD?

a. How do you perceive School _ attends to the health and wellness of its students?

7. Give these differences and the differences of the six other SUSD schools, can you offer some background on the SUSD health and wellness program?

a. When did it get started?

b. From your perspective, what does the program consist of?

8. What part of your school's health and wellness program has been most effective and why?

9. Have you encountered specific effects with certain student subgroups (upper/lower grade, gender, race, etcetera)?

a. If so, are their certain components you feel are contributing to those effects?

10. Are their less-effective health and wellness components, or components you do not intend to continue next school year?

11. To learn more about your school's health and wellness program, can you recommend other personnel I should speak with? 
Appendix D

Surfside Union School District Parent Volunteer Interview Protocol 


\section{Surfside Union School District Parent Volunteer Interview Protocol}

1. To the best of your knowledge, could you list and describe the health and wellness activities that are taking place at your son/daughter's school?

2. Of those activities, are there certain ones that your son or daughter have particularly liked?

a. How did he/she share this information with you?

b. Why do you think he/she especially favors this activity?

c. Have you observed any physical or psychological changes in your son/daughter as a result of that (or any) program?

3. Of the activities, are there certain activities that your son or daughter has not liked?

a. How did he/she share this information with you?

b. Why do you think he/she especially favors this activity?

c. Have you observed any physical or psychological changes in your son/daughter as a result of that (or any) program?

4. How do you feel about your school's attention to your son or daughter's health and wellness?

a. Are there certain activities that you're particularly happy your child experiences?

b. Why? How do you think your child is affected by this program?

c. Are there certain activities that you're less happy with?

d. Why? How do you think your child is affected by this program?

5. Are there other ways you wish your school would attend to your son/daughter's health and wellness?

6. Is there anything else you would like to add to help me better understand the health and wellness program at your son/daughter's school? 
Appendix E

Surfside Union School District Student Focus Group Protocol 
Surfside Union School District Student Focus Group Protocol

1. What do think of when you hear health and wellness?

a. What does it mean to you?

b. Converse until it's apparent kids understand the concept

2. Here are a list of health and wellness activities that I've heard are happening at your school:

a. Which of these have you participated in?

b. Any that you've never heard of?

c. How often do you do these activities

3. Of all these activities, which one is your favorite?

a. Why? What makes it your favorite?

b. How does it make you feel?

4. Which of these activities don't you like?

5. Do you do other health and wellness activities at school that aren't on the list?

6. What makes you happy at school?

7. What makes you unhappy at school?

8. Are there other things you wish your school would do or change to help improve your health and wellness?

9. Do you see your teacher do things to take care of their health and wellness?

10. Do you see your parents do things at your school to take care of their health and wellness?

11. Is there anything else you could share about being a student at ? 
Appendix F

Surfside Union School District Health and Wellness Instructor Focus Group 
Surfside Union School District Health and Wellness Instructor Focus Group

1. When I say "the health and wellness of your students," what does that mean to you?

2. What makes School C a unique school in SUSD?

a. How do you perceive School $\mathrm{C}$ attends to the health and wellness of its students?

3. What makes School B a unique school in SUSD?

a. How do you perceive School $B$ attending to the health and wellness of its students?

4. What makes School A unique school in SUSD?

a. How do you perceive School A attends to the health and wellness of its students?

5. Given these differences and the differences of the six other SUSD schools, can you offer some background on SUSD health and wellness program?

a. When do you believe it got started?

6. Has your schools individualized its health and wellness program? How?

7. Give $\mathrm{n}$ the background of each school and the district's health and wellness vision, what are the substantial differences I'm likely to uncover while talking to people and observing at each of the three schools?

8. Are students receiving different health and wellness experiences and affected differently at your school?

9. Are low-income students being supported differently at your school?

10. Are there differences in the health and wellness tools and life skills students are acquiring at your school? 
Appendix G

Physical Health and Subcategory Scores:

California Healthy Kids Survey Question Compilation 
Physical Health and Subcategory Scores: California Healthy Kids Survey Question Compilation

\section{Physical Health Score Questions}

Physical Wellness Subcategory Questions:

- 6. Did you eat breakfast this morning?

- 48. Do you think you are too skinny, about right, or too fat?

- 49. Are you doing anything to try to lose weight?

- 50. Have other kids at school teased you about what your body looks like?

- 51. How many days each week do you exercise, dance, or play sports?

- 52. When not exercising, do you ever have trouble breathing?

- 53. Has a parent or some other adult ever told you that you have asthma

- 54. Yesterday, how much time did you spent watching TV or playing video games?

Risky Behavior Avoidance Subcategory Questions:

- 7. When you ride in a car, do you wear a seat belt?

- 8. When you ride a bicycle, do you wear a helmet?

- 26. During the past year, did you ever bring a gun or knife to school?

- 31. Have you ever smoked a cigarette?

- 32. Have you ever chewed tobacco or snuff?

- 35. Have you ever used alcohol or an illegal drug like marijuana before school or at school?

- 40. In the past month, did you drink any beer, wine, or other alcohol?

- 41 . In the past month, did you smoke a cigarette? 
Appendix $\mathrm{H}$

Psychological Health and Subcategory Scores:

California Healthy Kids Survey Questions Compilation 
Psychological Health and Subcategory Scores: California Healthy Kids Survey Questions Compilation

\section{Psychological Health Score Questions}

Student's Connection to School:

- 9. Do you feel close to people at school?

- 10. Are you happy to be at this school?

- 11. Do you feel like you are part of this school?

- 16. How well do you do in your schoolwork?

- 29. Do you feel safe at school?

- 46. Do you try to do your best?

Bullying Avoidance:

- 21. During the past year how many times have you hit or pushed other kids at school when you weren't playing around?

- 22. During the past year how many times have you spread mean rumors or lies about other kids at school?

- 23. Do other kids hit or push you at school when they are not just playing around?

- 24. Do other kids spread mean rumors or lies about you?

- 25. Do other kids at school spread mean rumors or lies about you on the internet (i.e. Facebook, MySpace, email, Instant message)?

- 50. Have other kids at school ever teased you about what your body looks like?

Perception of Self and School:

- 12. Do teachers treat students fairly at school?

- 14. At school, do teachers and other adults care about you?

- 15. At school, do teachers and other adults tell you when you do a good job?

- 17. At school do the teachers and other adults listen to you when you have something to say?

- 18. At school, do teachers and other adults believe that you can do a good job? 
Appendix I

Surfside Union School District Health and Wellness Components 
Surfside Union School District Health and Wellness Components

Achieving your Potential through Education/PX2: A weekly direct instruction lesson is provided to all School $\mathrm{C}$ students by the health and wellness instructors or the principal in either Spanish or English. The program was designed by the Pacific Institute to support a child's beliefs and how they think in school at home, and in life to ultimately influence behavior. Lessons systematically discuss how the brain works, and how the mind affects behavior. Visit http://www.thepacificinstitute.asia/download/pdf/AYPTE.pdf for more information.

Annual Jog-a-thon: Annually, students participate in the school jog-a-thon to raise money for the Parent Teachers Association (PTA). Students receive private donations for each lap they complete during the event. Parent volunteers and staff members set up water stations, monitor student laps, and offer encouragement for students on the day of the event.

Aspire: All students at School C are eligible for after school care through the Aspire program. Low-income students are eligible to participate free of charge through a school wide grant. Participating students report to Aspire following the school day to receive academic support and engage in games, activities, and free play supervised by Aspire staff members.

Daily Affirmations: Following the daily SRRF lesson at School C, all students are led through centering and breathing techniques as the health and wellness instructor facilitates on the loudspeaker. She then provides context for the forthcoming affirmation, states the affirmation, and invites students to repeat after her. Affirmations change over the course of the year.

Family Wellness Program: Organized by a School A parent volunteer, all students and family members are invited on campus before school to run and walk on the field, or take a parent volunteer-led yoga, zumba, or pilates class (classes vary by weekly schedule). . Parents and students can collectively acquire points for the number of laps and classes they complete, and compile points into a classroom folder. Each month, an assembly is held to recognize students who met certain benchmarks. . Awards are distributed based on the number of laps or classes completed. Parent points contribute to the student's point total to encourage parents to exercise with their child.

Five Star Lunch Program: District marketing concept geared toward getting kids to make healthier choices in the lunch line at school. Schools must offer five categories of food (protein, grains, vegetables, fruit, and milk) and children are encouraged to take three of the five categories.

Garden Science/Cooking Lessons: A part of the garden science program at School C, children are exposed to different produce in the garden and taste the different fruits and vegetables throughout the science activity. On occasion, a cooking lesson occurs either in the outdoor kitchen or within a temporary space. 
International Baccalaureate Attitudes: The International Baccalaureate (IB) program is grounded in a set of learning outcomes deemed important for $21^{\text {st }}$ century students. The following twelve IB Attitudes are reportedly engrained into the real-world experiences, project-based learning, and instructional pedagogy at School A: Appreciation, commitment, confidence, cooperation, creativity, curiosity, empathy, enthusiasm, independence, integrity, respect, and tolerance. Visit www.ibo.org/pyp for more information about IB Attitudes.

Kindergarten Community (KC) Club: School A's KC Club is a campus organization that connects upper-grade students to the kindergarten classes. Fifth and Sixth grade students selected through an application process are scheduled to engage in play and mentorship with kindergarten students during both grades' lunch recess.

Lunchtime Physical Activity with University Students: Through a parent volunteer connection, undergraduate students from California State University, San Marcos receive extra course credit by volunteering at School A during lunchtime recess. University students organize games and activities designed to enhance physical activity for all students who wish to participate.

Physical Education: Mandated by the state of California for children to receive 200 minutes of physical activity every ten days while adhering to the grade level standards. Physical education teachers, heath and wellness instructors, and classroom teachers are all responsible for physical education, and utilize California's standards in lesson planning.

Playground Partners: YMCA sponsored program that offers YMCA memberships to parents who organize games and sports throughout recess. Four or more volunteer hours per week are required for parents to receive the YMCA membership.

Safe, Responsible, Respectful, Flexible (SRRF) Lessons: Daily, School C students are reminded about the school's commitment to being Safe, Responsible, Respectful, and Flexible during morning announcements. Each School $\mathrm{C}$ teacher has SRRF tickets available in their classroom. When a student or staff member witness a student or staff member exhibiting a SRRF characteristic, they complete a surf ticket describing the interaction, indicate if the action demonstrated safe, responsible, respectful, or flexible behavior, and submit the completed ticket to the office. The following morning, SRRF tickets are reported on the loudspeaker by the health and wellness instructor recounting the experience and describing how it demonstrated SRRF characteristics.

Safe School Student Ambassadors: Upper grade students are nominated by their teacher or other School C staff member and are reported to remain anonymous to students and most of the staff. Selected students are trained to diffuse bullying or inappropriate situations while on the playground. They are trained to reach out to adults when dangerous situations occur. Ongoing meetings are scheduled to allow participating 
students to meet and discuss their experiences with bullying and devise anti-bullying tactics to use at School C.

Sage Cooking: Funded through a Sage Garden Project grant, School A students all receive a cooking lesson every other week in the Sage kitchen. A full-size kitchen is available for approximately fifteen students to interactively engage in the cleaning, preparation, and cooking process using a Sage lesson, and sit together to eat their meal at the close of the lesson. Produce from the Sage garden, is incorporated into the cooking lesson. Visit www.sagegardenproject.org for more information.

Sage Garden Science: Funded through a Sage Garden Project grant, School A students all receive a garden science lesson every other week in the Sage Garden. Students activity participate in all components of garden science through hands-on lessons led by a garden instructor. Produce harvested from the garden is incorporated into Sage Cooking. Visit www.sagegardenproject.org for more information.

Sharing Our Acceptance and Respect (SOAR): Upper-grade students are selected and trained as buddies to help build the social skills of special needs student at all SUSD schools. Five buddies are paired with a student to help integrate him or her daily into playground games or socializing experiences.

Student Commissioners Club: Selected through an application process, upper-grade students are invited to join the Student Commissioners Club. Through membership, students are trained and work at School A's student store 'selling' items to students who have received Dolphin Dollars from school stakeholders for good behavior or other positive actions.

Y Club: Students at School B are eligible to receive free after school care from the YMCA through a school wide grant. Participating students report to Y Club following the school day to receive academic support and engage in games, activities, and free play supervised by a YMCA staff member.

Yoga: Funded through a district-wide grant, two yoga instructors are assigned to each school and leads coordinated yoga lessons two times each week during the school day through a standards-based yoga curriculum. Students learn to connect breath with movement building on their own bodily awareness. 